\title{
Stochastic adjustment models of labour demand
}

Citation for published version (APA):

Pfann, G. A. (1989). Stochastic adjustment models of labour demand. [Doctoral Thesis, Maastricht University]. Rijksuniversiteit Limburg. https://doi.org/10.26481/dis.19890616gp

Document status and date:

Published: 01/01/1989

DOI:

10.26481/dis.19890616gp

Document Version:

Publisher's PDF, also known as Version of record

\section{Please check the document version of this publication:}

- A submitted manuscript is the version of the article upon submission and before peer-review. There can be important differences between the submitted version and the official published version of record.

People interested in the research are advised to contact the author for the final version of the publication, or visit the DOI to the publisher's website.

- The final author version and the galley proof are versions of the publication after peer review.

- The final published version features the final layout of the paper including the volume, issue and page numbers.

Link to publication

\footnotetext{
General rights rights.

- You may freely distribute the URL identifying the publication in the public portal. please follow below link for the End User Agreement:

www.umlib.nl/taverne-license

Take down policy

If you believe that this document breaches copyright please contact us at:

repository@maastrichtuniversity.nl

providing details and we will investigate your claim.
}

Copyright and moral rights for the publications made accessible in the public portal are retained by the authors and/or other copyright owners and it is a condition of accessing publications that users recognise and abide by the legal requirements associated with these

- Users may download and print one copy of any publication from the public portal for the purpose of private study or research.

- You may not further distribute the material or use it for any profit-making activity or commercial gain

If the publication is distributed under the terms of Article $25 \mathrm{fa}$ of the Dutch Copyright Act, indicated by the "Taverne" license above, 
STOCHASTIC ADJUSTMENT MODELS OF LABOUR DEMAND

GERARD A. PFANN 

STOCHASTIC ADJUSTMENT MODELS OF LABOUR DEMAND

PROEFSCHRIFT

ter verkrijging van de graad van doctor aan de Rijksuniversiteit Limburg te Mastricht, op gezag van de Rector Magnificus, Prof.dr. F.I.M. Bonke, volgens het besluit van het College van Dekanen, in het openbaar te verdedigen op vrijdag 16 juni 1989 om 14.00 uur

door

Gerard Antonie Pfann

geboren te Dostzaan in 1959 
Beoordelingscommssid: Prof.dr. J. Muysen (voorzitter)

Prof.dr. J. Hartog

Professor S.J. Mickell

Oms 1 agontwerp :Anke Furnée 
"The truth is rarely pure and never simple" Oscar Wilde 

When I started with this research project, I knew next to nothing of time series econometrics and virtually none of stochastic adjustment models of labour demand. Now, after little more than three years; I have completed a thesis in which interrelated factor demand madels are surveyed; mew methods are discussed for obtaining closed form solutions of linear rational expecm tations models that provide deeper insights into the identification of structural parameters of underlying theoretical models; several time series techniques are applied in order to estimate structural parameters and test for model specification, stationarity, and stability through time new models are developed in which rather stringent and questionable restrictions (af symmetry) generally imposed upon stochastic adjustment models of labour demand are relaxed. Moreover, the models are analysed empirically using manufacturing data of the Netherlands and the U.K..

Thus, after three years, I know mare about time series econometrics and dynamic labour demand models of firms that operate under uncertianty. However, I believe that applied econometric research cannot be carried out thoroughly through mere estimation and testing of sophisticated econometric models by means of proper techniques, valuable data, and a $f$ at (personal) computer. Fieldwork, that is, the gathering of information through ${ }^{n}$ therviews and observation of subjects in the field of research, is at loastas important, as I have found out in interviews with personnel managers of several Large Dutch corporations. These also taught me a lot about the daly practice facing personnel managers, that 1 s, the reality our modelg aim to describe.

This book results from cooperation. Franz Palm proposed the topic to me 
and superviged my research. His profound knowledge has been an

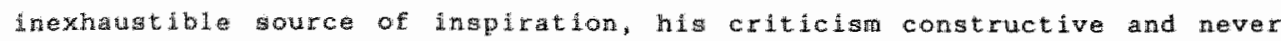
discouratig. I also thank the Department of Economics of the university of Limburg for its support.

Many colleagues and friends have beex helpful. I thank Manuel Arellano, Bert Balk, Harrie Blering, Jack Birner, Gillean Coates, Paul Diederen, Beti van Dijk, Nok Draper, Anton Dreesmann, Thijs wan Eijk, Chris Gilbert, Johan Grasman, Fons Groot, Joop Hartog, Ria Hazelzet, David Hendry, Kees Jansen, Jan Kivlet, Martin Kolk, Tryphon Kollintzas, Gerard Laman, Aad van Mourik, John Muellbatuer, Tony Murphy, Joan Muysken, Theo Nijman, Henk Nusteen, Masao Ogak1, Andrew Oswald, Hans Out, Eric de Regt, Rob Reuseler, Gert Ridder, Jo Ritzen, Rein Schalkwijk, Piet Scharloo, Peter Schotman, Hein Schreuder, Koos Sneek, Hans Verduin, Bart Verspagen, Carlo Winder and Jan Zater.

Most of the chapters presented in this book have benefited from the discusilons I have had with stephen Nickell. I am grateful to him for giving me the opportumity to visit the Institute of Economics and Statistics at the University of Oxford, and I gratefully acknowledge the Enatial support reculved by the Netherlands organisation for the Advancenent of Pure Research, KNP Paper, and DSM Chemicals.

I thenk Yolanda Paulissen and Karin van den Boorn for their outstanding secretarial work. I am proud of and thankful to Carina Furmé for her wambarted fiendship and cont nuous encouragement.

Oxford, November 1988. Mastricht, December 1988. 


\section{CONTENTS}

CHAPTER ONE

PAGE

INTRODUCTION

2

CHAPTER TWO

A PROTOTYPE MODEL FOR BLUE AND WHITE COLLAR EMPLOYMENT DECISIONS OF RATIONAL ENTREPRENEURS UNDER UNCERTAINTY

II. 1 Introduction

II. 2 Wage Costs, Employment and Causality

II.3 Modelling the Demand for Labour 16

II. 4 Empirical Results 24

II.5 Conclusions

$\begin{array}{ll}\text { CHAPTER THREE } & 36\end{array}$

INTERRELATED DEMAND RATIONAL EXPECTATIONS MODELS FOR TWO

TYPES OF LABOUR AND PREDETERMINED CAPITAL

III. 1 Introduction

III.2 The Model 38

III.3 Empirical Analysis 48

III.4 Conclusions

CHAPTER FOUR

EXOGENOUS SHOCKS AND COINTEGRATION IN MULTIWARIATE

FLEXIBLE ACCELERATOR MODELS OF LABOUR AND CAPITAL

IV.1 Introduction

IV. 2 The Model and its Solution 64

IV.3 An Empirical Analysis 70

IV. 4 Concluding. Remarks 81 
THE SIRUCTURE OF ADUUSTHENT COSTS FOR LABOUR IN THE DURCH MANUTACTORTHG SECTOR

V.1 Tntroduct lon

V.2 ACL in Practice

V.3 The Shape of the ACL Function

V.4. Conclusions

ASYMMETRIC ADJUSTMENT COSTS OE LABOUR IH NONLTNEAR RATIONAL EXPECWATONS DEMAND MODELS

VI. 1 Introduction

VI. 2 Labour Demand under Asymmetric Adjustment Costs and Predetermined Capital.

VI.3 Emplrical Analysis

VI. 4 Factor Demand and Asymmetric Adjustment Costs

VT. 5 Conclusions

CONCLUSIONS AND SUMMARY

VII. 1 Conclualons 
A.1 Outline of Asymptotic Least Squares Estimation 128

$\begin{array}{lll}\text { A.2 Proofs of Propositions of Chapter Three } & 129\end{array}$

A.3 Partial Adjustment, Error Correction and Cointegration 130

A.4 Forecast Errors, Expectational Errors and Random Shocks 131

A.5 The Data, Including Sources and Definitions 134

REFERENCES 


\section{.}


CHAPTER ONE

INTRODUCTIION 


\section{INTRODUCT ION}

The objective of this disertation is to provide new theoretical as well as empirical ingights into the decisiwe elements of firms labour demand through the, by generaldzing existing labour demand models derived from theories about decision making under uncertainty. The models will be aplied to time rates dat of the manufacturing sector in the Netherlands and U.K. for bilue and whte collar employment, using recently develaped econometric techniques, in order to examine the empírical applicability of the models.

Labour is a quasi-flxed production factor, that is, a production factor whose total employments costs are partially variable and partially fixed. The first economist to successfully uphold this thesis was walter ô in 1962 (cf. 01, 1962). From an employer'g point of view, the dynamics of labour demand are largely due to hiring and firing costes that exist next to regular payroll costs, when the firm changes its productive workforce. Consequently, future expectations have become an important issue in madeling employment decisions in dynamic context.

In 1976 Luca criticised the way in which econometricians modelied the reactons of economic agents to exogenous shocks in their environment. Lucas"s critique was focussed on the behavioural invariance of econometric moded in the presence of changes in the nature of these shocks. Froper models, he argued, must embody an implic it rule of adaptation to stochastic shocks, or "stochastically disturbed functions of the state of the system" (Lucas, $1976, \mathrm{p} .40)$

Q1's views on quasi-fixedness of labour and the Lucas-critique were integrated in Sargent's (1978) model for dynamic labour demand schedules. Sargent asserts that entrepreneurs determine labour demand at $t$ ime $t$ 
Table I.1 : Survey of Interrelated Factor Demand Hodels.

AGGREGATE LABOUR, CAPITAL (+ MATERIALS, ENERGY)

\begin{tabular}{|c|c|c|c|c|c|c|c|}
\hline & & & & & $\frac{\text { Varfable }}{\text { Inputs }}$ & $\frac{\text { Quas }-f 1 \text { xed }}{\text { inputs }}$ & Expoctattory \\
\hline $\begin{array}{l}\text { Nadir } \mathrm{g} \\
\text { Rosen }\end{array}$ & 1969 & Q: $1947 . I-62 . I V$ & US & Ma & & $\begin{array}{l}\text { Blue collar workers, } \\
\text { Hours worked } \\
\text { Capltal. Utilization } \\
\text { Rate }\end{array}$ & Static \\
\hline $\begin{array}{l}\text { Berndt, } \\
\text { Fliss, } \\
\text { Waveirnan }\end{array}$ & 1979 & $A: 1947-74$ & US & $\mathrm{Ma}$ & $\begin{array}{l}\text { Labour, } \\
\text { Energy: } \\
\text { Materials }\end{array}$ & Capital & Static \\
\hline Meese & 1980 & $0: 1947 . \mathrm{I}-62 . \mathrm{IV}$ & US & $\mathrm{Ma}$ & & Labour, Capltal & Rational \\
\hline $\begin{array}{l}\text { Hansen \& } \\
\text { Sargent }\end{array}$ & 1981 & Theoret 1 cal & & & & Labour, Capital & Rational \\
\hline McIntosh & 1982 & $A: 1950-73$ & UKK & $\mathrm{Ag}$ & & Labour, Capltal & Static \\
\hline $\begin{array}{l}\text { Pindyck \& } \\
\text { Rotemberg }\end{array}$ & $1983 a$ & A: $1948-71$ & US & $\mathrm{Ma}$ & $\begin{array}{l}\text { Energy, } \\
\text { Materials }\end{array}$ & Labour, Capltal & Retional \\
\hline $\begin{array}{l}\text { Epstein : } \\
\text { Denny }\end{array}$ & 1983 & A: $1947-76$ & US & Ma & Materlals & Labour, Capltal & Statlc \\
\hline Eichenbaum & 1984 & $M: 1959.1-78.12$ & US & Ma & & $\begin{array}{l}\text { Hours harked, } \\
\text { Inventorlos }\end{array}$ & Rational \\
\hline $\begin{array}{l}\text { Epsitein } 8 \\
\text { Vatchew }\end{array}$ & 1985 & A: $1947-76$ & US & Ma & & Labour, capltal & Nonstatlc \\
\hline Harris & 1985 & $Q: 1968 . I-81 . I V$ & UK & $E$ & & $\begin{array}{l}\text { Hours worked, } \\
\text { Capltal, Utiliza- } \\
\text { tion rate }\end{array}$ & Nonstatic \\
\hline $\begin{array}{l}\text { Kokkelem- } \\
\text { berg } \\
\text { Blsschoff }\end{array}$ & 1986 & Q: 1959. III-77. IV & US & $\mathrm{Ma}$ & $\begin{array}{l}\text { Labour, } \\
\text { Enargy }\end{array}$ & Capitall & $\begin{array}{l}\text { Weakly } \\
\text { ratllonal }\end{array}$ \\
\hline $\begin{array}{l}\text { Holly } \\
\text { Smith }\end{array}$ & 1986 & $Q: 1968.111-79.111$ & UK & Ma & & Labour, Capltal & Static \\
\hline $\begin{array}{l}\text { Koll11ntzas } \\
\text { \& Cassimgs }\end{array}$ & 1986 & Theoretical & US & Ma & $\begin{array}{l}\text { Energy: } \\
\text { Materials }\end{array}$ & Labour, Capltal & Rattonal \\
\hline Morrison & 1986 & A: $1947-81$ & US & $\mathrm{Ma}$ & $\begin{array}{l}\text { Labour. } \\
\text { Energy: } \\
\text { Mateirials }\end{array}$ & Capltal & Nonstatyc \\
\hline
\end{tabular}

TWO TYPES OF LABOUR AND CAPITAL

\begin{tabular}{|c|c|c|c|c|c|c|c|}
\hline $\begin{array}{l}\text { Nadiri \& } \\
\text { Rosien }\end{array}$ & 1974 & $Q: 1947.1-67.1 \mathrm{~V}$ & us & $\mathrm{Ma}$ & & $\begin{array}{l}\text { Blue collar workers, } \\
\text { whlte collat wor- } \\
\text { kers, hours worked, } \\
\text { Capltal, Ut } 11 \text { lzation } \\
\text { rate, Inventorles }\end{array}$ & Statlc \\
\hline $\begin{array}{l}\text { Pyndyck \& } \\
\text { Rotemberg }\end{array}$ & $1983 b$ & $A: 1947-76$ & US & $\mathrm{Mata}$ & $\begin{array}{l}\text { Blue collar } \\
\text { workers }\end{array}$ & $\begin{array}{l}\text { White calliar } \\
\text { workers, Caplital }\end{array}$ & Rat tomal \\
\hline $\begin{array}{l}\text { Kokkel en- } \\
\text { berg }\end{array}$ & 1984 & $Q: 1947.1-79.1 \mathrm{~W}$ & US & Ma & $\begin{array}{l}\text { Blue collar } \\
\text { warkers. } \\
\text { Inventorles, } \\
\text { Hours worked }\end{array}$ & $\begin{array}{l}\text { White collar } \\
\text { workers, Capltal }\end{array}$ & Nonstatic \\
\hline Shap Iro & 1986 & $Q: 1955.1-80 . \mathrm{IV}$ & US & $\mathrm{Ma}$ & & $\begin{array}{l}\text { Blule collar workers, } \\
\text { Whlte collar wor- } \\
\text { kers. Hours worked, } \\
\text { Capltal }\end{array}$ & Rat 1ana 1 \\
\hline
\end{tabular}

$A=$ anrual: $Q=$ quarterly; $M=$ monthly; $E=$ englneerlng; Ma wanufacturing; Ag = aggregate 
Joint tim's expected real present value of proflts. At time t+1 current employment decisions and future input schemes are revised in the light of new information that has become avilable. The occurence of hiring and/or firing costa, geretally referred to as adjustment costs of 1 abour (ACL), prevent firms from instantaneously adjusting the productive workforce to changes in the conomic environment. Generalizations of Sargent"s (1978) model play a central role in this dissertation.

Nickell (1986) presented an overwiew of what was known up unt 11 the early eighties about the size and structure of $A C L$, and surveyed dynamic models of labour demand. In fidition to Nickell"s survey table I. 1 presents an overview of the main econometric studies which examine interrelated input decisions of production factors. A1though already in 1974 Nadiri and Rosen pointed out that employment decisions for production workers differ from those of nonproduction workers, due to differences in hiring costs and fring costs, onlly few authors have considered more than one (aggregate) type of llabour in theit models.

As the overview in table $\mathbb{I} .1$ also shows, existing dynamic labour demand model malnly differ in the way expectations are modelled. In models with static expectations, varlables that are beyond the direct influence of the Elrm arosumed to be stotonary. At some initial time the firm chooses the optimal tume path for the decision variables by maximizing an intertemporal abjective function. The plan remalns unchanged through time, regardess of the new information that becomes available and unexpected changes that may take place. The driving forces of the economy are considered to be beyond the scope of this kind of model. Empirical applications are usua $11 \mathrm{y}$ based on detrended stationary data. 
In nonstatic expectations models, it is asumed that "decishons mate by optimizing the objective function with stochastic warlables replaced by their conditional expectations are close enough approximatoms to those which would result if the expected values mere maximized" (Morrison, 1986 , p.366). Future expectations of exogenous variables are obtained from solutions of ARIMA equations. The nonstationarity of the series of production Eactors is assumed to be deterministic, and is remedied by incorporating deterministic trends.

In rational expectations labour demand models economic agents (e. Reprem sentative firms) use current avaliable and relevant information (and, consequently, do not use past information only) in arder to maximize the expected real. present value of profits over a future time horizon. "ihe stochastic process of exogenous variables is used in forming expectation. In each period, expectations and contingency plans are revised in the light of new information. As a result, rational expectatlons models should not be subject to the lucas critique "

If an econometric model has been derived from econamic theory, its parameters have an economic interpretation. It is possible that the parametors of the stochastic processes of exogenous forcing varlables partially define the parameters of the econometrie nodel for the erdogenous variabes. For example, assume that wages are weakly exogenous ith respect to employmut. This means that past realizations of employment hate no effect on current realizations of wage rates. Assume also that past realization of wage rates however do play a role in the explanation of current employment 1evels. This is called unidirectional Granger-causality from wages to employment, which happens in a perfectly competitive labour market where Eirms are assumed to be price-takers. Now, let a structural break occur in the process that generates wages, consequently changlng (some of) the para- 
theter of the mage equation. Under rational expectations this structural break 111 have an lmpact on the parameters of the employment equation.

The underlyng ecomomic theory often imposes overidentifying restrictions on parameters of the econometric model for the endogenous variables. Structural paraters can be estimated and their plausibility can be exaw mined provided they are lidentified. Useful insights into parameter identification can be obtalned from closed form solutions of the firm's maximization problem first order (Euler) conditions (cf. Hansen and Sargett, 1980, 1981)). Closed form solutions of multivariate 1 inear rationall expectations models were provided by Kollintzas (1985). He showed that the forward looking solution of these models are uniquely determined in terms of structura 1 parameters.

Dynamic factor demand ratonal expectations models often fail to pass tests on overidentifying restrictions. It has been argued that the reason for this dilure may possibly be the simple quadratic specification of structural models from which linear reduced form demand equations are derived. Attempts to overcome this criticism have principally lead to generalizations of production, profit or cost functions (e.g. Berndt and Morrison (1981), itndyck and Rotemberg $(1983 a, b))$. However, since the dymamics of Labour demand in these models are malniy the result of adustment costs, one should seriously question the appropriateness of the quadratic shape of adjustment cost functions introduced by Holl, Modigliban, Muth and Simon in 1960 (cf. Holt et.al. $(1960)$ ) and used in many studies since then.

Recently, some evidence has been given for ACL functions not being stable through time. Smith (1984) has found the speed of workforce adjustment to be positively related to the rate of unemployment. Burgess (1988) has found evidence for a significant effect on ACL of labour market legisla- 
tions, labour market tightness, and union power. Hamermesh (1988) shows that non-convexities of the ACL function (fixed costs) give rise to lumpy adjustment of the firm's workforce to its target level. These authors model the costs that depend on the extent of labour adjustment through a quadratic ACL specification.

In this dissertation, existing rational expectations adjustment costs models for labour demand will be reconsidered, refined, generalized and applied to employment data in manufacturing in the Netherlands and in the UK. Stochastic optimal control techniques and recent econometric methods are used in the analysis. Each chapter has been witten such, that it can be read separately from the others. The dissertation is organized as follows. In chaptex 2 a prototype model of dynamic labour demand is presented. We modify Sargent's (1978) model and apply it to the demand of blue and white collar workers in the Dutch manufacturing sector. The empirical application is carried out using stochastic stationary variables. Nonstationarity in the time series have been removed through detrending of the data prior to estimation of the model. "The two types of labour are assumed to have different wage costs, different productivity and different adjustment costs. We show that Sargent unecessarily restricts the model In order to estimate the structural parameters. Moreover" it lo show that the structural parameters of the model are identified.

In chapter 3, the bivariate labour demand model is extended as follows. Blue and white collar labour demand are assumed to be interrelated. This means that lagged values of wage costs and employment of blue and white collar labour play an important role in the determination of current levels of white collar workers. Employment decisions are assumed to be taken con ditionaly on the capital stock. In contrast to the existing 1 iterature 
and in extendon of chapter 2 , where the nonstationarity of the series of production factor inputs is iewed to be nuisance that is beyond the scope of the theoretical model, me mod the nonstationarity of labour demand as being induced by the nonstatonarity of real wage costs and capital. Following Blamchard and Kann (1980), we use a methodology that iffers from Kollintzas (1985), which allows us to express the closed form solutions of more gonerd linear interrelated labour demand models in terms of structural parameter:

The solution of the sochastic quadratic control problem, applied in chapter 3 for the examination of a bivariate labour demand model with capital. being predetermined, is used in chapter 4 to get more insights into the mestrictions on the paraneters of multivariate flexible accelerator models (see e.g. Treadway (1971), Epstein and Denny (1983)), in which 1 abour and capital are determined simultaneously. Compared with Epstein and Yatchew (1985), we obtain optimal production factor trajectories without previously specifying an expectations formation process.

In line with the Lucas critique, we analyse the impact of structural changes in the processes of exogenous variables on demand for aggregate Labour and capltal in the Dutch manufacturing sector. We examine how the impacts of opl shocks, occurring, in 1973. IV and 1979. II, on real input prices influenced factor demand.

The identifled structural parameters of the models presented in the chapters 2,3 and 4 ate stmated using a two step estimation procedure proposed by Chamberlan (1982) and Gouriéroux et.al. (1985). In a first stage, an uricestricted version of the reduced form of the model is estimated that incorporates the restrictions on the order of the system implied. by the underlying theory. The identified structural parameters are often 
nonlinearly related to the parameters estimated in the first stage. In the second stage, the structural parameters are estimated using the method of Asymptotic Least Squares (ALS) which minimizes the distance between the unrestricted reduced form estimates and the reduced form coefficlents expressed as functions of the basic structural parameters. The Als procedure is asymptotical1y equivalent to Maximum Likelihood (ML) estimation methods, provided ML estimates of the parameter astimates from the first stage are used together with an optimal weighting matrix and all restrictions between structural parameters and reduced form coefficients have been imposed. In order to obtain the weighting matrix the derivatives of the nonlinear relationships between the parameters estimated in the first stage and the structural parameters are needed (see also Appendix A.1).

Chapter 5 examines the appropriateness of the hypothesis of quadratic adjustment costs with respect to dymamic labour demand. Quadratic ACL functions are symmetric. That is, the costs a firm faces when an amount of new warkers are hired (such as expenditures on advertising, screening and training) vary in the same way as when the same number of workers are fired. The quadratic assumption is made mainly for analytical convenience and computational ease, and is most probably at variance with the real structural form of $\mathrm{ACL}$, since "there is no reason for hiring costs to bo syrmetric" (Nicke11, 1986, p. 478).

To get information on the shape of the adjustment costs, interviewed personnel managers of Dutch manufacturing firms. The interviews focussed on decisions of firms to change their productive workforce, and the costs that arise from these changes. Based on the outcome of the interviews "we propose a new ACL specification. The merit of the specification is the possibility to measure the difference between hiring costs and firing costs 
of labour, whereby the asymetry parameter in the specification can be interpreted as a relative measure of the adjustment speed of labout to a target level of employment which increases in periods of economic uprise and decreases in recessfons. Chapter 5 has been coauthored with Bart Verspagen and is forthooming in Economics Letters.

Chapter 6 overcomes one of the shortcomings of the 1 inear rational expectations llabour demand model. We use the more general asymetric functional form as put forward and tested in chapter 5 to model adjustment costs. We present a multivariate asymetratc adjustment costs model of the firm's labour demand, in which the symmetric linear rational expectations model in nested. We analyse two intertemporal models for employment decisions. One model takes capital as a predetermined factor wh respect to employment decisions. The second assumes capital and employment to be simultaneously determined. Further, we examine the impacts of unanticipated shocks in real wage costs, labour productivity or technology on factor input decisions. We report empirical evidence for the two models, using Dutch and U.K. manufactuirng time series. We separately examine the firm"s demand for bllue and white collar labour allowing for ditierences in adjustment costs for the two types of labour. In this way we try to circumvent misleading (with regard to adjustment costs) explanations of employment dynamics in terms of aggregation (cf. Nickell (1984)). We apply the generalized method of moment (GMM) technique of Hansen (1982) in order to estimate the structural parameters of the nonlinear first order conditions derived from the intertemporal optimization model. Among the authors who estimate first order conditions of factor demand models we mention Kennan (1979), Pindyck and Rotemberg $(1983 a, b)$ and Shapiro (1986).

Finally, in chapter 7 the general findings presented in this dissertation are evaluated, and a sumary and conclusions are given. 
CHAPTER TWO

A PROTOTYPE FOR BLUE AND WHITE COLLAR EMPLOYMENT DECISIONS OF RATIONAL ENTREPRENEURS UNDER UNCERTAINTY 


\section{I Introduction}

In this chapter we present a prototype model for labour denand in the Dutch manufacturing sector assuing that firms face adjustment costs and operate under uncertalnty. Labour demand consists of blue and white collar workers. We use quarterly data for the period 1971.1 - 1984. IV to estimate the model. We modify Sargent'g (1978) paper on dynamic labour demand schedules. Using a closed form solution of a linear rational expectation model In which adjustment costs play a dominant role, we show that the structural parameters of the underlying economic theory are identified.

Chapter 2 is organized as follows. In section 2 empirical evidence is presented for uridirectional causality (in the sense of Granger) of wage costs to employment. Section 3 models the demand for blue and white collar labour and derives a closed form solution in terms of underlying structural parameters for a bivariate Inear symetric rational expectations model without interrellatedness of lagged employment declsions of the two types of labour.

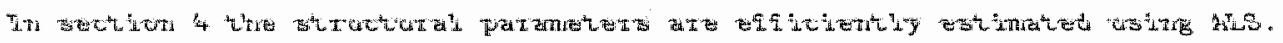
ALS is also used to estimate standard errors for the parameters of production and cost functions. At this point we notice that sargent does not glve standard exrors for the estimated parameters of interest.

The overidentifying restrictions implied by the underlying theoretical model are tested using a likelihood ratio type test. The appropriateness of the model is checked by means of a mutivariate portmanteau test on residual autocorrelation. Finally, the moving average representation of the model is reported along with percentage forecast error variance decompositions implied by vector autoregressions. The results suggest comple- 
mentarty over time between the two types of labour, a strong correlation between their wage costs, due to the way in which increses in wages and salaries are stipulated in labour contracts, and empirical support of oi"s (1962) hypothesis about the quasi-fixedness of costly adjustable labour. Section 5 concludes this chapter.

\section{2 Wage costs, Employment and Causaity}

Hage cosits and demand for labour are related over time. For instance Nefcti (1978) and Sargent (1978) find empirical evidence for unidirectional Granger causallty of wages to employment for post-World War II U.S. manufacturing data. Before investigating the dynamics between wages and employment the appropriate time serles have to be selected. As the flgures in table II. 1 indicate, there exists a considerable difference between hourly wages and wage costs per worker in the Netherlands in the period 1971-1984. This discrepancy is due to holiday allowances and soclal premiums paid by the employer. Assuming that the employment decislons of firms result from a cost-benefit analysis, it is appropriate to choose the wage costs series instead of the wage itself.

rable II.1 : Gross hourly wage and wae costs in the Dutch manufacturing sector in Dutch Guilders (current prices).

\begin{tabular}{|c|c|c|c|c|c|c|c|}
\hline & 1971 & 1972 & 1973 & 1974 & 1975 & 1976 & 1977 \\
\hline Gross hourly wage & 6.53 & 7.23 & 8.26 & 9.62 & 10.97 & 12.19 & 13.28 \\
\hline Hage costs per hour & 11.76 & $13 \cdot 10$ & 14,78 & 17.06 & 19.00 & 20.90 & 22.70 \\
\hline \multirow[t]{2}{*}{ Difference in $\%$} & 80.1 & 81.2 & 78.9 & 77.3 & 73.2 & 71.6 & 70.8 \\
\hline & 1978 & 1979 & 1980 & 1981 & 1982 & 1983 & 1984 \\
\hline Gross hourly wage & 14.23 & 15.04 & 15.85 & 16.96 & 18.37 & 19.08 & 19.54 \\
\hline Wage costs per hour & 25.23 & 27.05 & 28.40 & 29.90 & 32.03 & 33.61 & 35.18 \\
\hline Difference in $\%$ & 77.3 & 79.9 & 79.2 & 76.3 & 74.4 & 76.2 & 80.0 \\
\hline
\end{tabular}

Source : Central Bureau of Statistics. 
The data we ugd to study the caral relation between real wage costs and mploynent of blue and white collar morkers in the Duteh manufacturing seccor ate quarterly data for the period 1971.I - 1984.IV. A description of the data ard their sources is given in appendix $V$. We ignore the possible Influence of other to ime seies. That is, the information set used to test the catsaldty hypothesis omits information about time series, other than wage costg and employment. To check the direction of causality, we have chosen resonably long atoregressions. High order autoregressions should provide a rather good approximation for the second moments af a stationary stochastic process, thereby arolding that possible omission of past values with large coefficients induces spurious significant coefficients on lagged values of other axogenous variables (Geweke, 1978).

Consequently for the alm of testing causality a simple (linear) model with long lags will probably be sufficient. The length of the lagged endogenous variable is fixed at two years and the possible Granger-causing variable is lagged one year. More explicitly, the following bivariate model is considered.

$$
\begin{aligned}
& W_{t}=\text { determinisic part }+\sum_{k=1}^{8} w_{1 k} W_{t-k}+\sum_{1=1}^{4} \eta_{11} N_{t-1}+E_{1 t} \\
& N_{t}=\text { deterninistic part }+\sum_{k=\mathbb{1}}^{4} w_{2 k} W_{t-k}+\sum_{1=1}^{g} \eta_{21} N_{t-1}+E_{2 t}
\end{aligned}
$$

where $W=$ real wage costs, $N=$ number of people employed. The determinlstic pert consists of a constant, trend, quadratic trend and 3 seasonal dumies, and $\left(E_{1 t}, E_{2 t}\right)^{\prime} \sim \operatorname{IIN}\left(0, \Sigma_{2}\right)$

If the real wage costs are Granger-caused by employment we should reject the mypothesis $H_{1}: \eta_{11}=0,1=1, \ldots 4$ as being invalid. Analogously the hypothesis $\mathrm{IL}_{2}: \omega_{2 k}=0, k=1, \ldots 4$ should be rejected when wages Granger- 
cause the employment level. The bivariate madel is estimated for blue collar workers as well as for white collar workers. Testing for H we find 1 ikelihood ratio (LR) test statistics of 1.98 and 1.30 for blue and white collar workers respectively. The hypothesis H $\downarrow$ cannot be rejected at the conventional significance level of $5 \%$ for either sort of labour. The LR-statistics for $\mathrm{H}_{2}$ equal 11.64 and 9.40 respectively. These results indicate unidrectional causality from the real wage costs to employment in both cases.

Alternatively, we can take into account mutual influences between the two labour categories. Consequently we have fitted the data to a four-varlate vector AR(4) model for wage costs and employment, with deterministic part being identical to that of the prewious model. Then it is possible to test. simultaneousiy for feasible causal relations between the two wage costs series on the one hand and the employment series on the other. A Wald test. based on OLS estimates of the unrestricted four warlate model can straight forwardly be carried out. The hypothesis $\mathrm{H}_{1}$ and $\mathrm{H}_{2}$ are defined in accordance with the definitions above, aside from the fact that either hypothesis now implies eight restrictions (instead of four in the previous model). We find a Wald test statistic for the restrictions that miployment doos not Granger-canse wage costs of blue and white colltar workers of 7.80.

The Wald test statistic of the hypothesis that wage costs do not Grangercause employment equals 31.44 .

In conclusions we can say that these results are similar to the Neftci-Sargent finding on causality : Unidirectional causality from the real wage costs to employment is in accordance with the information in the data for both categories of labour in the Dutch industrial sector. 


\section{II.3 Modelling the Demand for Labour}

In this section, we introduce the theoretical model and we derive the implications of the theory for the time series process of wage costs and employment. We isime that a representative firm hires blue and white collar workers denoted by $\mathrm{n}_{1}$ and $\mathrm{n}_{2}$ respectively. The short-run production function (EF) of the firm is specified as

(II,1) $Y_{t}\left(n_{1 t}, n_{2 t}\right)=\sum_{i=1}^{2}\left\{\left(a_{i 1}+s_{i t}\right) n_{i t}-1 / a_{12} n_{i t}^{2}\right\} ; a_{11}>0, a_{i 2}, 0, i=1,2$.

$$
t=0,1,2, \ldots \ldots
$$

The rate of output per period of time is denoted by $\Psi_{t}, \alpha_{i 1}$ and $\alpha_{i 2}$ are constant parameters. Because capital is assumed not to be a decision variable in the short-run, it is assumed to be predetermined, and not explfcitly included in the production function. The variables $s_{1}$ and $s_{2} t$ are exogenous stochastic shocks of the production. The production function is specified in such a way that conditional on $\mathrm{n}_{1 \mathrm{t}}$, average productivity follows a stationary stochastic process $s_{i t}$. At every point in time a firm. maximizes the expected real present value of profits given all the available information. In reaction to a change in the environment such as for instance a change in relative factor prices or a shock in product demand, the firm wlll follow the same decision rule. But the result of the dectsion 11 depend on the realization of the exogenous shocks. A quadratic PF lacally approximates the range of diminishing productivity of factors of production.

In line with the literature on dynamic factor demand models (e.g. Holt, et al. (1960); Nickell (1986)), we assume that the adjustment cost function is quadratic. The adjustment costs of a reduction of the number of people 
employed, which are firing costs and the loss of firm spectellc knowledge are very difficult to measure. Although it is very unlikely that the casts of a reduction of the workforce will be similar to the costs of expansion, for computational ease, we assume a symmetric adjustment cost function

(II.2) $\quad \mathrm{AC}_{t}\left(\mathrm{n}_{1 t}, \mathrm{n}_{2 t}\right)=\sum_{i=\mathbb{1}}^{2} H_{i}\left(\Delta \mathrm{n}_{\mathrm{it}}\right)^{2} ; B_{\mathrm{i}}>0, i=1,2$.

The real adjustment costs $B_{i}$ are assumed to be constant. Normally, white collar workers will be employed in positions for which more job-specific knowledge is required. The hiring procedure will be more expensive, and the time before they are productive will be longer. Therefore, 1 t seems quite plausible that the adjustment costs for white collar workers will be higher than those for blue collar workers, $1 . e . \mathbb{B}_{2}>\mathbb{B}_{1}$ "

The variable wage costs are assumed to be proportional to the number of workers employed :

(II.3) $w_{t}\left(n_{1 t}, n_{2 t}\right)=\sum_{i=1}^{2} w_{i t} n_{i t}$.

The firm uses the relevant information up to time $t$, including the real. wage costs per worker at time $t$, denoted by $w_{1 t}$ and $w_{2 t}$ respectively, to choose contingency plans for the employment of blue and white collar workers. In order to determine the actual optimal employment decisions at time $t$, the rational entrepreneur has to plan future employment decisions. He will revise his plans at $t$ ime $t+1$ in the 1 ight of new information. The firm's objective is to maximize its real present value at time $t$, that is

(II.4) $\operatorname{Max} \mathrm{PV}_{t}=\operatorname{Max} E_{t} \sum_{j=0}^{\infty} \tau \tilde{j}\left[Y_{t+j}-\mathrm{AC}_{t+j}-W_{t+j}\right] ; 0<\tau<1$. 
The operator $\mathbb{E}_{\mathrm{t}}$ in defined as the conditional expectations $\mathrm{F}_{\mathrm{t}} \mathrm{x} \equiv \mathrm{E}\left(\mathrm{x} / \Omega_{\mathrm{t}}\right)$, where $x$ is a radon vartable and $\Omega_{t}$ is the set of information avallable to the frrm at the t: which includes $s$ and wt $\tau$ is a real discount factor. For the sake of simplicity of the notation, the arguments af the functions in (II.4) Wave been deleted. First arder necessary conditions for maximization of (II.4) consist of the Euler equations and a pali of transverality conditions which asure the finiteness of the process (see e.g. Sargent, 1979 , chpts. 9 and 14 ).

The wolution at time $t$ of the Euler equations to this infinite time hor izon problem, which satisfy the transversality conditions is as follows

$$
\begin{gathered}
\text { (II.5) } \mathbb{E}_{t} n_{1 t+1}=k_{1} n_{i t}-\tau^{-1} n_{1 t-1}-\left(\beta_{i} \tau\right)^{-1}\left(a_{1 i}-w_{i t}+s_{i t}\right), \\
\text { with } k_{1}=\left(\beta_{i}(\tau+1)+a_{2 i}\right) / \beta_{i} \tau, \quad i=1.2 .
\end{gathered}
$$

According to (II.5), at time $t$, the expected or planned employment level in period $t+1$ is 1 inearly related to the current and one period lagged employment 1 wel and to the current wage costs.

The axpected or planned value of $\mathrm{n}_{1}$ in the future, $\mathrm{E}_{\mathrm{t}} \mathrm{n}_{\mathrm{i}}+1$, can not be observed as such but has to be determined in the model. To find a solution of the buler linem diference model under rational axpectations, we follow Blanchard \& Khn (1980) and augment (II.S) as follows

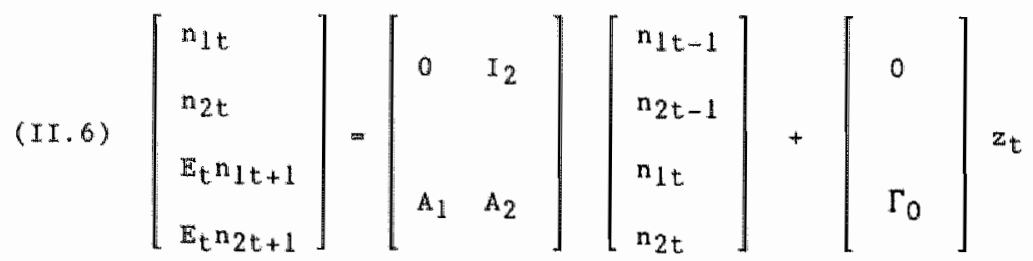

with $A_{1}$ belig a $2 \times 2$ diagonal matr $1 \times$ with $-\tau^{-1}$ on the dilagonal, 
$A_{2}=\left[\begin{array}{cc}k_{1} & 0 \\ 0 & k_{2}\end{array}\right] \quad \Gamma_{0}=\left[\begin{array}{ccc}-\alpha_{11} / B_{1} \tau & 1 / B_{1} \tau & 0 \\ -\alpha_{12} / B_{2} \tau & 0 & 1 / B_{2} \tau\end{array}\right]$, and

$z_{1 t}^{\prime}=\left(1 w_{1 t}-s_{1 t} w_{2 t}-s_{2 t}\right)^{\prime} ; 1=1, \ldots, 4 ; z_{t}=\left(z_{1}, \ldots, z_{4 t}\right)^{\prime}$

We transform the companion matrix $A=\left[\begin{array}{cc}0 & I_{2} \\ A_{1} & A_{2}\end{array}\right]$ into Jordan's canonical

form $A=c^{-1} A C$, where $C^{-1}$ consists of eigenvectors of A associated with the eigentalues on the diagonal of matrix $\Lambda$.

$\Lambda$ is partitioned as $N=\left[\begin{array}{ll}\Lambda_{1} & 0 \\ 0 & \Lambda_{2}\end{array}\right]$, where $\Lambda_{1}$ has on the diagonal all the eigenvalues of $A$, that lie on or ithin the unit circle and $A_{2}$ contains all the eigenvalues that lie outside the unit circle. The number of diagonal elements of $\Lambda_{2}$ defines the number of stationarity solutions of the difference equations in (II. 6). For models with a quadratic objective function the number of eigenvalues greater than one equals the number of eigenvalues within the unit circle (see e.g. Kollintzas, 1985). This fmplies that both $\Lambda_{1}$ and $\Lambda_{2}$ are diagonal matrices of order 2 , and that a unique, otationary forward looking solution exists for the expectations variables.

Bartitioning $C$ in accordance with $A$ the unique solution af the Euler equations (see Blanchard \& Kahn (1980) at time $t$ can be expressed as

$n_{t}=-C_{22}^{-1} \quad C_{21} \quad n_{t-1}-C_{22}^{-1} \sum_{1=0}^{m} A_{2}^{-i-1} \quad C_{22} \Gamma_{0} E_{t}\left(z_{t+i} \mid \Omega_{t}\right)$

where $n_{t}=\left(n_{1}, n_{2 t}\right)^{\prime} \cdot A s C_{22}^{-1}$ and $\Lambda_{2}$ are diagonal and $-C_{22}^{-1} C_{21}=M_{1}$, the solution can be simplified further to become

(II. J) $\mathrm{n}_{t}=\Lambda_{1} n_{t-1}-\sum_{i=0}^{\infty} \Lambda_{2}^{-i-1} \Gamma_{0} E_{t}\left(z_{t+i} \mid \Omega_{t}\right)$. 
In (1.7) the employment level in period t is expressed as a Inear relationship of the enployment level in the previous period and of the expected walues of the exogenous vatiabes $z$ over the infinite future horizon. The parameters in (II.7) are nonjinear functions of the structural parameters In the objective function (II.4). More specifically, the elgenvalues of A which are the elagonal lements of $\Lambda$, can be expressed as follows

$$
\begin{array}{ll}
\lambda_{1}=1 / 2 k_{2}+\frac{1 / 2}{\sqrt{k_{2}^{2}-4 / \tau}}, & \lambda_{2}=1 / k k_{2}-1 / 2 \sqrt{k_{2}^{2}-4 / \tau} \\
\lambda_{3}=k / k_{1}+1 / 2 \sqrt{k_{1}^{2}-4 / \tau} & \lambda_{4}=1 / k_{1}-1 / 2 \sqrt{k_{1}^{2}-4 / \tau}
\end{array}
$$

From the asimption that the parameters $\alpha_{21}, \alpha_{22}, \beta_{1}, \beta_{2}$ and the real discount factor $\tau$ are nonnegative, it follows that

$$
\left|\lambda_{1}\right|>1 ;\left|\lambda_{2}\right| \leq 1 ;\left|\lambda_{3}\right|>1 ;\left|\lambda_{4}\right| \leq 1
$$

The matrix $C^{-1}$ partitioned according to $\Lambda$ can be written as

$$
C^{-1}=\left[\begin{array}{cccc}
1 & 0 & 1 & 0 \\
0 & 1 & 0 & 1 \\
\lambda_{4} & 0 & \lambda_{3} & 0 \\
0 & \lambda_{2} & 0 & \lambda_{1}
\end{array}\right] ; \quad \Lambda=\left[\begin{array}{cccc}
\lambda_{4} & 0 & 0 & 0 \\
0 & \lambda_{2} & 0 & 0 \\
0 & 0 & \lambda_{3} & 0 \\
0 & 0 & 0 & \lambda_{1}
\end{array}\right] .
$$

By assuming linear stochatic processeg for $s_{t}=\left(s_{1 t}, s_{2 t}\right)^{\prime}$ and wt (wt, wet)' we can express $\mathrm{n}_{\mathrm{t}}$ in (II.7) as a linear function of observed wariables, with parameters which are nonlinear functions of the structural parameters of production and labour costs functions and the parameters of the exogenous stochastic processes. Assuming that the stochastic components of labour productivity $s_{t}$ are generated by a first order Markov process 
$s_{t}=R s_{t-1} * \xi s_{t}$

where

$R=\left[\begin{array}{ll}\rho_{1} & 0 \\ 0 & \rho_{2}\end{array}\right]: \xi_{t}^{S}=\left[\begin{array}{l}\xi_{1 t} \\ \xi_{2 t}\end{array}\right]$, being an innovation with $E \xi_{t}^{S}=0$,

$E \xi_{t}^{s} \xi_{t}^{s}=\Sigma_{1}$, we have

(II.8) $E_{t} s_{t+i}=R^{i} s_{t}, i \geq 0$.

Further we assume that wh is generated by a second order autoregressive process

(II.9) $w_{t}=C_{0}+M_{1} w_{t-1}+M_{2} w_{t-2}+\xi_{t}^{w}$

with constant term $C_{0}, M_{j}=\left[\begin{array}{cc}\mu_{1 j} & 0 \\ 0 & \mu_{2 j}\end{array}\right]$ and $\underset{t}{\xi^{\omega}}=\left[\begin{array}{c}\xi_{3 t} \\ \xi_{4 t}\end{array}\right]$ being the wage innovation with $E \xi_{t}^{W}=0$ and $E \underbrace{\xi_{t}^{W}}_{t} \xi_{t}^{w^{n}}=\Sigma_{2}$.

We are looking for an explicit solution of the second right handside (r.h.s.) teerm of (II, 7)

$$
\begin{aligned}
& (\mathbb{I} I .10)-\sum_{i=0}^{\infty} \Lambda_{2}^{-i-1} \Gamma_{0} E_{t}\left(z_{t+i}\right)=\delta_{0}+\sum_{i=0}^{\infty} \Lambda_{2}^{-i-1} \Gamma E_{t}\left(s_{t+1}\right) \\
& -\sum_{i=0}^{\infty} \Lambda_{2}^{-i-1} \Gamma E_{t}\left(w_{t+i}\right)
\end{aligned}
$$

where $\delta_{0}$ is a $(2 \times 1)$ vector with constant elements and $\Gamma=\left[\begin{array}{cc}1 / \beta_{1} \tau & 0 \\ 0 & 1 / \beta_{2} \tau\end{array}\right]$

Substituting (II.8) into the second r.h.s. term of (II.1.0) and using the fact that $\Gamma$ is diagonal, we find that 
(II.1.1) $\sum_{i=0}^{\infty} \Lambda_{2}^{-i-1} \Gamma \mathbb{E}_{\mathbb{E}}\left(s_{t+1}\right)=\mathbb{E}_{1} s_{t}$

where $P_{1}=\Gamma \Lambda_{2}^{-1}\left(I-\Lambda_{2}^{-1} R\right)^{-1}$

Similarly the thitd r.h. s. term of (II.10) can be expressed as

$(I 1.12) \Gamma \sum_{1 \neq 0}^{\sum} A_{2}^{-1-1} \mathrm{E}_{t}\left(w_{t+1}\right)=\mathbb{P}_{2}\left(w_{t}+\Lambda_{2}^{-1} M_{2} w_{t-1}\right)$,

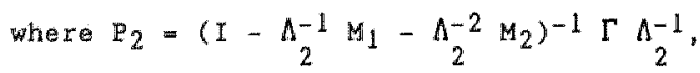

as $\mathbb{E}_{t}\left(w_{t+1}\right)=M_{1} E_{t}\left(w_{t+1-1}\right)+M_{2} E_{t}\left(w_{t+1-2}\right)$ if we ignore the constant term. Substituting the expressions (II.10), (II.11) and (II.12) into (II.7), and deleting the constant terms 1), we find that

(II. 13) $n_{t}=\Delta_{1} n_{t-1}+P_{1} s_{t}-\mathbb{P}_{2}\left(w_{t}+\Lambda_{2} M_{2}^{-1} w_{t-1}\right)$

To eliminate the autocorrelation of $s_{t}$, we apply the Koyck transformation to (II.13). Unexpected economfo changes will affect productivity $\left(\xi_{t}^{s}\right)$ as we l. as wage costs $\left(\xi^{W}\right)$. This effect is partly specific to productivity or wage costs, and it party causes a mutually dependent inmovation. Conseguentiy, we substutute the process (II.9) for to to derive the reduced form of the joint process for wh and $n_{t}$, which is a four wariate autoregression of the form

1) The dat used to estimate the parameters of the model have been adjusted for a constant, trend and seasonal dummies for reasons to be explatined in section 4 . 
(II.14a) $w_{t}=M_{1} w_{t-1}+M_{2} w_{t-2}+\xi w_{t}$

(II. 14b) $\mathrm{n}_{t}=\left(\mathrm{R}+\Lambda_{1}\right) \mathrm{n}_{\mathrm{t}-1}-\mathrm{R} \Lambda_{1} \mathrm{n}_{t-2}+\mathrm{P}_{2}\left(\mathrm{R}-\mathrm{M}_{1}-M_{2}^{-1} M_{2}\right) w_{t-1}$

$\mathbb{P}_{2} M_{2}\left(R A^{-1}-I\right) w_{t-2}+P_{1} \xi_{t}^{s}-P_{2} \xi_{t}^{w}$

The disturbance term $\left[\xi_{t}^{w},\left(P_{1} \xi_{t}^{s}-P_{2} \xi_{t}^{w}\right)\right]^{\prime}$ is assumed to be serially uncorrelated, normally distributed with mean zero and covariance matrix $\Sigma$, which is unrestricted (symmetric), as a result of the assumed diffusion of innovations in the system.

The restricted model, expressed in structural parameters, follows from (II.14)

(II. 15a) $w_{1 t}=\mu_{11} w_{1 t-1}+\mu_{12} w_{1 t-2}+\xi_{1 t}^{w}$

(II.15b) $w_{2 t}=\mu_{21} w_{2 t-1}+\mu_{22} w_{2 t-2}+\xi_{2 t}^{w}$

(II.15c) $n_{1 t}=\left(\lambda_{4}+p_{1}\right) n_{1 t-1}-\lambda_{4} \rho_{1} n_{1 t-2}+\varepsilon_{1}^{-1}\left(\rho_{1}-\mu_{11}-\tau \lambda_{4} \mu_{12}\right) w_{1 t-1}$

$+\delta_{1}^{-1}\left(\mu_{12}\left(\tau \lambda_{4} p_{1}^{-1}\right)\right) w_{1 t-2}+e_{1 t}$

(II.15d) $n_{2 t}=\left(\lambda_{2}+\rho_{2}\right) n_{2 t-1}-\lambda_{2} \rho_{2} n_{2 t-2}+\delta_{2}^{-1}\left(\rho_{2}-\mu_{21}-\tau \lambda_{2} \mu_{22}\right) w_{2 t-1}$

$+\delta_{2}^{-1}\left(\mu_{22}\left(\tau p_{2} \lambda_{2}-1\right)\right) w_{2 t-2}+2 t$

where

$$
\begin{aligned}
& \delta_{1}=\tau \beta_{1}\left(\lambda_{3}-\mu_{11}-\mu_{12} \lambda_{3}^{-1}\right), \delta_{2}=\tau \beta_{2}\left(\lambda_{1}-\mu_{21}-\mu_{22} \lambda_{1}^{-1}\right) \text {, and } \\
& \left(e_{1 t} e_{2 t}\right)^{\prime}=\mathbb{P}_{1} \xi_{t}^{s}-P_{2} \xi_{t}^{w} .
\end{aligned}
$$




\section{II.4. Fmp ixical Results}

In this aection the model is estimated using quarterly data on employment (measured in thowands of men), and indices of real weekly wage costs of blue and white collat workers in the Dutch industrial sector. These data are obtained from the Central Bureau of Statistics and cover the period from 1971.I through 1984.IV. A more detailed description of the data is giver in append g $_{\mathrm{W}} \mathrm{V}$. We assume that the impact of production factors, such as capttal stock, which are not explicitly modelled, can be approximated by determintistictrend. Therefore, in a first instance, we detrend the data by regression us lng a constant, a linear and a quadratic trend and three seasonal dumies. The residuals from these regressions are used as data the subsequent analysis.

An interesting feature of the causality hypothesis is that it offers the possibility to determine the order of the wage costs series independently from the employment data. This can be done straightforwardly by analyzing the bivariate process for wage costs which is assumed to be a simple Markov-process (II.9). In table HI.2, the values of three order selection crttera are pregented for the wage costs equations in (II. 15). "Two of then denoted by MSBIC and HKBIC respectively are multivariate variants of Schwarz's univariato Bayesian information criterion. Both criteria ylela strongly consistent astimates of the order of the model. The third denoted by LR, is the likelihoad-ratio test, which compares the system (2.9) with an autoregressive system with diagonal parameter matrices and one additional lag. Under the null hypothesis, the LR is asymptotically $x^{2}(2)-$ distributed. From table II.2 it results for all three criteria that the order of the wage costs series can be chosen to be two. Given the order of the process for wage costs, the order of the wage costs in the equations for employment is completely determined. 
Table II.2 : Bivariate order selection tests of $(2.9)$ *

\begin{tabular}{crrr} 
order & MSBIC & HKBIC & \multicolumn{1}{l}{-} \\
1 & -3.834 & -3.980 & - \\
2 & -4.354 & -4.649 & 45.788 \\
3 & -4.040 & -4.489 & 0.379 \\
4 & -3.739 & -4.347 & 1.534
\end{tabular}

* The criteria MSBIC and HKBIC are given by Lutkepohl (1984) and Hannan and Kavalieris $(1984)$ respectively. MSBIC $=\operatorname{Minimize}\left(\log \left|\Omega_{\mathrm{p}}\right|+\mathrm{T}^{-} \mathrm{l}^{2} \mathrm{p}\right.$ in $\left.\mathrm{T}\right)$ HKBIC $=$ MinImize $\left(\log \left|\hat{\Omega}_{\mathrm{p}}\right|+\mathrm{T}^{-1} \mathrm{~d}(\mathrm{p})\right.$ ln $\left.\mathrm{T}\right)$, where $\mathrm{T}$ is the number of observations, $k$ is the dimension of the process, $\hat{\Omega}_{\mathrm{p}}$ is the ML-astimate of the residual covariance matrix, $p$ is the estimated order of the process and $d(p)$ is the number unknown system parameters.

The determination of the order of the employment process from the data is mare difficult. We know that the number of lags in employment in the $f$ inal madel (II.15) is always one more than the order of the stochastic process of $s_{t}$ in (II.B). This could be checked against the information in the data. We could investigate the order of the four-variate moded (II. 15). But in absence of computational facilities yet, we assume that the number of lags in the firal model (II.15) equals two. Later we will check whether this assumption is in accordance with the sample informaton. The param meter estimates of (II.15) are obtained from ful1 infomation maximum $11 k e-$ 1.hood, where $\mathrm{V}$ is unknown and updated ewery 1teration according to the Bard-criterium minimizing $|v|$. We used the Davidson- Fletcher- powell. technique to find the maximum of the 1 lkelihood function; the parameter $t$ was chosen a priori to be 0.98 . Once the estimates re of (II.15) are obtained, estimates of the structural parameters of both the production function and the adjustment cost function can be computed by asymptotic least squares estimation (ALS). 
Table II.3: Estimation of the resticted model from seasonally adfusted quarterly data 1971. III - 1984. IV (standard errors are given whin parentheses).

blue collat workers

FIMI :

$$
\begin{aligned}
& \mu_{11}=1.245 \quad(0.127) \\
& \mu_{12}=-0.478 \quad(0.150) \\
& \rho_{1}=0.845 \quad(0.082) \\
& \delta_{1}=1.261 \\
& \lambda_{4}=0.373 \quad(0.824)
\end{aligned}
$$

ALS: :

$\alpha_{12}=0.82$

\begin{tabular}{|c|c|c|}
\hline & 1.19 .4 & 60 \\
\hline & $=-0.431$ & $(0.192)$ \\
\hline & 0.714 & $(0.168)$ \\
\hline & 2.680 & $(2.334$ \\
\hline 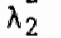 & 0.80 .4 & $(0.178$ \\
\hline
\end{tabular}

$B_{1}=0.752$

(. 539$)$

$(.430)$

\section{white collar workers}

$a_{22}=0.381 \quad(0.332)$

$B_{2}=6.188 \quad(5.725)$

$\Sigma=\left[\begin{array}{rrrr}.066 & & \\ .065 & .154 & \\ -.007 & -.015 & .093 & \\ -.002 & .009 & .019 & .021\end{array}\right]$

$10 \mathrm{I}-8.747$. 
Table II.3 shows that the two equations for wage costs satisfy the stabl1ity conditions. The fact that the estimate of $\rho_{1}$ exceeds that of $\rho_{2}$ can be interpreted as a faster reaction of blue collar productivity to exogenous shacks. In other words, blue collar productivity is more flexible. The estimate of the adjustment costs parameter of white collat workers $1 \mathrm{~s}$ much higher than that of blue collar workers, a finding that is intuitively plausible. The number of parameters of the restricted model amounts to ten. If we ignore the restrictions on the model (II.15) which are implied by the underlying optimisation model, an unrestricted model with 12 parameters results. To check whether the restrictions are in agreement with the information in the data, we compute the likelihood value of the restricted $\left(L_{r}\right)$ and unrestricted $\left(L_{u}\right)$ models respectively. The associated liked ihood ratio statistic equals 3.466 . It is asymptotically chi-square distributed with two degrees of freedom, so that we can conclude that the restricted model is in agreement with the sample information.

To see whether the dynamics of the restricted model are carrectly specified, we computed the multivariate Box-Plierce (BP) dignostic test for residual autocorrelation given by Hosking (1980). The BP test has an asymptotic chi-square distribution with $16.5-10$ degrees of fredom, where is the number of autocorrelation matrices on which the test ls based, and 10 the number of $A R$ parameters in the model. Results are given in table II.4. The test points out that some autocorrelation occurs in the residuals for lags up to five. Given that the test has 11 tele power if $s<10$, the conclusion might be justified that no serious residual autocorrelation Is left, that could influence the parameter estimates. This aspect has to be further investigated. 
Tabie II 4: Multuariate Box-Pierce test on residual aucocorrelation. *

\begin{tabular}{|c|c|c|c|c|c|}
\hline 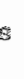 & $\mathrm{BP}$ & $x^{2} .95$ & $s$ & $\mathrm{BP}$ & $x^{2} .95$ \\
\hline 1. & 27.86 & 12.95 & 6 & 105.82 & 108.65 \\
\hline 2 & 54.79 & 33.92 & 10 & 172.54 & 179.59 \\
\hline 3 & 67.60 & 53.38 & 15 & 255.93 & 266.38 \\
\hline$L_{*}$ & 87.11 & 72.15 & 20 & 329.02 & 352.06 \\
\hline 5 & 97.81 & 90.53 & & & \\
\hline
\end{tabular}

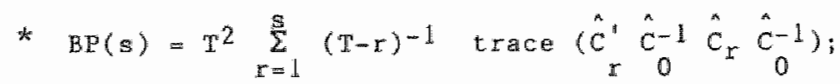

whate $\hat{C}_{r}=1,1 \sum_{t \in r}^{T} \epsilon_{t} \hat{E}_{t-r}^{*}$.

More insights into the dynamics of the modal can be obtained by analyzing its moving everage representation (MAR). For a closed linear dynamic system the MAR corresponds to the impulse response function to a unit innovation. The MAR is non unique. As we shajl see, some response functions have an ecomomic interpretation. In figures II. 1 - II.4 we give the coefficients of the MAR whare the cowarlance matrix of the innovations of (wt, $2 t$, ndt, nzt ' has been diagonalized by a lower triangular matrix.

The following inferede can be drawn from figures II. 1 to II 4 :

(i) A random shock of the wge costs of blue collar workers affects the wage costs of blue and whte collar workers, in almost the same way. This lis the result of a positive correlation between the two wage costs series. 
(ii) In the short-run, a decrease of the wage costs is paired by a rise in the labour demand, and vide versa.

(1ii) A positive shock of the wage costs of white collat workers has as very smal negative effect on the demand for blue collar workers amd hardly any shortrun effect on the demand for white collar worker.

(iv) A positive random shock in the equation of employment of blue col lar workers has a long positive effect on both sorts of workers. This suggests complementarity of the two production factors.

The positive correlation between the two wage costs series can be explained by institutional factors, like wage-bargaining between employers ard unions. In the industrial sector of the Netherlands colloctive wage agreements between employers and labour unions are negotiated every year for both sorts of workers. Economic theory gives an explantion for the result (ii). A fall in prices leads to a rise in demand. The finding (iij) is due to the difference in quasi-fixedness of both labour categories. This phenomemon has been observed also in table II.3, where it is expressed in terms of differences in adjustment cost.

In tables II.5 and II.6, for the various wariables in the model and for the various orders of orthogonaliztion, we present the percentag of the for cast error variance accounted for by the different variables in the model after 40 periods. Table II.5 shows the decomposition of variance implied by the restricted model (II. 15) for parameter estimates which are reported in table II.3. The variance decomposition in table II.6 in implied by an unrestricted second order vector autoregression for (wit, wht, n1t, n2t)" These results are strong evidence for a causal direction from wage costs to employment, since a considerable percentage of variance in employment forem casting errors is due to innovations in real wage costs. There lis much 
legs ewdence for causalty in the opposite direction. However, a substantial percentage of varance in forecat errors in enployment of one type of workes can be ascribed to innovations about two types of labour are dyna-

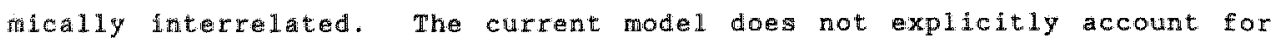
interaction of production factors, so that in this respect the model could be further refined.

Table II.5: Percentage forecast error variance decomposition up to $40-$ steps-ahead Implied by the model (1971. III - 1984. IV).

\begin{tabular}{|c|c|c|c|c|c|c|}
\hline \multicolumn{2}{|l|}{ Orthogonalization } & $x \backslash y$ & $w \mathbb{1}$ & 2 & $\mathrm{n}_{1}$ & $\mathrm{n}_{2}$ \\
\hline \multirow[t]{4}{*}{$\operatorname{ordet}: " w_{1}, \mathrm{n}_{1}}$, & $\mathrm{n}_{2}$ & $w_{1}$ & 100 & 0 & 0 & 0 \\
\hline & & $w_{2}$ & 39.5 & 60.5 & 0 & 0 \\
\hline & & $n_{1}$ & 25.4 & 1.4 & 73.2 & 0 \\
\hline & & $n_{2}$ & 4.8 & 26.2 & 17.1 & 51.9 \\
\hline \multicolumn{2}{|l|}{ Orthogonalization } & $x \backslash y$ & $w_{1}$ & $w_{2}$ & $\mathrm{n}_{1}$ & $\mathrm{n}_{2}$ \\
\hline onder: $w_{2}, n_{\Downarrow}, \mathbf{n}_{2}$ & $w_{1}$ & $w_{1}$ & 57.2 & 39.5 & 0 & 3.3 \\
\hline & & $w_{2}$ & 0 & 100 & 0 & 0 \\
\hline & & $n_{1}$ & 17.5 & 8.8 & 72.7 & 1.0 \\
\hline & & 2 & 0 & 27.9 & 17.1 & 55.0 \\
\hline \multicolumn{2}{|l|}{ Orthogonalization } & $x \mid y$ & $W$ & $w_{2}$ & $\mathrm{n}_{1}$ & $\mathrm{n}_{2}$ \\
\hline \multirow{4}{*}{$\operatorname{order:} n_{1}, n_{2}, w_{1}$} & $w_{2}$ & $w_{1}$ & 98.6 & 0 & 1.4 & 0 \\
\hline & & $w_{2}$ & 38.1 & 51.7 & 3.3 & 6.9 \\
\hline & & n 1 & 30.2 & 0 & 69.8 & 0 \\
\hline & & $n_{2}$ & 6.6 & 8.9 & 10.6 & 73.9 \\
\hline \multicolumn{2}{|l|}{ Orthogonalization } & $x \backslash y$ & $w_{1}$ & $N_{2}$ & $\mathrm{n}_{1}$ & $n_{2}$ \\
\hline \multirow{4}{*}{ order : $n_{2}$ " $w_{1}, w_{2}$} & $m_{1}$ & $w_{1}$ & 99.6 & 0 & 0 & 0.4 \\
\hline & & $w_{2}$ & 41.1 & 56.5 & 0 & 2.4 \\
\hline & & $n_{1}$ & 26.4 & 4.9 & 55,2 & 13.5 \\
\hline & & $n_{2}$ & 7.1 & 9.8 & 0 & 83.1 \\
\hline
\end{tabular}


Table II.6 : Percentage forecast error variance decomposition up to $40-$ quarters-ahead implied by vector autoregression for

$$
\begin{aligned}
& \left(w_{1}, w_{2}, n_{1}, n_{2}\right) . \\
& (1971 . \text { III }-1984 . I V) .
\end{aligned}
$$

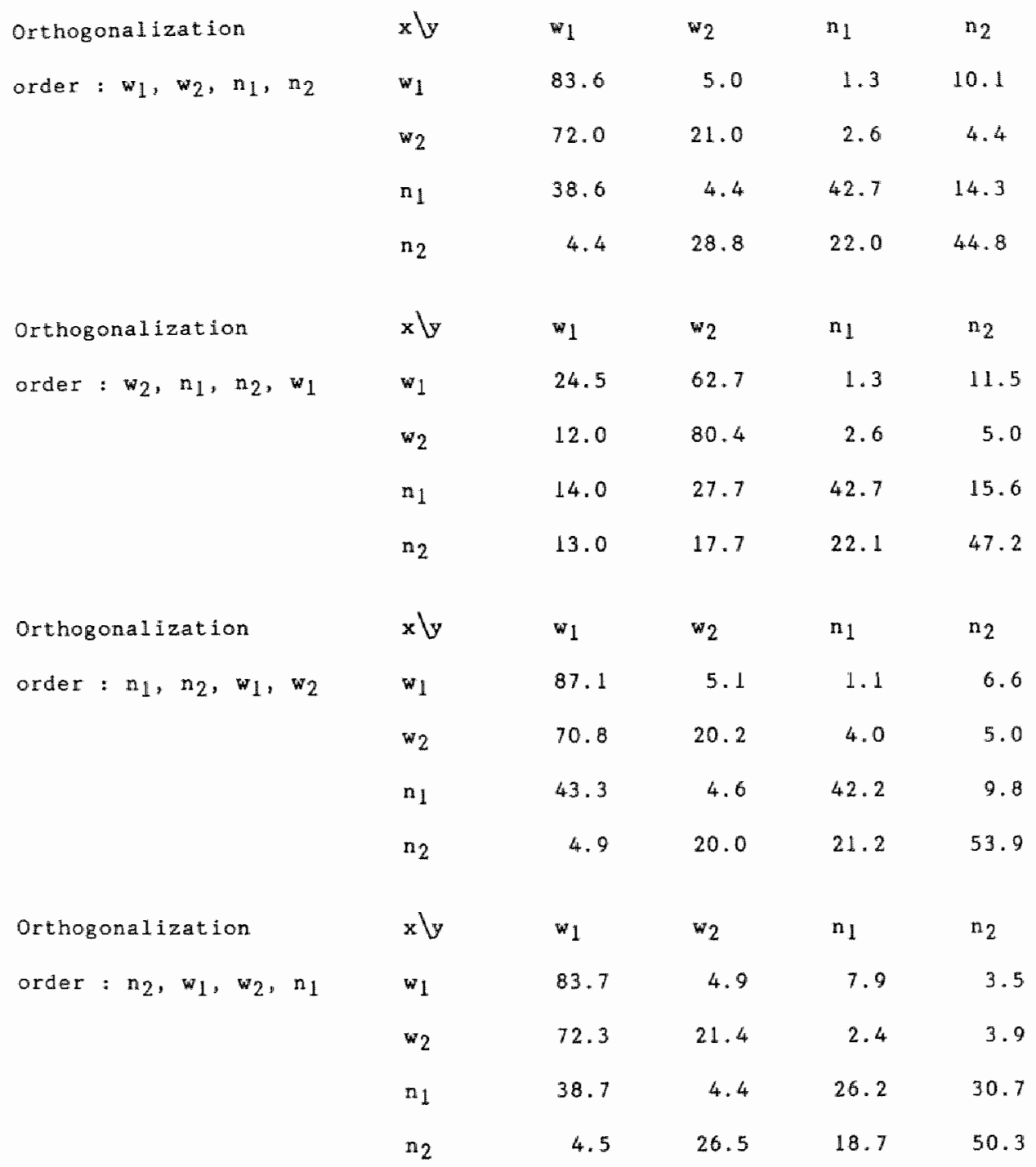


Eipure II.1: Impulse Response of $W_{1}, W_{2}, N_{1}, N_{2}$ to Innovation of $H_{1}$.

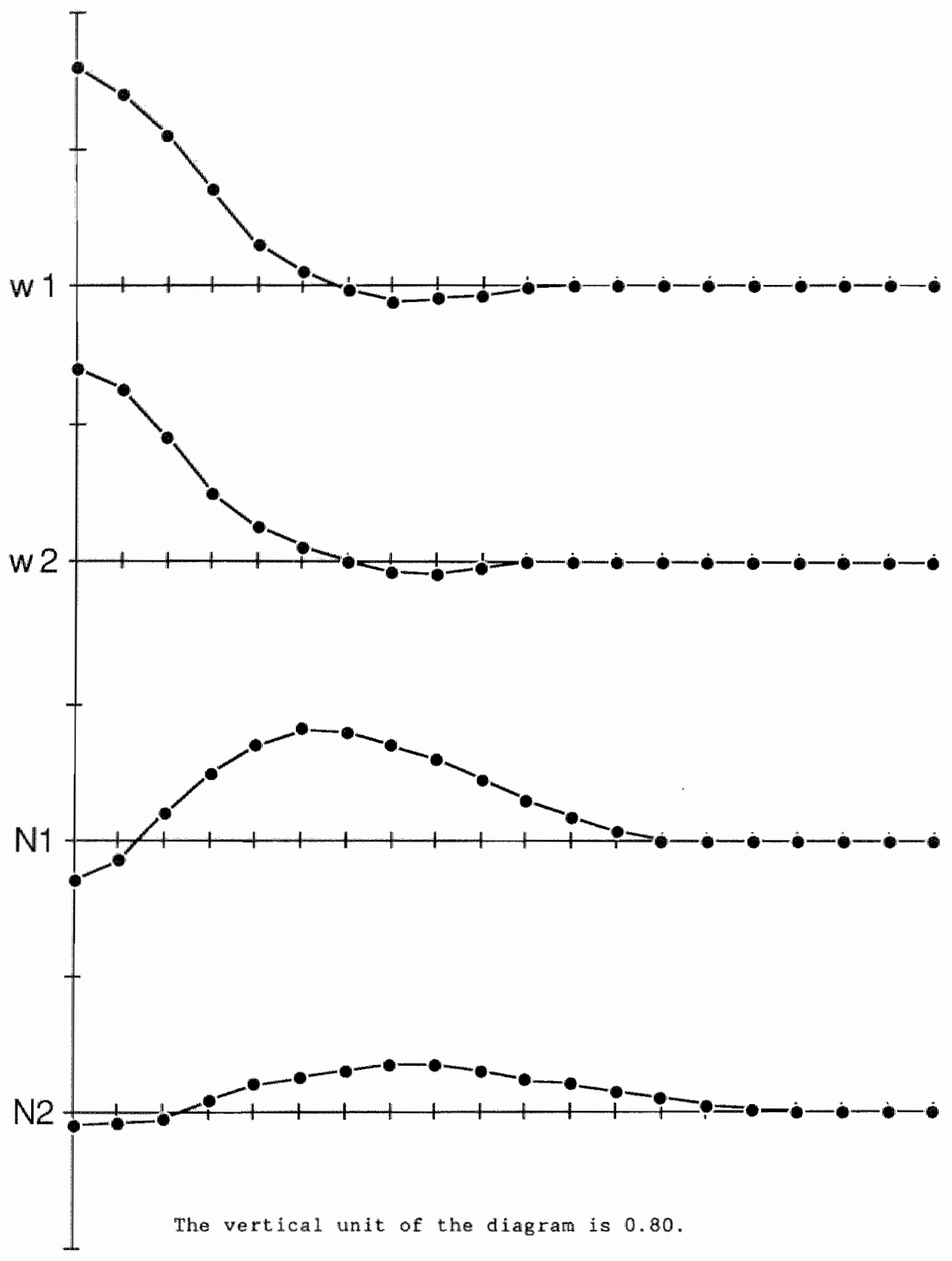


Figure II.2 : Impulse Response of $\mathrm{W}_{2}, \mathrm{~N}_{1}, \mathrm{~N}_{2}$ to Innovation of $\mathrm{N}_{2}$ "

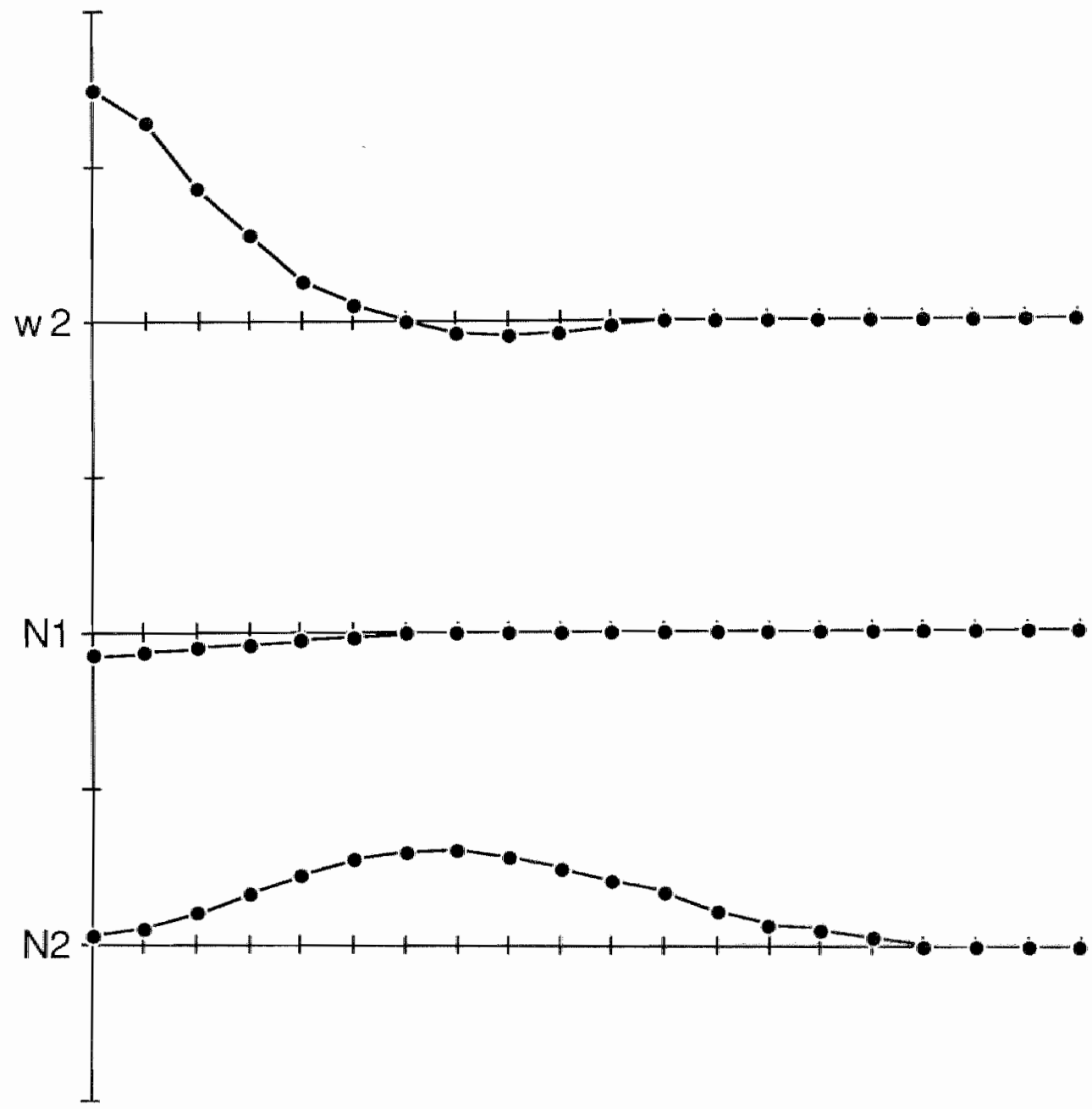

The vertical unit of the diagram is 0.80 . 


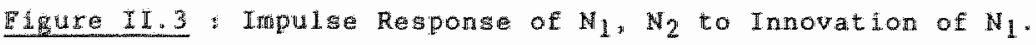

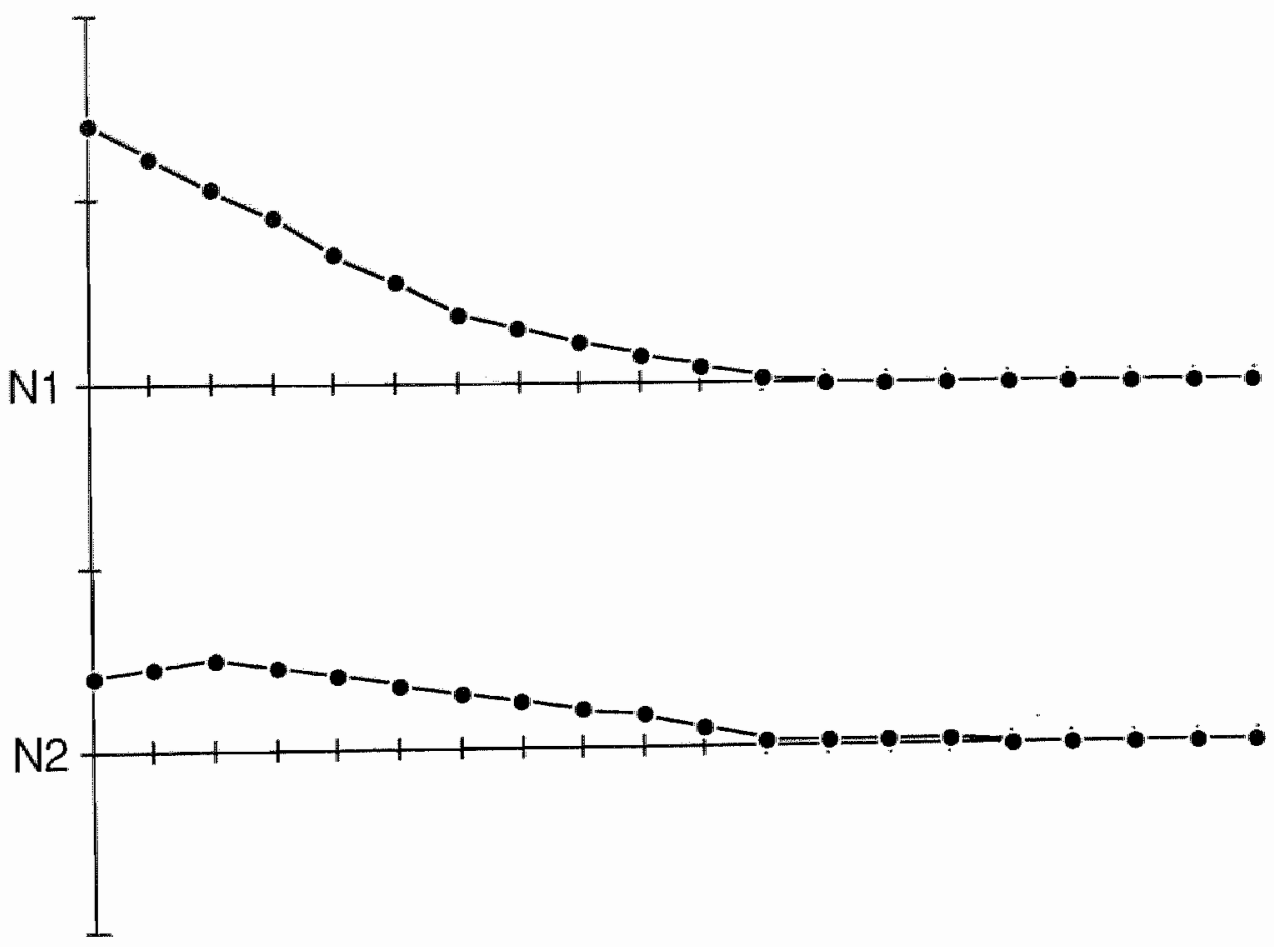

The vertical unit of the diagram is 0.80 .

HAure TI.4 : Inpulse Response of $\mathrm{N}_{2}$ to Innovation of $\mathrm{N}_{2}$.

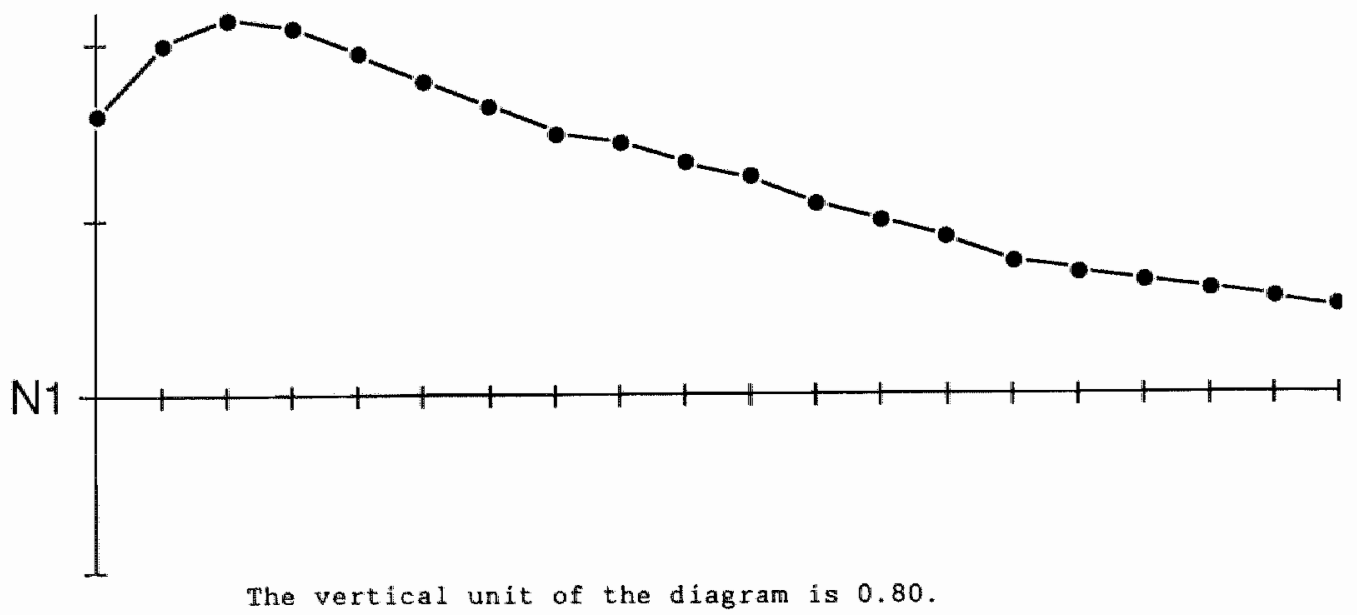




\section{II.5 Conclusions}

In chapter 2 we have modeled the dynamic demand for two sorts of labour of firms that are operating under uncertanty in the Dutch manufacturing sector. We modified Sargent's 1978 model of dynanic labour demand. We showed that under the assumption of unidirectional causality of wages to employment it is possible to 1 ink the parameter estimates of the model with the structural parameters of a production function and an adjustment cost function.

Our findings can be summarized as follows.

First, white collar labour is a much more quasi-fixed production factor than blue collar labour. In other words, the adjustment costs are much higher for white collar warkers than for blue collat workers. This confirms the result found by Nadiri \& Rosen (1969) who concluded that the demand for blue collar workers adjusts much more quickly to the desired level than that for employees and for capital goods.

Second, the empirical results suggest a positive correlation between the wage costs of both labour categories, which is the result of the fact that wage bargaining by unlons is done for a whole sector or for a single firm. Third, blue and white collar labour seen to be complementary production factors. Employment decisions about the two types of labour have been found to be dynamically interrelated.

Chapter 2 shows that a model based on intertemporal optimization under uncertainty can be used to describe the serial correlation structure of quarterly data on employment and wages in the industry in the Netherlands. The model put forward in this chapter is a prototype model. Several refinements are considered in the following chapters. 
CHAPTER THFEE

INTERRELATED DEMAND RATIONAL EXPECTATIONS MODELS FOR THO TYRES OF LABOUR AND RREDETERMINED CAPITAL 
III. Introduction

A closed form solution (CFS) of a short-run dynamic model of interrelated demand of costly adjustable blue and white collar labour is investigated. Employment decisions are based on rational expectations. The representative firm is assumed to maximize the expected real present value of profits, given the techrology and quadratic adjustment costs. Interrelation results from the impact of unpredicted exogenous shocks on the firm's employment policy outcome. This finding is at wariance with Nadirl and Fosen (1969) and Meese (1980) who argue that interrelation is due to tradew offs in costs or production.

The theoretical model of the previous chapter is extended modelling interrelated of employment decisions of blue and white collar labour and collar labour and predetermined capltal. We obtain interrelation between the two types of labour when the unpredictable components in employment are mutual1y dependent. Nonstationarity in labour demand is a result of nonstationarity in the forcing variables, wage costs and capital, which are assumed to be given to the firm.

Chapter III is organized as follows, section 2 outines the extended model. In section 3, the model in CFS is applied to quarterly data of the Duteh manufacturing sector for the period 1971. I - 1984. IV. The structural paraw meters are estimated using ALS. Interrelation turns out to be esantal to appropriately model the dynamics between blue and white collar labour, whithout previously detrending the data. Moreover, white collar labour appears to be more quasi-fixed and is found to be substitutable for blue collar labour, whereas blue collar labour is complementary with whte collar labour. Conclueling remarks are given in section 4. 


\section{II.2. The node 1}

A representative film maximizes its real present value of proflts over an Inflinte time horlwon. It employs blue collar workers (nI), white collar workers $\left(\mathrm{n}_{2}\right)$ and uses caplat (k). Decisions to change the capital stock ary based on costs which are fixed in the short run, and differ materially from short run decisions to change the input of labour. Consequently, the caplat stock is assuned to be predetermined. The adjustment of the decision wariables of the firm, blue and white collar labour, is costiy. The firm operates under uncertainty. In order to determine the optimal level of the varlables $\mathrm{n}_{1}$ and $\mathrm{n}_{2}$, it uses all the relevant information available up to time t. Current real wage costs are part of the employer"s information set.

The firm is asumed to be a price-taker on both factor and output markets. This implies that real wage costs are not Granger-ciaused by employment. For empirical evidence on unidirectional causality from real wage costs to employment, we refer to Neftçi (1978) and Sargent (1978) for the U.S., to Harris (1985) for the U.K., and to Palm and Pfan (1987) and section 3 of this ebapter for the Netherlands.

The production technology obeys the usual regularity conditions $\left(\partial x / \partial x_{1}>0\right.$, $x=\left(n_{1}, n_{2}, k\right)$; the Hessian matrix is negative definite) and is locally approxitneted by a guadratic function

$$
\begin{aligned}
& \text { (III.1) } x_{t}\left(n_{1 t}, n_{2 t}, k_{t}\right)=\sum_{1=1}^{2}\left\{\left(\alpha_{11}+s_{1 t}\right) n_{1 t}-\frac{1}{2} a_{i 2} n_{1 t}^{2}\right\}+a_{31} k_{t}-\frac{1}{2} a_{32} k_{t}^{2} \\
& +a_{41} n_{1} k_{t}+a_{42} n_{2 t} k_{t}+a_{43} n_{1} n_{2 t} .
\end{aligned}
$$

$Y_{t}$ denotes the real output per time period, the $a_{1 j}$ 's are constant positive parameters. The variables $s_{1}$ and $s_{2}$ are exogenous stochastic shocks in 
the marginal product of labour resulting from changes in the economic environment of the firm.

Rapid adjustment of factor inputs to changes in maket conditions can be very costly. Adjustment therefore takes place gradually. In the model, the adjustment costs of labour are assumed to be approximately quadratic. As capital is predetermined, the adjustment costs of capital are not explicitly included in the adjustment cost function. Although it is unlikely that the adjustment cost function is symmetric, for computational ease we use the following adjustment cost function

(III.2) $A C_{t}\left(\Delta 1 t, \Delta n_{2 t}\right)=\sum_{i=1}^{2} 4 / 2 B_{1}\left(\Delta n_{i t}\right)^{2}+B_{3} \Delta n_{1 t} \Delta n_{2 t}$.

It is worth to emphasize here that Nadiri and Rosen (1969) point out that the existence of dynamically interrelated factor input decisions could be explained by implicit trade-off costs that can occur when a firm follows a mixed strategy of holding inventories of production and hoarding some inputs. Therefore $\beta_{3}$ is expected to be negative. With more specific knowledge required, higher screening and hiring costs, and longer starting period, it seems plausible that the real costs of adjustment for white collar workers will be higher than those for blue collar workers, 1.e. $\beta_{2}>\beta_{1}>0$.

The variable cost of factor services are assumed to be as follows

(III.3) $V C_{t}\left(n_{1 t}, n_{2 t}, k_{t}\right)=w_{1} n_{1 t}+w_{2 t} n_{2 t}+c_{t} k_{t}$,

where $w_{1} t, w_{2 t}$ and $c_{t}$ denotes real input prices.

Given the capital stock and investment plans, the rational entrepreneur chooses contingency plans for blue and white collar employment. As a con- 
wequare of adjustwent costs, at time t, the actual employment level and future enploymert plang have to be detemined simultaneously. In the next pertod, mev information forces the firm to revise its employment plans for the future to determine the optimal employment level at time tfl. The firma objective is to maximate its real present value of profits (PV) at time t. that is

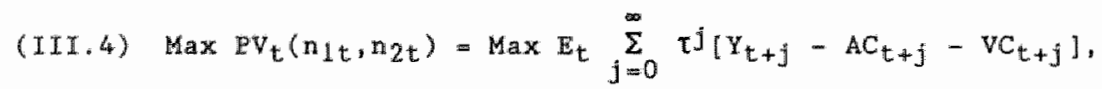

where b 1 a real discount factor, $0<\tau<1$, and $E_{t}()=.E\left(* \mid \Omega_{t}\right)$, with $\Omega_{t}$ being the avallable set of information at $t$ lime $t$. First order necessary conditions for maximization of (III.4) with respect to the decision Variables $\mathrm{n}_{1}$ and $\mathrm{n}_{2}$ consists of the set of Euler equations and a par of transwersality conditions which assure the finiteness of the process.

The Euler equations to this infinite time horizon problem can be expressed a.s follows

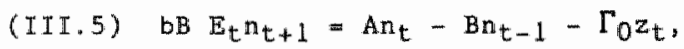
where $n_{t}=\left(n_{1}, n_{2 t}\right)^{\prime}, z_{t}=\left(1, s_{1 t}, s_{2 t}, w_{1 t}, w_{2 t}, k_{t}\right)^{\prime}$,

$$
\begin{aligned}
& A=\left[\begin{array}{cc}
\alpha_{12}+\beta_{1}+\pi \beta_{1} & \beta_{3}-\alpha_{43}+\tau \beta_{3} \\
\beta_{3}-\alpha_{43}+\pi \beta_{3} & \alpha_{22}+\beta_{2}+\pi \beta_{2}
\end{array}\right], \\
& B=\left[\begin{array}{ll}
\beta_{1} & \beta_{3} \\
\beta_{3} & B_{2}
\end{array}\right], \\
& \Gamma_{0}=\left[\begin{array}{lll}
a_{1} & I_{2}-I_{2} & a_{2}
\end{array}\right],
\end{aligned}
$$

with $a_{1}=\left(\alpha_{11}, \alpha_{21}\right)^{\prime \prime}, a_{2}=\left(\alpha_{41}, \alpha_{42}\right)^{\prime}$ and $I_{2}$ the $(2 \times 2)$-identity matrix.

The planned employment in period $t+1 E_{t} n_{t+1}$ is linearly related to the current and one period lagged employment level and to the current wage 
costs and the capital stock. Since $\mathbb{E}_{t} \mathbf{n}_{t+1}$ cannot be observed as such it has to be determined within the model. To find a statonary forward Looking solution of the Euler linear difference model under rational expectations, that satisfies the transversality conditions we follow Blanchard and $\operatorname{Kahn}$ (1980) and transform (III.5) into

(III.6) $\mathrm{E}_{\mathrm{t}} \mathrm{WN}_{\mathrm{t}}=\mathbb{A} \mathrm{W}_{\mathrm{t}-1}+\mathbb{W} \mathbf{z}_{\mathrm{t}}$

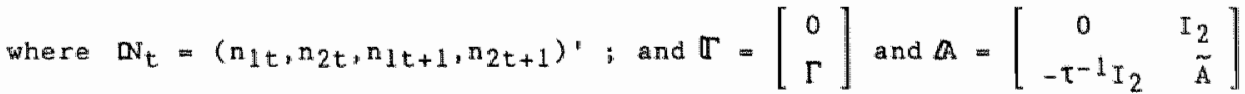

are $(4 \times 2)$ and $(4 \times 4)$-matrices respectively with $\Gamma=(T B)-1 \Gamma_{0}$ and $A=$ $(\pi B)^{-1} A$. The assumption of $\mathrm{A}$ being digonal implies the absence of mutual dependence in the production process $\left(\alpha_{43}=0\right)$ and in the adjustment costs $\left(\beta_{3}=0\right)$. This "diagona1" mode1, in wich the dynamic demand curves are separable, has been analysed by Sargent (1978) among others. Sargent"s model is diagonal for a specific reason, i.e. he distinguishes between straight-and overtime work.

In the sequel of this section, however, we assume $\tilde{A}$ to be a regular $(2 \times 2)-$ matrix. We have the following result.

Eroposition 1 : Let $A$ be the regular matrix defined in (III.6). Lat further A be a regular $(2 \times 2)$-matrix with elgerwalues $\mu_{1}$ and $\mu_{2}$. Then the characteristic polynomial of the matrix a can be writuen as $\left(-\lambda^{2}+\mu_{1} \lambda-\tau^{-1}\right)\left(-\lambda^{2}+\mu_{2} \lambda-\tau^{-1}\right)$

Proof : See Appendix II.

According to proposition 1 the eigenvalues af matrix $A$ can be found anallytically as the roots of a product of two quadratic equation. 
Proposition 2: For the quadratic equation $\lambda^{2}-\mu \lambda-5=0$ to have one real root $\lambda_{a t}$ with $\left|\lambda_{a}\right| \leq 1$, and one real root $\lambda_{b}$ with $\left|\lambda_{b}\right|$, is, the following conditions are necessary and sufficient

(i) $\mu^{2}+48 \geq 0$

(ii) $(1-6)^{2}<\mu^{2}$ or $(1-6)^{2}=\mu^{2}$ together ith $6^{2}>1$.

Proof : Trivial.

If the roots of the characteristics equation of A satisfy the conditions of proposition 2, the diagonal (4x4)-matrix $\mathbb{M}$ of eigenvalues of $a$ can be partitloned as $a=\left[\begin{array}{cc}\Lambda_{1} & 0 \\ 0 & \Lambda_{2}\end{array}\right]$, where $\Lambda_{1}$ is a diagonal matrix with eigenvalues $\lambda_{1}$ and $\lambda_{2}$ smaller than or equal to one in absolute value. The diagonal elements of $\Lambda_{2}$ consist of the eigenvalues $\lambda_{3}$ and $\lambda_{4}$ of $A$ that 1 ie outside the unit circle. The number of elements of diag $\left(\Lambda_{2}\right)$ equals the number of stationary forward looking solutions of the difference equation (III.5). When the objective function is quadratic, the number of elements of diag $\left(\Lambda_{1}\right)$ equals that of diag $\left(\Lambda_{2}\right)$ (see Hansen and Sargent (1981), Kollintizas $(1985)$ ).

The unlque gtationary forward looking solution of the "diagonal" model y $101 d$ d

(III. 7) $n_{t}=\Lambda_{\downarrow} n_{t-1}-\sum_{i=0}^{\infty} \Lambda_{2}^{-i-1} \Gamma E_{t} z_{t+1}$

Note that $T \Lambda_{1}=\Lambda_{2}^{-1}$. The solution is expressed in terms of the elgenvalues of A which are functions of the structural paraneters of the underlying theoretical model.

The difference between the "diagonal" model and the model in (III.5) shows up in the dynamic interrelation of labour demand decisions which is expli- 
citly modeled in the latter one. If $\mu_{\mathbb{I}} \neq \mu_{2}$ the matrix $A$ in (III.6) can be transformed such that $\tilde{A}$ is transformed into the diagonal matrix $S^{m} \tilde{A S}_{\mathrm{S}}$ with the columns of $S$ being the eigenvectors of $\tilde{A}$. If $C$ is the matrix of the eigenvectors of $\mathbb{s}^{-1} \mathbb{A} \mathbb{s}$ and $\mathbb{C}$ is partitioned according to $\mathbb{M}$, we have

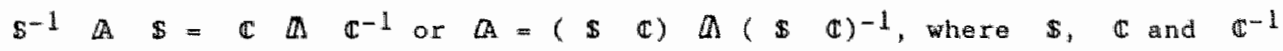
are (4x4)-matrices decomposed according $1 y$

$$
\mathbf{s}=\left[\begin{array}{cc}
S & 0 \\
0 & S
\end{array}\right] ; \quad \mathbb{C}=\left[\begin{array}{ll}
B_{11} & B_{12} \\
B_{21} & B_{22}
\end{array}\right] ; \quad \mathbb{C}^{-1}=\left[\begin{array}{ll}
C_{11} & C_{12} \\
C_{21} & C_{22}
\end{array}\right]
$$

Now A is written in its Jordan canonical form, where $\tilde{A}$ is diagonalized.

The unique stationary forward looking solution of the expected variables in the linear difference equation (III.5) can now be written as follows

(III.8) $\mathrm{n}_{\mathrm{t}}=\Lambda_{1} \mathrm{n}_{\mathrm{t}-1}-\left(\mathrm{SC}_{22}\right)^{-1} \sum_{i=0}^{\infty} \Lambda_{2}^{-1-1} \mathrm{sC}_{22} \Gamma \mathrm{E}_{\mathrm{t}} \mathrm{z}_{\mathrm{t}+\mathrm{i}}$

since $-\left(S C_{22}\right)^{-1}\left(S C_{21}\right)=\Lambda_{1}$.

Expression (III.8) is the CFS of the labour demand equations for an interrelated factor input decision model under uncertainty. The current employment of blue and white collar workers is linearly related to respectively blue and white collar employment lagged one pertod, and the expectations of wage costs, capital stock and exogenous shocks in productivity over an infinite time horizon. The parameters of (III.8) are nonlinear functions of the structural parameters of the theoretical model (III.4).

The inding that $\Lambda_{1}$ in (III.8) is diagonal is remarkable. The implications of this finding for identification, stability, and comparative dynamic properties of the model have been thoroughly discussed by Kollintzas (1985). In the present framework it means that interrelation between two production 
factorg through mutual dependence in the production process and in adjustment cost $\left(\alpha_{43} \neq 0, B_{3} \neq 0\right)$ does not lead to dynamically interrelated factor demand equations. Therefore, the arguments of Nadiri and Rosen (1969) concerning the dynamic interrelationship between employment decisions do not apply in the present context.

The second of the right hand side term of (III.B) can be expressed as

$$
\begin{aligned}
& \left(\operatorname{IIT.9)}-\left(S \mathrm{C}_{22}\right)^{-1} \sum_{i=0}^{\infty} \Lambda_{2}^{-1-1} \operatorname{SC}_{22} \Gamma E_{\mathrm{t}} z_{\mathrm{t}+1}=\right. \\
& \delta_{0}+\sum_{i=0}^{\infty} H^{-i-1}(T B)-1 E_{t} s_{t+i} \\
& -\sum_{i=0}^{\infty} H^{-1-1}(\tau B)^{-1} E_{t} w_{t+1} \\
& +\sum_{i=0}^{\infty} H^{-i-1}(\tau B)^{-1} a_{2} E_{t} k_{t+i}
\end{aligned}
$$

where $\mathrm{H}^{-1-1}=\left(\mathrm{SC}_{22}\right)^{-1} \Lambda_{2}^{-1-1}\left(\mathrm{SC}_{22}\right)$, and $\delta_{0}$ is a $(2 \times 1)$-vector composed of the unconditional means and deterministic fluctuations of marginal labour productivity.

Now we make assumptions on the stochastic properties of the forcing variables $s_{t}$, $w_{t}$ and $k_{t}$. The stochastic components of labour productivity $S_{t}$ are assumed to be generated by a stationary first order Markov process $\mathrm{E}_{t} \mathrm{~s}_{t+1}=\overrightarrow{\mathrm{R}} \mathrm{s}_{\mathrm{t}}$, where $\tilde{\mathrm{R}}$ is a $(2 \times 2)$-matrix. Let $\mathrm{Q}_{\mathrm{g}}$ be a $(2 \times 2)$-matrix, such that $\mathrm{Q}_{\mathrm{s}} \mathrm{s}_{\mathrm{t}}$ is a stationary $\mathrm{AR}(1)$ process with innovation $\xi_{\mathrm{t}}^{\mathrm{s}}$

$$
\begin{aligned}
& \text { (II. 10) } Q_{S} s_{t}=R_{S} s_{t-1}+\xi_{t}^{s} . \\
& \text { where } R=Q_{S} \tilde{R}_{S}^{-1} \text {, is a stationary }(2 \times 2) \text {-matrix. }
\end{aligned}
$$


$\underline{\text { Proposition } 3}$ : Let $\mathrm{Q}_{\mathrm{S}}=\sum_{i=0}^{\infty}\left(\mathrm{SC}_{22}\right)^{-1} \mathrm{~A}_{2}^{-1-1} \mathrm{SC}_{22}(\tau \mathrm{B})^{-1} \tilde{\mathrm{F}}^{\mathrm{i}}$. Then vec $\left(\mathrm{Q}_{\mathrm{s}}\right)=$ $\left[I_{2} \otimes\left[\left(S C_{22}\right)^{-1} \Lambda_{2} S C_{22}\right]-\tilde{\mathbb{R}}^{\mathbb{T}} \cdot I_{2}\right]^{-1} \operatorname{vec}((\tau B)-1)$

Proof: See Appendix II.

The results of proposition 3 enable us to find an explicit solution of $\sum_{i=1}^{\infty} H^{-i-1}(\tau B)^{-1} E_{t} s_{t+1}$ in terms of the structural parameters.

In accordance with the literature on dynamic labour demand, real wage costs are assumed to be generated by a bivariate autoregressive process. The order of the process has been determined prior to estimation of the model in CFS. A justification of the prior analysis is given in the next section; $w_{t}$ is described by a bivariate second order autoregression

(III.11) $w_{t}=\delta_{w}+M_{1} w_{t-1}+M_{2} w_{t-2}+\xi_{t}^{w}$,

where $\delta_{w}$ is a $(2 \times 1)$-vector of constants, $M_{1}$ and $M_{2}$ are $(2 \times 2)$-matrices and $\xi_{t}^{w}$ is a $(2 \times 1)$-vector of innovations of the wage costs. The second r.h.s. term of (III.9) becomes

$\sum_{i=0}^{\infty} H^{-i-1}(\tau B)^{-1} E_{t} w_{t+1}=P_{1} w_{1}+P_{2} w_{t-1}$

with $\mathrm{P}_{1}+\mathrm{H}^{-1}(\tau \mathrm{C})^{-1} \mathrm{~V}$ and $\mathrm{P}_{2}=\mathrm{H}^{-2}(\tau \mathrm{B})^{-1} \mathrm{~V} \mathrm{M}_{2}$, where $\mathrm{V}$ is a $(2 \times 2)$-matrix such that $\mathrm{HVM}_{1}+\mathrm{H}^{2} \mathrm{VM}_{2}=\mathrm{I}_{2}$.

Finally, empirical evidence that will be presented in the next section shows that the first difference of the predetermined capital stock can be represented as a random walk with drift

(III.12) $\Delta \mathrm{k}_{\mathrm{t}}=\delta_{\mathrm{k}}+\xi_{\mathrm{t}}^{\mathrm{k}}$. 
Hence, an explicit solution for the thitd r.h.s.term in (III.9) is $\left(\mathrm{H}-\mathbb{1}_{2}\right)^{-1}(\mathrm{~b} \mathrm{~B})^{-1} \mathrm{a}_{2} \mathrm{k}_{\mathrm{t}}$

Elimation of the autocorrelation of $\mathrm{Qg}_{\mathrm{g}} \mathrm{t}$ is achleved using a Koyck transformation. We gubstitute the expressions for the expected values of $s_{t}$, wt and $k_{t}$ into (III.8), asguming that the lagged values of the forcing varlables are not correlated wth the composite disturbance term $\xi_{t}$. Applying proposition 3, the reduced form of the labour demand equations becomras s

$$
\begin{aligned}
n_{t} & =\delta+\left(\Lambda_{1}+R\right) n_{t-1}-R \Lambda_{1} n_{t-2}+C k_{t-1} \\
& +\left(P_{1} M_{1}-R P_{1}+P_{2}\right) w_{t-1}+\left(\mathbb{E}_{1} M_{2}-R P_{2}\right) w_{t-2}+\xi_{t}^{n}
\end{aligned}
$$

where $C=\left(I_{2}-R\right)\left(H-I_{2}\right)^{-1}(\tau B)^{-1} a_{2}, \delta=\delta\left(\delta_{0}, \delta_{w}, \delta_{k}\right)$, and $\xi_{t}^{n}=\xi_{t}^{n}\left(\xi_{t}^{s}, \xi_{t}^{w}, \xi_{t}^{k}\right)$.

Labour demand innovations, $\xi_{t}^{n}$, is linearly related to unanticipated changes in labour productivity $\left(\xi_{t}^{s}\right)$, wage costs $\left(\xi_{t}^{w}\right)$ and capital ( $\left.\xi_{t}^{k}\right)$. From (III.13) It follows that dynamic interrelation in the autoregressive part of the employment equations can only result from the serial crosscorrelation in the exogenous productivity shocks. Or, stated more formaty, when the objective function is quadratic, interrelation between degitions on the current lovel of employment of blue and white collar workers occurs if and ondy if the matrix $R$ of the process for the stochastic components of labour productivity is nondiaganal. If $R$ is a diagonal matrix, both labour demand equations are dynamically interrelated via the caplital stock and the wages ondy. Consequently, the assumption in Meese (1980) of marginal labour productivity being white noise implies that the parameters of intercelution in the reduced form equations can not be Ldentified. 
The system of equations (III.11) and (III.13) ylelds a complete liner multivariate model which can be empirically analysed. The disturbance term $\left(\xi_{t}^{w}, \xi_{t}^{n}\right)$ ' is assumed to be normally distributed with mean zero and cow ce matrix $\Sigma$, which, as a result of the mutual influences of unanticipated exagenous movements of productivity, wage costs, and capital, is assumed to be unrestricted except for symmetry and positive definiteness. 


\section{3 An empirical analygis}

In this action apply the model for interrelated labour demand in CFS to quartexly data of the Dutch manufacturing sector for the period 1971.I to 1984.IV. All series are seasonally unadjusted. The data are obtained from the Central Bureau of Statistics and the Central Planning Bureau. A description of the series and the data are given in Appendix I. Labour demand has been disaggregated into the demand for blue and white collar labour, both expressed in terms of working hours times the number of workers for each category respectively. The effects of possible substitution between hours worked and persons employed has not been taken into account.

Prior to the econometric analysis of labour demand equations, we have tested for Granger causality between wage costs and employment. Possible caugal relations between wage costs and employment were examined separately for each sort of labour by means of a bivariate AR(4)-model, ignoring the possible influences of other time series. The chi-square values of leaving four lags of employment out of the wage costs equation were 5.56 and 7.46 (p-values .24 and .12 ) for blue and white collar labour respectively.

Leaving the four lags of wage costs out of the employment equation yielded chi-square values of 16.80 and 11.18 (p-values .00 and .02 ) respectively. Consequently, the hypothesis of unidirectional causality from real wage costs to employment is found to be in accordance with the empirical evidence when each type of labour is considered separately. When we consider blue and white collar labour simultaneously we also find stronger evidence in favour of the unidirectional relationship. However, the significance of these tests is not so clear-cut. Chi-square values for joint causality tests with 16 degrees of freedom on a four variate AR(4) model for the four 
series amounted to 29.97 (p-value .02) when unidirectional causality from wage costs to employment is tested, and 47.59 (p-value . 00 ) when unidirectional causality of employment to wage costs is analysed.

The unidirectional causality assumption enables us to model the dymamic interactions between real wage costs and employment along the lines outlined in the previous section. Moreover, then the wage costs equations can be analysed independently from the employment data. Fullets tT statistic testing for unit roots in $w_{1 t}$ and $w_{2 t}$ applied to an AR(2) model with constant term yield $-1.27\left(\bar{R}^{2}=0.99\right)$ and $-2.09\left(\bar{R}^{2}=0.99\right)$, which does not lead to the rejection of the hypothesis of a unit root in both cases.

Bivariate identification of the rage costs series has been earied out by means of a computer package provided by Liu et al (1986). The results for the first differences of the cost series are presented in Table III.2. First differencing yields stationary wage series. Standard errors (s.e.) are giver between parentheses. Stationary vector time series can be usefully described by their cross correlation (CCM) (see for further details e.g. Tiao and Box $(\mathbb{1 9 8 1 )})$. The $x^{2}$-test for the $\mathbb{l}$ ag length, and the Aka 1ke Information Criteria (AIC) can be used to determine the order of an atoregressive model.

The CCMs of $\Delta w_{t}$ cut off after one lag. The $X^{2}$-gtatistic and AIC suggest an AR(1) process. Since after one lag the autacorrelations of $\Delta w_{1}$ and $\Delta w 2 t$ die out and their partial autocorrelations equal zero, we teritatively select a bivariate AR(1) process for $\Delta$ w with a diagonal first order autoregressiwe parameter matrix. 
Table III.2 : Identification of the Wage Costs Series.

1 : QIVARIATE IOENTIFICATION OF $\Delta w_{t}=\Delta\left(w_{1} t, w_{2} t\right)^{t}$

The Cross Correlation Matrices of Dut

\begin{tabular}{ccccccccc}
$\operatorname{lag}$ & 1 & 2 & 3 & 4 & \multicolumn{2}{c}{5} & \multicolumn{2}{c}{6} \\
$\operatorname{ccM}$ & $.42^{*} .40^{*}$ & .13 .14 & .04 .18 & -.10 .07 & -.09 & -.16 & -.14 & -.20 \\
& $.41^{*} .53^{*}$ & .19 .26 & .06 .17 & -.01 .04 & -.05 & -.13 & -.15 & -.24
\end{tabular}

Crlterla for Autoregressive Order Identification

$\begin{array}{lcccccc}\operatorname{lag} & 1 & 2 & 3 & 4 & 5 & 6 \\ \text { CHI(4) } & 18.21 & 1.90 & 5.94 & 2.59 & 3.23 & 1.85 \\ \text { AIC } & -5.887 & -5.788 & -5.788 & -5.711 & -5.654 & -5.564\end{array}$

II : UNIVARIATE ORDER SELECTION

Autocorrelations of Univarfate Series

$\Delta w_{1 t}[$ mean $=.143(.285)]$

$\begin{array}{lcccccccc}\text { lag } & 1 & 2 & 3 & 4 & 5 & 6 & 7 & 8 \\ \text { AC } & .419 & .125 & .032 & .109 & -.081 & -.143 & -.027 & -.047 \\ \text { s.e. } & (.137) & (.160) & (.162) & (.162) & (.163) & (.164) & (.166) & (.166)\end{array}$

$\Delta w_{2 t}[$ mean $=.234(.460)]$

$\begin{array}{lcccccccc}\text { lag } & 1 & 2 & 3 & 4 & 5 & 6 & 7 & 8 \\ \text { AC } & .528 & .252 & .162 & .017 & -.156 & -.250 & -.254 & -.113 \\ \text { s.6. } & (.137) & (.171) & (.178) & (.181) & (.181) & (.184) & (.190) & (.196)\end{array}$

Partial Autocorrelations of Univarilate Serfes

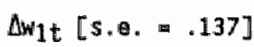

$\begin{array}{lcccccccc}\text { lag } & 1 & 2 & 3 & 4 & 5 & 6 & 7 & 8 \\ \text { PA } & .950 & -.057 & -.006 & -.078 & -.062 & -.036 & -.006 & -.030\end{array}$

$\Delta w_{2 t}\left[s, \theta_{0}=.137\right]$

$\begin{array}{lllllllll}\operatorname{lag} & 1 & 2 & 3 & 4 & 5 & 6 & 7 & 8\end{array}$

$\begin{array}{lllllllll}\text { PA } & .528 & .037 & .061 & -.120 & -.172 & -.126 & -.058 & .136\end{array}$

"*" larger than $2 n^{-1 / 2}$, where $n$ denotes the number of observations. 
On the basis of the empirical findings, the model (III, 11) becomes

$(\operatorname{III.11})^{\prime} w_{t}=(I+M) w_{t-1}-M w_{t-2}+\xi_{t}$

with $M=\operatorname{diag}\left(m_{1}, m_{2}\right)$.

Fuller"s $T_{\tau}$ statistic testing for a unit root in kt applied to an AR(1) process with constant term yields $-0.16\left(\mathrm{R}^{2}=0.99\right)$. Wherefore, we assume that $\Delta \mathrm{k}_{\mathrm{t}}$ follows a random walk with drift, which leads to the explicit solution of the infinite future expectations of capital as presented in the previous section.

Consequently, the reduced form employment equations fitted to the data are as follows

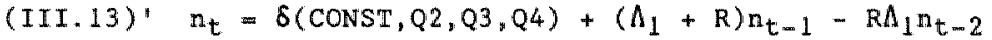

$$
\begin{aligned}
& +C k_{t-1}+\left(P_{1}\left[\mathbb{I}+M \rrbracket-R P_{1}+P_{2}\right) w_{t-1}-\left(P_{1} \mathbb{M}+R_{2}\right) w_{t-2}+5 w_{t}\right. \text {, }
\end{aligned}
$$

where $R$ is a nondiagonal $(2 \times 2)-m a t r i x$ and $Q 2, Q 3, Q 4$ denote seasonal dummies for the second, third and fourth quarter, respectively.

The identified structural parameters of the model presented in section 2 are estimated using a two step estimation procedure proposed by chamberlain (1982) and Gouriéroux et al. (1985). In a first stage, an unrastuctud version of the reduced form of the model is estimated that incorporates the restrictions on the order of the system implied by the underlylig theory. This model, that wil be referred to as mode1 1 , is equitalent to the model of (III.11)" and (III.13)" in which the autoregressiwe matrices $\Lambda_{1}+R$, R $\Lambda_{1}$, $\mathrm{P}_{1}[\mathrm{I}+\mathrm{M}]-\mathrm{RP}_{1}+\mathrm{P}_{2}$ and $\mathrm{P}_{1} \mathrm{M}+\mathrm{RP}_{2}$ are assumed to be unrestricted nondiagonal $(2 \times 2)$-matrices, and $C$ is a $(2 \times 1)$-vector of unrestricted parameters. Parameter estimates of model 1 are obtained by maximum 1ikelihood, and are given in table III.3a. In the second stage, the structural parameters are 
Labe II.3a : Maximut Likelihood Estimates of the Unrestricted Hodel 1 .

Blue Collar Horkers

Wage: Costs

Emp loyment

$$
\begin{array}{llll}
n_{1 t-1}=1.27 & (8.75) & n_{1 t-1}=-0.10 & (-1.42) \\
n_{1 t-2}=-0.29 & (-2.70) & n_{1 t-2}=0.16 & (3.06) \\
n_{2 t-1}=-1.12 & (-3.47) & n_{2 t-1}=1.22 & (7.69) \\
n_{2 t-2}=0.99 & (2.89) & n_{2 t-2}=-0.28 & (-1.64) \\
w_{1 t-1}=-0.13 & (-1.64) & w_{1 t-1}=-0.06 & (-1.50) \\
w_{1 t-2}=0.07 & (0.88) & w_{1 t-2}=0.001 & (0.37) \\
w_{2 t-1}=-0.09 & (-1.50) & w_{2 t-1}=-0.002 & (-0.70) \\
w_{2 t-2}=0.16 & (2.73) & w_{2 t-2}=0.07 & (2.57) \\
k_{t-1}=-0.03 & (-1.31) & k_{t-1}=0.01 & (0.54)
\end{array}
$$

White Collar Workers

$$
\mathrm{H}_{2}=0.58(4.25)
$$

* Aymptotie tavalue are given within parentheses. The estinated coefficients of constants and seasonal dumisg are not reported in the table. 
Tab1e III.3b : Asymptotic Least Squares Structural Pameter Estimates when

$$
B_{3}=0, \alpha_{43}=0 \text {, and } t=0.98^{*} \text {. }
$$

Blue Collar Workers White Collar Workers

\begin{tabular}{|c|c|c|c|c|c|c|c|c|}
\hline Wage Costs & $m_{1}$ & $=$ & 0.48 & $(4.98)$ & $m_{2}$ & $=$ & 0.53 & $(3.83)$ \\
\hline \multirow[t]{2}{*}{ Technology } & $a_{12}$ & $=$ & 1.08 & $(2.61)$ & $a_{22}$ & $=$ & 1.17 & $(2.40)$ \\
\hline & $a_{41}$ & $=$ & 0.41 & $(1.49)$ & $a_{42}$ & $=$ & 0.20 & $(1.12)$ \\
\hline Adjustment Costs & $B_{1}$ & $=$ & 34.31 & $(5.89)$ & $\mathrm{B}_{2}$ & $=$ & 85.07 & $(4,3.1)$ \\
\hline Serial Correlation $R$ & $p_{11}$ & 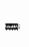 & 0.51 & $(2.40)$ & $\rho_{12}$ & $=$ & -0.81 & $(-1.59)$ \\
\hline of Productivity Shocks & $\rho_{21}$ & $=$ & -0.10 & $(-0.84)$ & $p_{22}$ & $=$ & 0.62 & $(1.92)$ \\
\hline
\end{tabular}

* Asymptotic t-values are given within parentheses. 
estimated using the method of Asymptotic Least Squares (ALS) which minimizes the distance between the uncestricted reduced form estimates and the reduced form coeficients expressed as functions of the identifled structuraI parameters. The ALS procedure $\mathbb{i s}$ asymptotically equivalent to Maximum Likelihood (ML) estimation methods, provided ML estimates of the parameter estlmates from the first stage are used together ith an optimal we ighting matrix and all restrictions between structural parameters and reduced form coefficients have been imposed. In order to obtain the weighting mat $r$ the derivatives of the nonlinear relationships between the parameters estimated in the first stage and the structural parameters are needed.

Simce the capital stock is assumed to be predetermined (in the short run), the technology parameters $\mathbb{a}_{31}$ and $\alpha_{32}$ in (III.1) are not identified; $\alpha_{43}$ and $B_{3}$ are not identified separately elther. We impose the prior restricm tions $B_{3}=0$ and $\alpha_{43}=0$; the parameter $\tau$ was chosen a prior to be 0.98 for quarterly data. ALs estimates of $\alpha_{12}, \alpha_{22}, \alpha_{41}, \alpha_{42}, \beta_{1}, \beta_{2}$, and the ellementis of the $(2 \times 2)$-matrices $R$ and $M$ are obtained from the set of implicit relationships relating the 20 parameter estimates of the unrestricted model 1 to the 12 structural parameters of the model in CFS. Estimation results are given in table III.3b.

As a byproduct, we computed a WALD statistic testing the appropriateness of the overidentifying restrictions imposed by the underlying theory. We compare the model of the form of (III.11)' and (III.13)' in which all the parameters are functions of the 12 structural parameters with model 1 . (We abstract from tho parameters of the seasonal dumies which have been included in both models). The test, which is equivalent to the standard LR test on overidentifying restrictions, is asymptotical1y $x^{2}(8)$-distributed and $y$ ields a value of 10.80 (p-value 0.22$)$. 
The ostimates of the serial correlation matrix $R$ can be interpreted a measures of the speed of adjustment of productivity of both types of labour to unforeseen productivity shocks. For instance, a positive shock in prow duct demand implying an increase in $\xi_{t}$ is initially absorbed by a large change of biue collar productivity compared with that of white collar labour, in such a way that the discounted effect of both types of labour productivity is positive. This result is a first ind ication that blue collar labour is more flexibly adjusted than white collar labour. "Lhe estimates of the adjustment costs parameters $\beta_{1}$ and $\beta_{2}$ indicate that white collar labour is more quasi-fixed than blue collar labour. Since the hiring procedure will be more expensive, and white coldar workers is expected tio need more job-specific training, it is plausible that the costs of adjustment (hiring and/or firing) will be much higher for white collar labour than for blue collar labour.

The technology parameters are found to be positive. These findings are in agreement with the assumptions underlying the theoretical madel, i.e. technology, adjustment costs and the process for productivity shocks are specified such that the optimality conditions (concavity of production technology, canvexity of adjustment costs, both locally approximated using

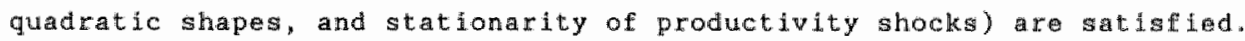

Using proposition 1 and the structural parameter estimates from table 3 wa can compute $\lambda_{1}=0.85$ and $\lambda_{2}=0.90$, and the eigenvalues of $A_{1} \mathrm{sc} \mu_{1}$ $\left(\pi^{-1}+\lambda_{1}^{2}\right) / \lambda_{1}=2.05$ and $\mu_{2}=\left(\tau^{-1}+\lambda_{2}^{2}\right) / \lambda_{2}=2.03$. Both the eisenvaluea satisfy the necessary and sufficient conditions of proposition 2 . Moreover, the estimates of the diagonal elements of $\Lambda_{2}, \lambda_{3}=1 / 2\left(\|_{1}+\sqrt{\|_{1}^{2}}-4 / \pi\right)=$ 1.20 and $\left.\lambda_{4}=1 / \mu_{2}+\sqrt{\mu_{2}^{2}-4 / T}\right)=1.14$ lie out ide the unit circle. 
In adition, we compute a Lh test comparing model 1 with less complex geparte dyname wge and employment curves. The model with separate demand curves 1 th be refered to as model 2 , and is equivalent to the

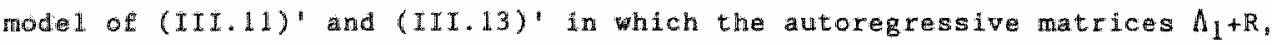
$\mathrm{RH}_{1}, \mathrm{P}_{1}[\mathrm{I}+\mathrm{H}]-\mathrm{RP}_{1}+\mathrm{P}_{2}$ and $\mathrm{P}_{1} \mathrm{M}+\mathrm{RP}_{2}$ are assumed to be unrestricted diagonal materices and $\mathrm{C}$ is a $(2 \times 1)$-vector of unrestricted parameters. The LR test 1 asyratotically $x^{2}(8)$-distributed and yields a ralue of 42.20 (p-value $0.00)$

The multivariate portmanteau test suggested by Hasking (1980) is a conSistent LM Statistic for residual atocorrelation. Table III.4 contains LM tests for the model (III.11)" (III.13)' for model 1 , being the unrestrictued version of the model with intermated employment equations in CFS, and for model 2. The LM test has an asymptotic chi-squared distribution 1 th degress of redom that depend on s, the order of autocorrelated lags, the dimension of the model (4), and the number of estimated autoregresifive parameters.

Table III.4: Multivariate Lagrange Multiplier Tests on Residual Autocorrelation.

Equations

$(I I I, 11)^{\prime}$

(III.13)"
Model 1

Model 2

$\begin{array}{ccccccc}3 & \text { LM } & X^{2}(.95) & \text { LM } & X^{2}(.95) & \text { LM } & X^{2}(.95) \\ 3 & 40.19 & 46.19 & 37.22 & 43.77 & 53.93 & 48.60 \\ 4 & 56.96 & 65.17 & 52.45 & 62.83 & 66.85 & 67.51 \\ 5 & 66.64 & 83.68 & 61.37 & 81.38 & 82.09 & 85.97 \\ 10 & 119.52 & 173.00 & 124.15 & 170.81 & 139.46 & 175.20 \\ 15 & 210.76 & 259.92 & 206.62 & 257.61 & 241.03 & 262.07 \\ 20 & 293.02 & 345.67 & 280.08 & 343.53 & 322.08 & 347.80\end{array}$


Erom TabIe III.4 we see that the inclusion of interrelition in labour demand decisions removes the lower order residual autocorrelation. on the whole, we find that the interrelated model is superiar to the diagonal mode1. To sumarize, we may conclude that dynamic interrelation between the demand of blue and white collar labour is probably the result of the serial correlation of productivity shocks, and that the imclusion of interrelations between the two types of labour demand has improwed the model significantly. The overidentifying restrictions of the rational expectations model, implied by underlying economic theory do sem to be corroborated by the sample evidence.

In order to get a better insight into the dynamic properties of the model we compute a mowing average represemtation in terms of orthogonal disturbances of the model in CFS. Figure III.L shows the impulse responses of the denand for blue and white collar labour to anit innovation of bilue and white collar employment respectively. The impulse response traces out the reaction of a firm to uncorrelated shocks in the two demand functions. Wo note that $\xi^{\mathrm{n}}$ is a linear combination of $\xi^{\mathrm{s}}$, $\xi^{\mathrm{w}}$, $\xi^{\mathrm{k}}$, such that a positive unit innovation in $\xi^{n}$ can be interpreted as a positive shock in labour productivity or capltal, or as a negative shock in real wage costs.

The impulse responses to innovations of 1 abour input differ between the two types. A postive shock in the demand for blue collar workers lead to a rise in the employment of blue as well as white collar labour. Ihe ogtimated response of $n_{1}$ is stronger but shorter, while the est 1 mated response of $n_{2}$ is more moderate but lasts longer due to higher adjustment costs. This result could be interpreted as follows. The ampact of a shock damps out very quickly with employment returning to its original level. Conversely, if the hiring of white collar labour is costly, the adjustment 
to a shock negatively affects employment of blue collar workexs. This leads to the conclusion that on the one hand white collar labour is complementary to blue collar labour. When more workers are hired, more supervisors 11 be needed. On the other hand, a single upswing in white collar labour demand leads to a displacement effect on the employment of blue collar workers. The firm"s work force is upgraded. BIwe collar labour can be substituted by white collar labour. 
Figure III.1 : Impulse response of $\mathrm{n}_{1}$ and $\mathrm{n}_{2}$ to innovations in $\xi^{\mathrm{n}_{1}}$ and $\xi^{\mathrm{n}_{2}}$.

The Imput se response of $n_{1}$ to innowattons in $\xi^{n_{1}}$ Impulse response of $n_{2}$ to Innovations in $\xi^{n_{1}}$
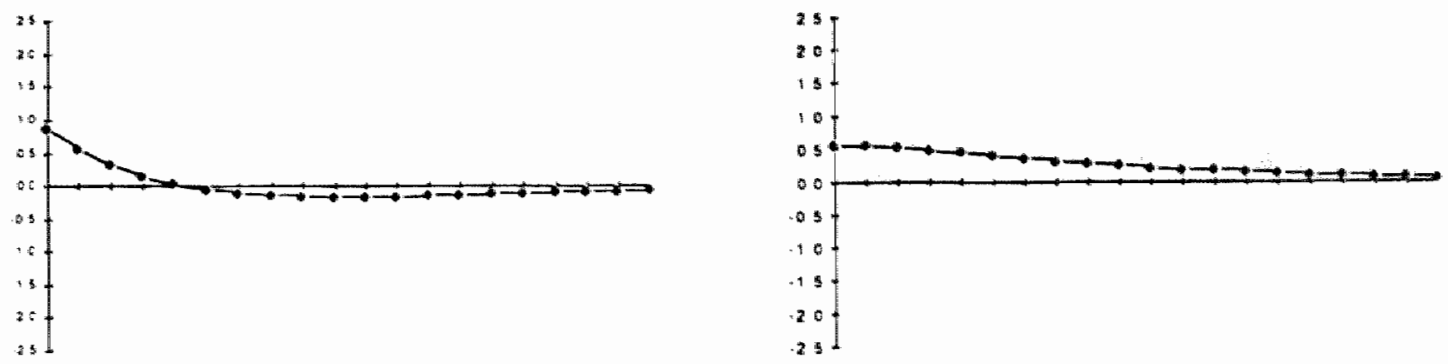

The Impul se response of $n_{1}$ to linnowations in $\xi^{n_{2}}$

Impul se response of $n_{2}$ to innovations in $\xi^{n_{2}}$
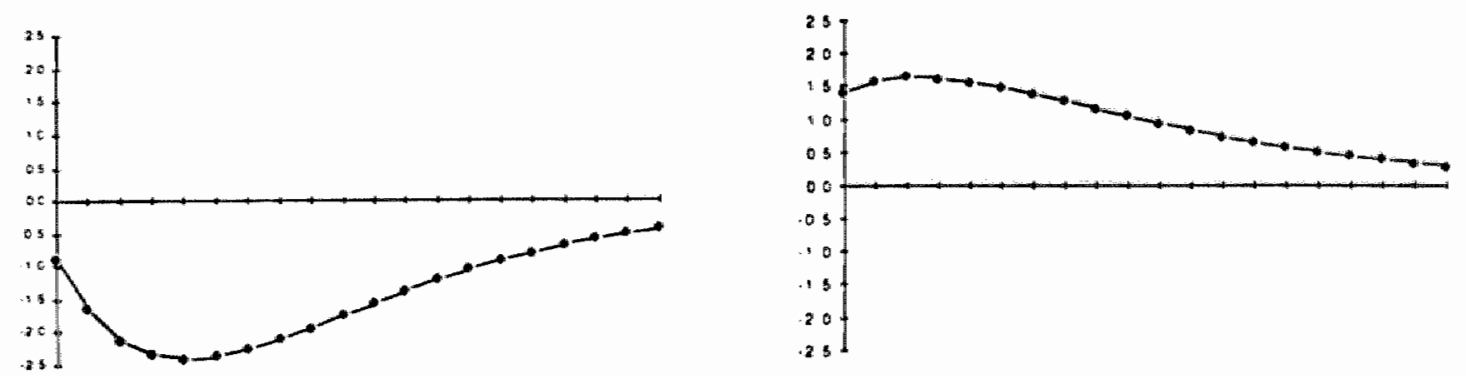


\section{4 Conclusions}

In the present chapter the relation between the parameters of the econometric model and the structural parameters have been derived. Although these relationships are highly nonlinear, the structural parameters, which have an economic interpretation can be estimated. The adjustment costs and productivity of the two types of labour were assumed to be interrelated. We showed that when an employer maximizes a quadratic objective function, interrelation of the two decision variables does not energe from interrelated mutual dependence in the production process. Costs trade offs do not lead to interrelation in the labour demand equations either. In ational expectations framework with quadratic objective function, interrelation of employment decisions can only result from the interdependence of the exogenous shocks in the firm's economic environment.

Application of the model to analyse labour demand schedules of the Dutch manufacturing sector showed that interrelation is in accordance with the sample data. An earlier finding by e.g. Nadiri and Rosen (1969), that white collar labour is more quasi-fixed than blue collar labour due to higher adjustment costs is conflrmed by this research. The moving average representation of the labour demand aquations of the estimated model showed that the number of blue collar workers employed cannot be increased without ralsing the number of white collar workers employed. On the other hand, a simgle upswing in white collar labour demand has a displacement effect on blue collar workers employment. Therefore it can be stated that blue collar labour is complementary with white collar labour, whereas white collar labour is substitutable for blue collar 1 abour in the Dutch manufacturing sector. 
The present model can easily be extended to include more than two intor lated inputs. For instance, the capltal stock can be introduced as decision variable. Application of such a model is expected to give more insights into the relation between quasi-fixed white collar labour and the capital stock, which is fixed in the short-run.

Matters concerned with the adjustment of labour input and the flexibility of working hours in reaction to unforeseen shocks in the environment of the firm are not considered either. Another interesting subject of analysis is concerned wh the stability of the fim's decision rule when expecm tations are rational. Do all the parameters of this process remaln unchanged when a shift in product demand of factor prices occurs which was not anticipated? To put it differently, does the firm interpret an unexpected change in its enviromment as an innovation or as atruetural change in the process generating the exogenous variables ? These questions will be addressed in the next chapter. 


\section{CHAPTER FOUR}

EXOGENOUS SHOCKS AND COINTEGRATION IN MULTIVARIATE FLEXIBLE ACCELERATOR MODELS OF LABOUR AND CAPITAL 


\section{IV.1 Introduction}

This chapter is concerned with dynamic factor demand systems. First, the solution of the stochastic control problem, applied in chapter 3 for the examination of a bivariate labour demand model with capital being predetermined, is used in this chapter to get more insights into the restrictions on the parameters of multivariate flexible accelerator models in which capital and labour are determined simultaneously. Second, in line with the Lucas critique, the impact of a structural change in the process of the exogenous variables for the factor demand is analysed. Third, the nonstationarity of the factor demand series can be accounted for by the nonstationarity in the relative factor prices when the demand and price series are cointegrated.

The plan of chapter four is as follows. Section 2 describes the theoretical model and gives a closed-form solution for the linear rational expectations factor demand model. The impact of both temporary innovations and structural changes in the process of the exogenous variables on factor demand is discussed. Section 3 contains an empirical analysis of the Dutch manufacturing sector for the period 1971.I - 1984.IV. Capltal and 1abour are found to be cointegrated with the real price of assets and real labor costs. The model is estimated using a two step estimation procedure which is asymptotically equivalent to maximum likelihood (ML) estimation. The impacts of the oil price shocks in 1973 . IV and 1979. II are modelled as a structural change in the process of the exogenous variables. This approach leads to an improvement of the model. Section 4 concludes this chapter. 


\section{IW.2 The Model and its Solution}

A representative efrm produces output $y$ using an 2 -vector of inputs $\mathrm{x}=$ $\left(l, k^{\prime}\right)$ ", where $l$ is an numector of employment and $k$ is an n-vector of capital stocks depreciating through time. At time $t$, the production function of the firm is defined as

$y_{t}=y\left(x_{t}, s_{t}\right)=\left(a+s_{t}\right) \cdot x_{t}-1 / 2 x_{t}^{\prime} A x_{t}$

where a is a 2 n-vector of positive constant parameters, A is a symmetric, positive definite $(2 n \times 2 n)-m a t r i x$ and $s_{t}$ is a $2 n$-vector of exogenous stochastic shocks of the production technology.

When the firm wants to alter the factor inputs, it faces adjustment costs which reflect the quasi-fixedness of inputs. Costs of search, training, market research, reorganization are examples of adjustment costs of factor inputs. The adjustment cost function, $a c$, is given by

$a c_{t}=a c\left(\Delta x_{t}\right)=1 / \Delta x_{t}^{\prime} B \Delta x_{t}$

where $\Delta$ is the difference operator, $B$ is a regular $(2 n \times 2 n)$-matrix with offdiagonal ellements reflecting the trade-off of costs resulting when several input are altered simultaneously. The variable costs, vc, consist of wage and investment costs

$v c_{t}=v c\left(x_{t}, w_{t}, q_{t}\right)=w_{t}^{\prime} \ell_{t}+q_{t}^{\prime}\left(k_{t}-(I-\delta) k_{t-1}\right)$

where $w_{t}$ and $q_{t}$ are $n$-vectors of stochastic real labor costs and real prices of investment goods respectively and $\delta$ denotes a diagonal ( $n \times n$ ) matrix with constant depreciation rates on its diagonal. All prices are normalized by the price of output and assumed to be given to the firm.

The firm's objective is to maximize its real present value of profits, that is 
$\underset{\ell, k}{\operatorname{maximize}} E\left[\sum_{i=0}^{\infty} \tau^{i}\left(y_{t+i}-a c_{t+i}-v c_{t+i}\right) \mid \Omega_{t}\right]$,

where $\Omega_{t}$ is the information set available to the firm at time $t$, and $T$ is constant real discount factor. At each period t, the firm chooses contingency plans for $\ell$ and $k$, by solving the first order conditions

$$
\begin{aligned}
E\left[x_{t+1} \mid \Omega_{t}\right]= & -(\tau B)^{-1} \alpha+\left((1+\tau-1) I+(\tau B)^{-1} A\right) x_{t}-\tau-1 x_{t-1} \\
& -(\tau B)^{-1} s_{t}+(\tau B)^{-1} p_{t}-(\tau B)^{-1} d E\left[p_{t+1} \mid \Omega_{t}\right]
\end{aligned}
$$

where $I$ is the $(2 n \times 2 n)$-identity matrix, $p_{t}=\left(w_{t}^{n}, q_{t}^{n}\right)$ and $d$ is a diagonal $(2 n \times 2 n)$-matrix $\left[\begin{array}{ll}0 & 0 \\ 0 & \tau(I-S)\end{array}\right]$. We can rewrite (IV.5) as follows

$$
\left[\begin{array}{c}
x_{t} \\
E\left[x_{t+1} \mid \Omega_{t}\right]
\end{array}\right]=\left[\begin{array}{cc}
0 & I \\
-\tau-1 I & \widetilde{A}
\end{array}\right]\left[\begin{array}{c}
x_{t-1} \\
x_{t}
\end{array}\right]+\left[\begin{array}{c}
0 \\
(\tau B)^{-1} z_{t}
\end{array}\right] *
$$

where $\tilde{A}=\left(\left(\mathbb{1}+\tau^{-1}\right) I+(\tau B)^{-1} \mathbb{A}_{A}\right)$ and $z_{t}=-a_{-} s_{t}+p_{t}-d E\left[p_{t+1} \mid \Omega_{t}\right]$.

Hansen en Sargent (1981) have proved that for a quadratic objective function the number of stationary solutions to (IV.5) is equal to the number of non-stationary solutions. Kollintzas (1985) generalized this finding, proving that a multivariate symetric adjustment costs model has structural parameters that are real.

If $\tilde{A}$ has $2 n$ eigenvalues stored in two diagonal ( $n \times n)$-matrices $M_{1}$ and $M_{2}$ then the characteristic equation associated ith (IV.6) becomes

$$
\left(-\Lambda^{2}+M_{1} \Lambda-\tau^{-1} I\right)\left(-\Lambda^{2}+M_{2} \Lambda-\tau^{-1} I\right)=0
$$

If all the eigenvalues of $\tilde{A}$ differ, then a unique stationary forward looking solution of the limear difference equation set (IV.5) exists (see Blanchard and Kahn (1980), and chapter 3 of this dissertation)

$$
x_{t}=\Delta_{1} x_{t-1}-C^{-1} \sum_{i=0}^{\infty}\left(\Lambda_{2}\right)^{-i-1} \mathrm{C}(\tau B)^{-1} E\left[z_{t+1} \mid \Omega_{t}\right]
$$


whe $\|_{2}$ is a diagonal (2nx2n)-thatrix of solutions of (IV.7) which are greater than one in absolute value, and $\Lambda_{1}$ is a diagonal $(2 n \times 2 m)-n a t r i x$ that contains the elenwalues of (IV.7) that do not lie outside the unit circle.

We note that $\Lambda_{\Lambda_{2}} \Lambda_{2} \tau^{-1} \mathbb{I}$, according to (IV. 7$)$. If $\widetilde{A}$ and $\Lambda_{1}$ are partitioned as follows:

$\tilde{A}=\left[\begin{array}{ll}A_{11} & A_{12} \\ A_{21} & A_{22}\end{array}\right]$, and $\Lambda_{1}=\left[\begin{array}{cc}\Delta_{11} & 0 \\ 0 & \Lambda_{12}\end{array}\right]$, then

$C=\left[\begin{array}{cc}A_{12} & A_{12} \\ M_{1-A_{11}} & M_{2}-A_{11}\end{array}\right]\left[\begin{array}{cc}\tau \Lambda_{11}\left(\tau \Lambda_{11}^{2}-I\right)-1 & 0 \\ 0 & \tau \Lambda_{12}\left(\tau \Lambda_{12}^{2}-I\right)^{-1}\end{array}\right]$

where all submatrices are of order nxn.

By definition the autoregressive part of (IV.8) is stationary. This important restriction implies that a non-stationarity of factor inputs arises through current and expected future levels of the exogenous variables, such as factor prices.

In the multivariate flexible accelerator type models (e.g. Treadway (1971) and Epstein and Denny (1983)), the interrelated adjustment path for factor Inputs, lis as follows

$\Delta x_{t}=M\left(x_{t-1}-x^{*}\right)$

where $x^{*}$ is a steady state equilibrium and M denotes a stable adjustment matrix of order $2 \mathrm{n}$. However, from (IV.8) we get that I+M $\Lambda_{1}$, which Implies that $M$ must be diagonal if the structural model is quadratic. We note that Epstein and Yatchew (1985), hereafter denoted as EY, argue that $M$ has $2 \mathrm{n}$ elgenvalues 1 ying between -1 and 0 .

EY solve a deterministic (certainty equivalence) version of (IV.4) 
replacing all randon variables by their conditional expected values. Ex "avold the difficulty of solving" (IV.4) (p.240) to find the closed form solution (IV.5) with $\Lambda_{1}\left(=I+M\right.$ in $E Y$ ) expressed as a function of $a_{\text {, }} A$ and $B$, by reparametrizing the production function $f$ in terms of $\alpha, B$ and $\mathbb{A}_{1}$. This technique, however, cannot be applied if $f$ contains a multiplicative disturbance term $s_{t} x_{t}$ as in (IV, 1). Moreover, by reparametrizing, Information on $\Lambda_{1}$ is lost which appears to be crucial when modeling interrelated factor demand given a quadratic objective function, since $\Lambda_{\perp}$ is diagonal. Although nome of structural parameter matrices, $A$ and $B$, were assumed to be diagonal, we find that independently from assumptions on expectations formations processes the adjustment matrix is diagonal. $\mathbb{E Y}$ estimate $\mathbb{P}=\mathbb{B M}$, assuming $B$ is diagonal. Consequently, $P$ is diagonal, which is confirmed by the empirical results of EY, where unrestricted estimates of the offdiagonal parameter $P_{2}$ of the symetric matrix $P$ are -.001 and 0.00000 respectively for different periods (see EY, table 5, p. 249).

In order to derive explicit factor input decision rules we specify the stochastic processes, $s_{t}$ and $p_{t}$. Stochastic movements of factor productivity are assumed to follow a stationary first order Markov process $E\left[s_{t+i} \mid \Omega_{t}\right]=\widetilde{\mathbb{R}} s_{t}$, where $\widetilde{\mathbb{R}}$ is a $(2 n \times 2 n)-\operatorname{mat} \mathbf{r} i x$. Let $s$ be a $(2 n \times 2 n)-\operatorname{mat} r i x$, such that $S s_{t}$ is a stationary $A R(1)$ process with innovation $\xi_{t}^{S}$

$s_{t}=R S s_{t-1}+\xi_{t}^{s}$

where $R$ is a $(2 n \times 2 n)-m a t r i x$ satisfying the stabllity conditions and let

$\operatorname{vec}(S)=\left(I \otimes C^{-1}\left(\tau \Lambda_{1}\right)^{-1} C-\tilde{R}^{\prime} I\right)^{-1} \operatorname{vec}\left((\tau B)^{-1}\right)$

then

$C^{-1} \sum_{i=0}^{\infty}\left(\tau \Lambda_{1}\right)^{i+1} C(\tau B)^{-1} E\left[s_{t+i} \mid \Omega_{t}\right]=s s_{t}$. 
The proof of this resut is falry stralghtforward and is given in chapter three.

The stochastic proces for $p_{t}$ is asumed to be an autoregressive process of order 9 ."

$\mathrm{P}_{\mathrm{t}}=\mathrm{c}^{\mathrm{p}}+\mathrm{Q}_{1} \mathrm{P}_{\mathrm{t}-1}+\mathrm{Q}_{2} \mathrm{p}_{\mathrm{t}-2}+\ldots+\mathrm{Q}_{\mathrm{p}} \mathrm{P}_{\mathrm{t}-\mathrm{q}}+\mathrm{E}_{\mathrm{t}}$

where $c^{p}$ is a $2 n$-vector of congtants $Q_{1}$ to $Q_{q}$ are $(2 n \times 2 n)-m a t r i c e s$ of constant parameters and $\mathrm{gp}_{\mathrm{t}}$ is the innovation of prices. Then

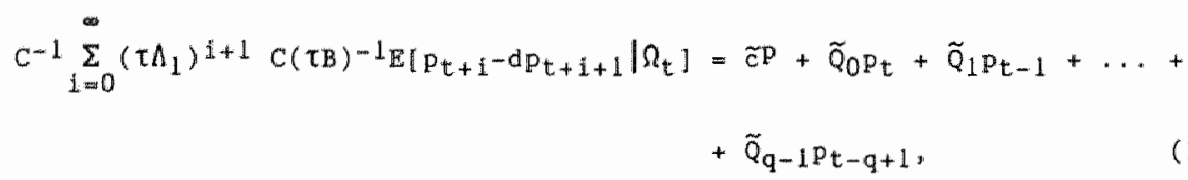

where $\left.\tilde{c} \mathrm{p}=\mathrm{C}^{-1}\left(\left(\tau \Lambda_{1}\right)^{-1}-1\right)^{-1} \mathrm{C}(\tau \mathrm{TB})^{-1}-(\tau B)^{-1} \mathrm{~d}\right) \mathrm{c}^{\mathrm{p}}$

$$
\begin{aligned}
& \tilde{Q}_{0}=C^{-1} \Lambda_{1} C^{-1} W_{,} \\
& \widetilde{Q}_{1}=\sum_{j=2}^{q_{-1}+1}\left(C^{-1}\left(\tau \Lambda_{1}\right) j-1 C\right)\left(C^{-1} \Lambda_{1} C^{-1}-(\tau B)^{-1} d\right) V Q_{j}+\mathbb{1}-1 ; i=1, \ldots, q=1
\end{aligned}
$$

and where $V \mathbb{i s}$ a $(2 n \times 2 n)-m a t r i x$ such that $\sum_{j=1}^{q} c^{-1}\left(\tau \Lambda_{\perp}\right) j c V Q_{j}=I$.

Subst1tuting (IV.11), (IV.12) and (IV.13) into (IV.8), and applying a Koyck transfomation to liminate the autocorrelation in $(1 W .10)$, the reduced form of the factor demand equations becomes

$x_{t} c^{x}+\left(\mathbb{R}+\Lambda_{1}\right) x_{t-1}-\mathbb{R} \Lambda_{1} x_{t-2}+u_{1} p_{t-1}+u_{2} p_{t-2}+\ldots+u_{q} p_{t-q}+\xi_{t}^{x}$

with $\mathrm{c}^{\mathrm{x}}=\mathrm{c}^{\mathrm{x}}(\mathrm{c}, \mathrm{a}, \mathrm{A}, \mathrm{B}, \mathrm{R}, \tau, s)$;

$$
\begin{aligned}
& \Lambda_{1}=A_{1}(A, B, \tau) ; \\
& U_{j}=\mathbb{R}_{j-1}-\tilde{Q}_{0} Q_{j}-\widetilde{Q}_{j}=U_{j}\left(A, B, R, Q_{1}, \ldots, Q_{q}, \tau, \delta\right), j=1, \ldots, q-1 ; \\
& U_{q}=\mathbb{R} \tilde{Q}_{q-1}-\tilde{Q}_{0} Q_{q}=U_{q}\left(A, B, R, Q_{1}, \ldots, Q_{q}, \tau, \delta\right) ;
\end{aligned}
$$

and $\xi_{t}^{x}=\left(\xi_{t}^{s}-\tilde{Q}_{0} \xi_{t}^{p}\right)$ being the innovations in factor inputs. 
Equation (IV. 14) is a closed form solution of (IV.5). The overidentifying restrictions and relationships between the parameters of the structural equations (IV.1), (IV.2), (IV.3), (IV.10) and (IV.12), and the factor demand equations (IV.14) can be made explicit. An important restriction is the diagonality of the adjustment matrix $\Lambda_{1}$ : In a rational expectations model with a quadratic objective function the occurrence of trade-offs of costs (the nondiagonality of matrix B) or of complementarity in the production (the nondiagonality of matrix $A$ ) does not lead to interrelatedness in the adjustment process. Interrelated multivariate adjustment, however, results from serial cross-correlation of the unforseen shocks in the firms technology (the nondiagonality of matrix R).

A second important finding is that the stability of the autoregressive part of equation (IV.14) follows from the properties of $\Lambda_{1}$ and $R$. In this model a non-stationarity in $x_{t}$ results from non-stationary factor prices..

The explicitness of the closed from solution (IV.14) emables us to identify the impact of a change in the process for exogenous prices on the firm's factor demand. For instance, a (structural) step change in the real price level, $C^{P}$, which is immediately recognized as such, wll lead to a step change in factor demand, $c^{x}$. The magnitude of the step change in factor demand, however, depends also on the size of adjustment costs (B) and the firm's technology $(a, A)$.

A structural change in the autoregressive part of the process for real input prices, $Q_{1}, \ldots, Q_{\mathrm{g}}$, influences the factor imput decisions through price effects $\mathrm{U}_{\mathfrak{i}}$. However, the agent may not immediately correctly assess size and sign of a change in the parameters of $Q_{1}$, in which case the firm's uncertainty about the environment is increased. As a result the (subjective) variances of the innovations increase. When more information 
bout the exogenous variables becomes available, the uncertainty about the structure of the process of the exogenous wariables will decrease again. consequently, the process of learning about the rature and size of the structural charge in $Q_{1}$ may possibly induce autoregressive conditional heteroskedagticity (ARCH) in the disturbances of the dynamic factor demand equatlons (IV. 14$)$.

The explicit closed form solution (IV.14) also throws light on the identifleation problem of the structural parameters. EY argue that the technological parameters $(\alpha, b, \tau, A, B)$ and the parameters of the exogenous Warlables $\left(\mathbb{R}, Q_{1}, \ldots, Q_{q}\right)$ can only be identified if the output supply equation is included in the system to be estimated. We find that under RE's this 1 s only true for the off-diagonal parameters of $A$ and $B$, the real digcount rate $\tau$, and the capital depreclation rate $\delta$.

Finally, innovations in technology and prices lead ta innovations in factor demand, since $\xi_{t}^{X}=\xi_{t}^{s}-\tilde{Q}_{0} \xi_{t}^{p}$. Accordingly, the disturbances of the systems $\left(\right.$ IV.12) and $(I V .14), \quad \xi_{t}=\left(\xi_{t} \mathrm{p}^{\prime \prime}, \xi_{t}^{\mathrm{x}^{\prime}}\right)^{\prime}$, are contemporaneously correlated. In the squel we asume that $\xi_{t}$ is independently normally distributed with zero mean and an unrestricted symmetric positive definite covariance matrix $\Sigma$.

\section{IV.3 An Empirical Analysis}

In this section, we apply the model (IV.12) and (IV.14) to quarterly aggregate manufacturing data in the Netherlands for the period 1971. I-1984. IV.

In figure 1 time series are given for aggregate employment ( $l$ ), capital. $(k)$, real labour costs ( $w$ ) and real prices of investments (q), the base year for 11 data being 1980 . A description of the data sourcesis iven in appendix A.5. In the empirical analysis n equals 1 . 
Unfortunately time series on branches of industry are mot atollable for the Metherlands. Therefore we have to rely on sectoral aggregates. We cannot take into account the shifts win the industry. In the last two decades some branches of the industry threatered to collapse under the increasing production costs and the growing foreign competition (e.g. textile, paper, shipbuilding), whereas capital and know-how-intensive industries, such as chemistry and electrotechnology, experienced a substantial expanston.

Energy supply and prices were strongly affected by the world oil crises which occurred in 1973 . IV (OC1) and in 1979. II (OC2). OCl reduced the profitability of firms. Heavy foreign competition prohibited the price increases necessary to cover the increase of product ion costs. Sales fell off as a result of depressed demand. Bankruptcy was a major cause of rising unempl oyment.

Anticipating price increases due to oc2 the export of energy intensive industries such as chemistry and steel expanded. In our analysis, however, we do not discuss the effects of a foreseen price change, but the impact of oc2 on wage costs and factor demand after it had occured. The slow-down of the growth of domestic sales was caused by the dectage of real disposable income. The market share of imported goods increased again. Employment decreased and profit shares deteriorated in the yours after oc2. Wage restraints reduced the ratio of wage costa to total production costs (see figure IV, 1 ).

We start our empirical investigation with an analysig of the single data series. First, we test for the order of integration of the series. We assume that each time series can be adequately represented by the univariate model

$$
\hat{v}_{t}-V_{t-1}=B_{0}+B_{1} O C_{1}+B_{2} O C_{2}+a_{1} v_{t-1}+a_{2} \Delta v_{t-1}+E_{t} \text {, }
$$


where $O C_{1}$ and $O C_{2}$ are oll shock dummies being 1 for 1973 . IV and 1979. II respectively ath zero otherwise, fi the model is estimated in first differencs, and being 1 for the periods 1973.IV-1984. IV and 1979.II-1984.IV respectively and zero otherwise if the model is estimated in levels; Et is an 1.1.d. $N\left(0,0^{2}\right)$ randon variable; and $V_{t} \in\left\{w_{t}, q_{t}, k_{t}, k_{t}\right\}$. Three dumies were added to the equation to account for seasonality in the data.

To test the hypothesis that the second order process $\nabla_{t}$ has anit root without a drift, or Ha: $a_{1}=0$, we computed Fuller"s $\tau^{\text {t }}$ yielding -1.38 , $-1.99,-.79$ and -.15 for $w_{t}, q_{t}, l_{t}$ and $k_{t}$ respectively, with $\bar{R}^{2}$ being $.987, .897, .997$ and .998 , and the DW being $2.05,1.95,2.08$ and 2.01 respectively. Consequently, on the basis of a comparison with the values in table 8.5.2. of Fuller (1976) we cannot reject the hypotheses of wt, $9 t$, $\ell_{\mathrm{t}}$ and $\mathrm{k}_{\mathrm{t}}$ being $I(1)$.

In the RE-model (TV.14) the autoregressive part af $l_{t}$ and $k_{t}$ is restricted to be stationary. Yet, figure IV.1 clearly indicates that both series are non-stationary. In the literature, a non-stationarity is often viewed as beling beyond the scope of the economic model, and 1 s renedied by incorporating detarmitistic trends. However, when factor demand and real input prices are colntegrated, the non-stationarity of the latter may capture that of the input demand. To test for colntegration we compute the cointegrating regressions for $\ell_{t}$ and $k_{t}$ and the corresponding augmented Dickey-Fulder regressions for the period 1971.I-1984.IV, and find (asymptotic t-gtatistics are glven within parentheses, seasonal dummies are not reported). 
Figure IV.1 : Factor Inputs and Real Input Prices of the Dutch Manufactum ring Sector $(1971 . I-1984 . I V)$.

Index numbers manufacturing employment $(1980=100)$

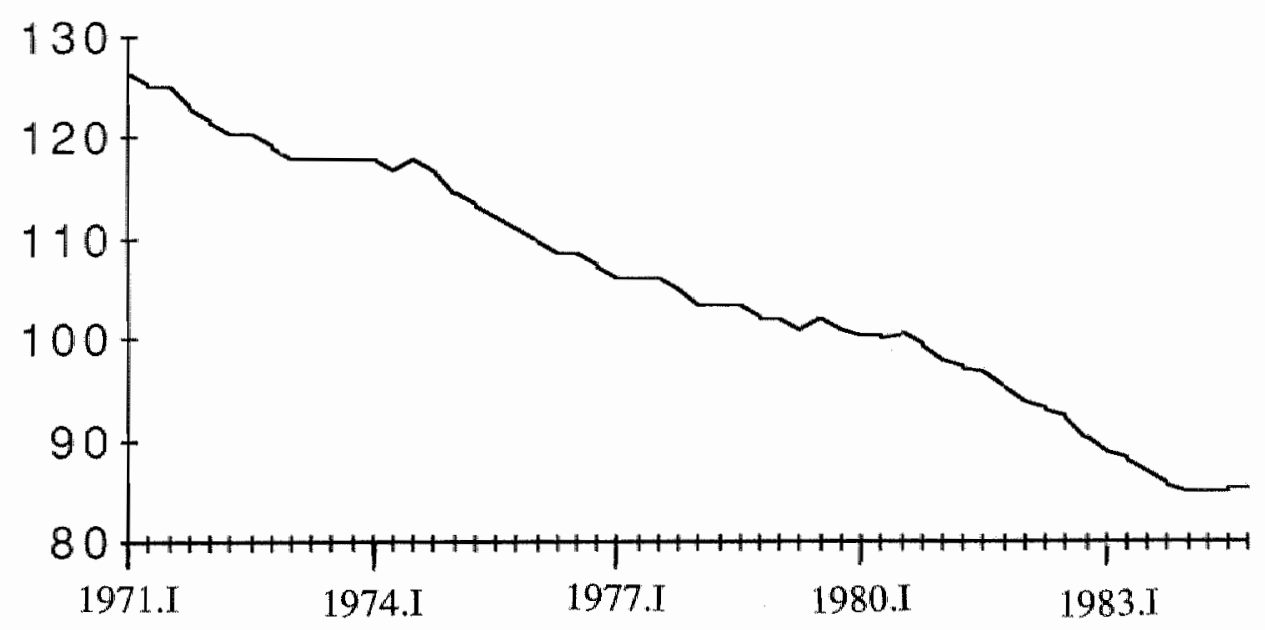

Real price index manufacturing labour costs $(1980=1 \quad)$

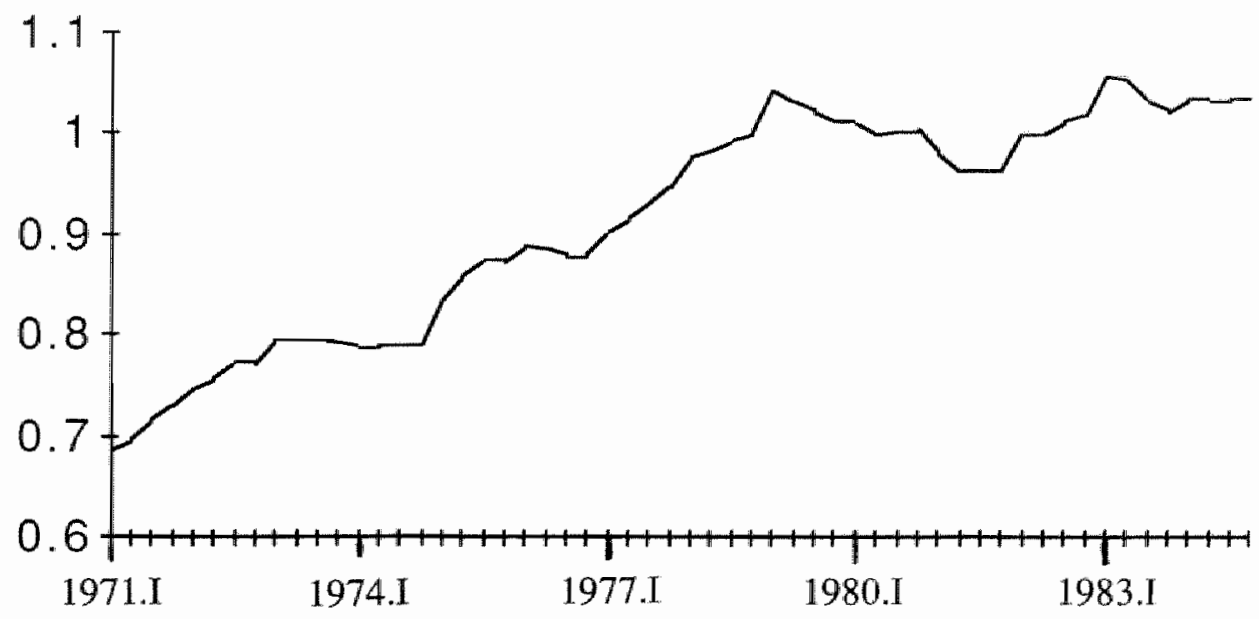


Pigure IV 1 : Factor Inputs and Real Input Prices of the Dutch Manufacturirg Sector (1971.I - 1984.IV).

Index numbers capital stock $(1980=100)$

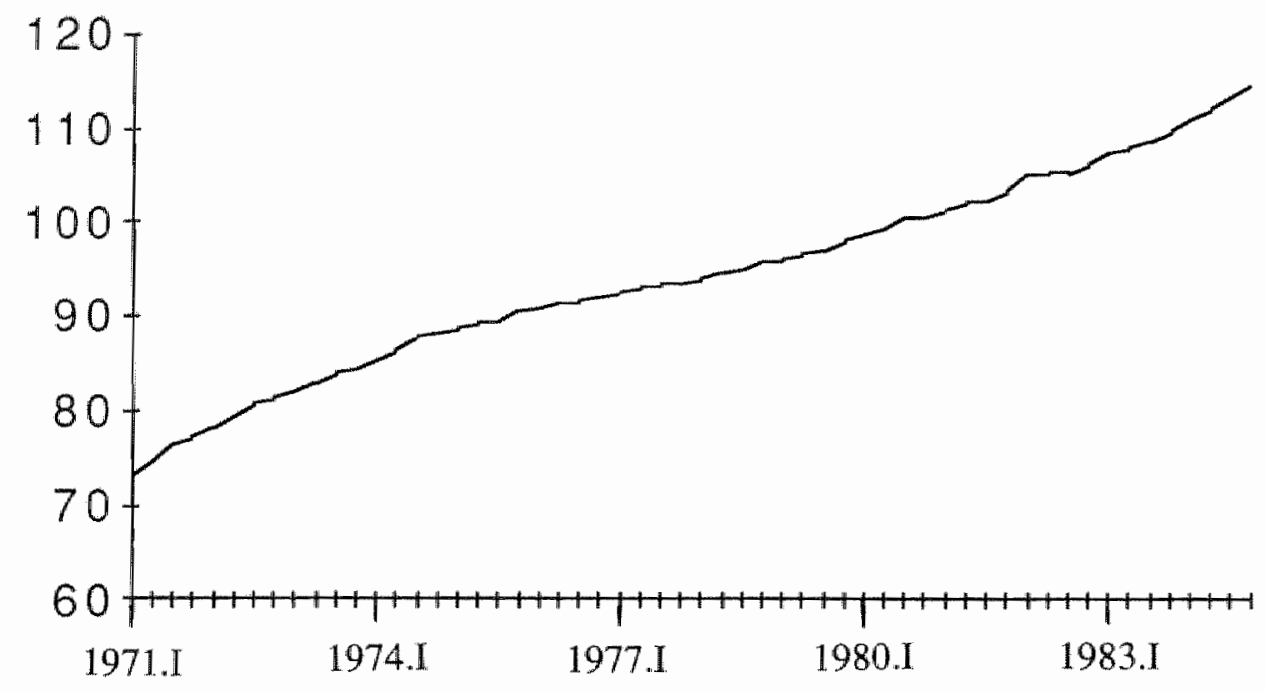

Real price index capital stock

$(1980=1)$

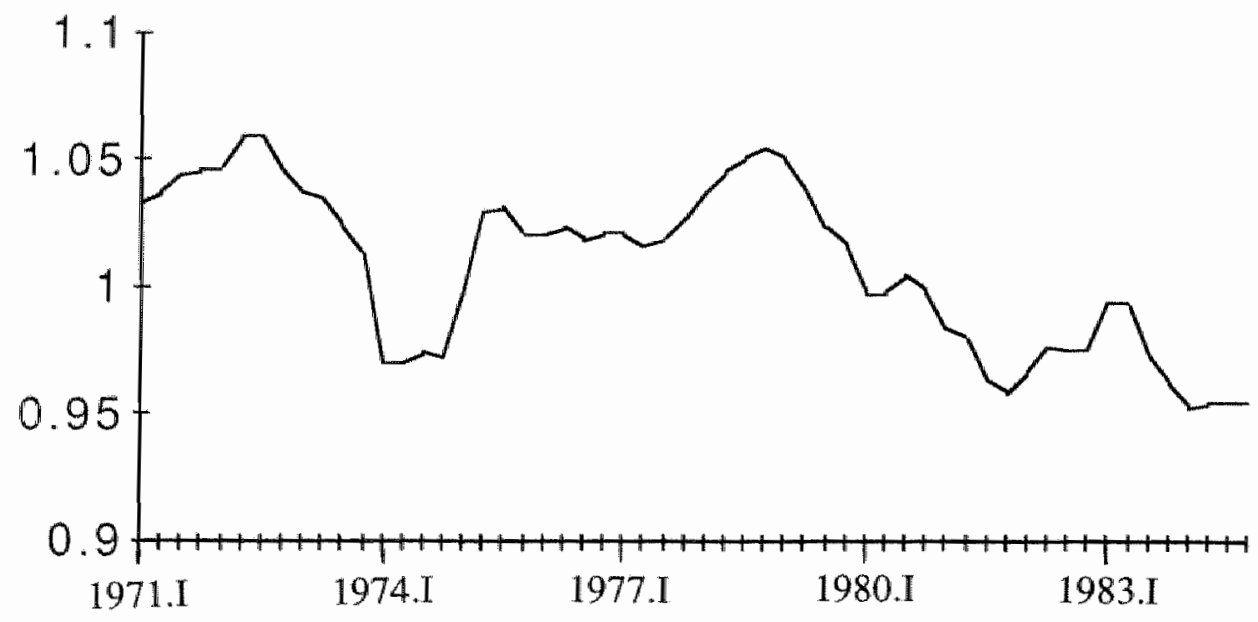




$$
\begin{aligned}
& x_{t}=.464+.0850 C_{1}+.0340 C_{2}-1.164 w_{t}+1.5639 t\left(+u_{t}\right) \\
& \begin{array}{lllll}
(2.85) & (4.77) \quad(2.21) & (-15.35) \quad(8.76)
\end{array} \\
& \overline{\mathrm{R}}^{2}=.964 ; \mathrm{DW}=.620
\end{aligned}
$$

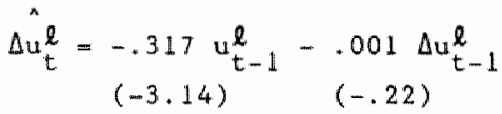

$$
\begin{aligned}
& k_{t}=1.740-.0470 C_{1}-.0290 C_{2}+.917 w_{t}-1.580 \mathrm{q}_{t}\left(+\mathrm{u}_{t}\right) \\
& (14.21)(-3.91) \quad(-2.69) \quad(17.22) \quad(-11.70) \\
& \overline{\mathrm{R}}^{2}=.976 ; \quad \mathrm{DW}=.774 \\
& \begin{aligned}
\Delta u_{t}^{k}= & -.375 u_{t-1}^{k k}-.001 \Delta u_{t-1}^{k} \\
& (-3.29)^{k}
\end{aligned}
\end{aligned}
$$

The CRDW-statistics (Cointegrating Regressions Durbin-Watson statistic) are .620 and .774 for $\ell_{t}$ and $k_{t}$ respectively. By comparison of higher order cointegrated systems of Engle and Yoo (1987), the CRDW-statistics seem to reject the nul1 at a 5 percent level, indicating that both $\ell_{t}$ and $k_{t}$ are cointegrated with factor prices. A similar conclusion can be drawn from the augmented Dickey-Fuller (ADF)-atistic with values -3.14 and -3.29 respectively; using tables II and III of Engle and Yoo, the nuld 1 , rejected at a $10 \%$ level for $\ell_{t}$ and $k_{t}$. Accordingly, $\ell_{t}$ and $k_{t}$ may be viewed as being cointegrated with $w_{t}$ and $q_{t}$. Excluding $O C_{1}$ and $O C_{2}$ from the cointegrating regregsions we find. 16 and .35 for the CRDW-gitatsics of $\mathfrak{L}_{\mathrm{t}}$ and $\mathrm{k}_{\mathrm{t}}$ respectively and -1.33 and -1.57 for the $A D F-g$ tatistics. This finding and the $t$-statistics of $O C_{1}$ and $O C_{2}$ in both colntegratirg regressions indicate that $l_{t}$ and $k_{t}$ have undergone (structural) step charges due to price increases of $O C_{1}$ and $O C_{2}$. 
垈xciuding the seasonal durmies from the cointegratimg regressions leads to even stronger spport for the cointegrating assumption, with CRDH-gtatistics that equal .757 and 1.057 respectively. and ADF-statistics ylelding -3.50 and -4.31 . This finding irdicates that the long rua relationship bethen the colntegrating variables has been distinctively difEerent for each seasion.

The cointegrated system must have a causal ordening in at least one direction (Engle and Granger, 1987). In section 2, we asstumed unidirectional causal ordeming in the sense of Granger from prices to factor demand. We use a fourth order VAR of $\mathrm{w}_{\mathrm{t}}, \mathrm{q}_{\mathrm{t}}, \mathrm{l}_{\mathrm{t}}$ and $\mathrm{k}_{\mathrm{t}}$ in levels, including a contant, $O C_{1}$ and $O C_{2}$, and three seasonal dumies, to test the hypothesis that the coefictents of all lagged factor inputs in the price equations are zero. The size of the WALD test may be smaller than the nominal size because of the possible occurence of unit roots. Comseguently, a WALD test. beimg computed from a regression in levels, that rejects the hypothesis of Granger causality, implicitly refects the hypothesis when the estimation was carried out in first differences. The WALD statistic which is asymptotically $x^{2}(16)$ distributed equals 24.38 . The WALD statistic associated wth the rull hypothes is of no causality from prices to derand equals 39.26

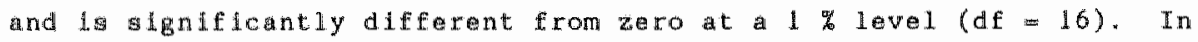
conclusion can say that undidrectiond causality from input prices to factor domand is found to be in accordance with the information in the data.

Under the null hypothesis of unidirectional causality from input prices to factor demand, we cam examine the process for the price seziles independently from the factor input data. Bivariate identification of $p t=$ $\left(w_{t}, g_{t}\right)^{\prime}$ has been carried out using the SCA statistical system provided by Litu et.a1. (1986). The results for Akaike's Information Criterion (AIC) and 
a statistic, $\mathrm{CHI}^{2}$, testing the significance of an additional lag of the bivariate lag-polynomial, are given in table $\mathbb{I V} .1$. CHI $^{2}$ is based on the logarithmic difference of the residual covariance matrix ML-estimates of autoregressions with and whout an additional $1 \mathrm{ag}$ and is asymptotically $x^{2}$ (4) distributed. On the basis of the results in table 1. and the tests for unit roots we assume that the process of $p_{t}$ can be adequately modeled as follows

$\Delta \mathrm{p}_{\mathrm{t}}=\mathrm{c}_{0}^{\mathrm{P}}+\mathrm{c}_{1}^{\mathrm{P}} O C_{1}+\mathrm{c}_{2}^{\mathrm{P}} O C_{2}+\mathrm{Q} \Delta \mathrm{p}_{\mathrm{t}-1}+\xi_{\mathrm{t}}^{\mathrm{P}}$

Where $c_{0}^{p}$ is a $(2 \times 4)$-matrix including a constant and three seasonal dummies, $c_{1}^{p}$ and $c_{2}^{p}$ are 2 -vectors and $Q$ is a $(2 \times 2)$-matrix of constant parameters.

Table IV.1 : Bivariate order selection of $p=(w, q)$ '

$\begin{array}{lcccc} & \mathrm{p}_{-1} & \mathrm{p}_{-2} & \mathrm{p}_{-3} & \mathrm{p}_{-4} \\ \text { CHI }^{2} & 93.67 & 20.57 & .90 & 5.18 \\ \text { AIC } & -15.75 & -16.12 & -16.00 & -15.99 \\ & \Delta \mathrm{p}_{-1} & \Delta \mathrm{p}_{-2} & \Delta \mathrm{p}_{-3} & \Delta \mathrm{p}_{-4} \\ & 25.94 & 2.57 & 4.52 & 5.65 \\ \mathrm{CHI}^{2} & -16.01 & -15.94 & -15.91 & -15.93 \\ \text { AIC } & & & & \end{array}$

Basically, $x_{t}$ can be written as the partial adjustment model (IV.9). Moreover $x_{t}$ and $p_{t}$ were found to be $I(1)$. In that case it can be shown (cf. Mickel1 (1985)) that equation (IV.9) will reduce to an exror correction mechanism (see appendix A.3). According to the Granger Representation Theorem (see Engle and Granger (1987)) and the results of (IV.2.1) - 
(IV.2.4) this implies that the theoretical considerations indicate that $x_{t}$ and $p_{t}$ should cointegrate. This finding has been confirmed empirically.

For reasons explained in the previous section we assume that the structural parameter matrices $A$ and $B$ are diagonal, whout loss of generality. Then the dynamic factor input demand equation (IV,14) becomes

$x_{t}=c_{0}^{x}+c_{1}^{x_{O C}}+c_{2}^{x_{O}} C_{2}+\left(R+\Lambda_{1}\right) x_{t-1}-R_{1} \Lambda_{t-2}+U_{1} p_{t-1}+U_{2} p_{t-2}+\xi_{t}^{x}$

where $U_{1}=(I-R) \Lambda_{1} B^{-1} V+\left(I+d-\tau \Lambda_{1}\right) \Lambda_{1} B^{-1} v Q_{n}$

$U_{2}=(I-R)\left(d-\tau \Lambda_{1}\right) \Lambda_{1} B^{-\Perp} V Q$,

$V$ is a $(2 \times 2)$-ratrix solving $\tau \Lambda_{1} V(I+Q)-\left(\tau \Lambda_{1}\right)^{2} V Q=I$,

and $\quad F_{t}^{x}$ is a 2-vector of innovations.

Note that $C^{-1} \Lambda_{\mathbb{L}}^{i} C=\Lambda_{1}^{i}$, since $C=I$ if $A$ and $B$ are diagonal. The 4-vector of disturbances $\left(\underset{t}{\left(p^{\prime}\right.}, \xi_{t}^{x^{\prime}}\right) "$ is assumed to be i.i.d. N(0, $\left.\Sigma\right)$ distributed.

Seasonal dumies were added to the regression equations to take account of the seasonality in the data.

Estimates of the structural parameters of the system (IV.3.1) and (IV.4.1) ar obtained using the method of asymptotic least squares (ALS).

The nonlinear functions are known when a closed form solution has been obtalned, as described in section 2. The ALS-estimation results are given in table IV,2. On a priori grounds we assume the quarterly real discount factor $\tau$ to be 98 ; the depreciation rate $\delta$ for capital is set equal to .047, for the perlod $1971-1984$ and has been obtalned from the CBS.

The assumptions underlying our model appear to be corroborated. The technological shocks follow a stationary process, and the structural matrices $A$ and $B$ are positive definite. The adjustment costs of labor are smaller 
than those of capital $\left(\mathbb{B}_{11}<B_{22}\right)$, and $\mathbb{B}_{11}$ is not significantig different from zero. This finding is intuitively plausible, and is consistent ith findings from similar comparable empirical reseatch (seve e. Plndyck and Rotemberg $(1983))$.

Apart from the 1 ikelihood ratio (LR)-statistic, testing the appropriateness of the parameter restrictions implied by the theoretical model and which is significant at the $5 \%$ level but not at the $1 \%$ level, the bottom part of table 2 shows that the model fits the data fairly well. Although the Durbin-Watson statistic is biased towards 2, the walues are very close to 2, which is remarkably good for this type of dymamic model. The consistent mulivariate portmanteau test statistic of Hosking (1980) i. an IM test and does not point to any higher order significant residual autocorrelation. The significance at the $5 \%$ level (but not at the $1 \%$ level), of the LR-statistic may be due to the rather simple functional form of the firm's technology and costs structure.

The ARCH-statistics in table IV.2 (see Engle (1982)), do not indicate any significant residual autoregressive conditional heteroskedasticity. This finding suggests that the agents' learnjing in the presence of a structural change has indeed been modeled in way that is not in contradictolon with sample evidence, by adding dumy variables for the effects on demand of a step change in the process of input prices. OC leads to a significant scrapping of capital. oc significantly reduced the demand for labor, thereby increasing the unemployment in the Netherlands. 
Table IV.2 : ALS-egimation results and tests of the RE-factor demand model for the period 1971. III-1984.IV*

$$
\begin{aligned}
& p=(w, q) \cdot: c^{p}=\left[\begin{array}{cc}
.019 & (5.95) \\
-.002 & (.63)
\end{array}\right] \quad 0 c_{1}=\left[\begin{array}{ll}
.001 & (.13) \\
.004 & (.45)
\end{array}\right] \\
& O C_{2}=\left[\begin{array}{ll}
-.022 & (1.90) \\
-.018 & (2.24)
\end{array}\right] \quad Q=\left[\begin{array}{llll}
.394 & (2.02) & .146 & (.66) \\
.147 & (.85) & .293 & (1.51)
\end{array}\right] \\
& x=(k, k) \cdot: c^{x}=\left[\begin{array}{ll}
.006 & (.34) \\
.005 & (.49)
\end{array}\right] \quad \mathrm{OC}_{1}=\left[\begin{array}{c}
.003(1.32) \\
-.005(2.41)
\end{array}\right]
\end{aligned}
$$

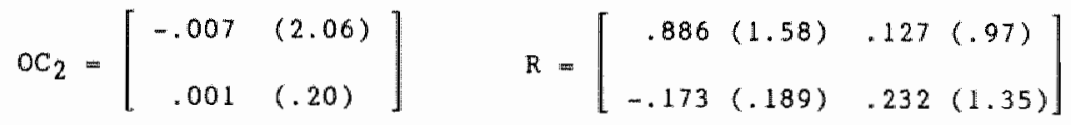

$$
\begin{aligned}
& A=\left[\begin{array}{ccc}
1.774 & (.28) & 0 \\
0 & 1.450 & (2.20)
\end{array}\right] \quad B=\left[\begin{array}{ccc}
.354 & (.39) & 0 \\
0 & .730 & (4.62)
\end{array}\right] \\
& \Sigma_{4}=\left[\begin{array}{rrrr}
12.23 & & & \\
7.65 & 9.88 & & \\
-1.20 & -2.21 & 2.82 & \\
-.24 & .33 & .21 & 1.21
\end{array}\right] \times 10^{-5} \quad \log \mathrm{L}=795.55
\end{aligned}
$$

\begin{tabular}{|c|c|c|c|c|c|c|c|c|c|}
\hline & & $\mathbb{s}$ & LM & $x^{2}(.95)$ & 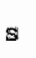 & $w$ & $q$. & 2 & $k$ \\
\hline $\mathrm{DW}(\mathrm{w})$ & $=1.99$ & 5 & 68.25 & 88.25 & 1 & .35 & .09 & .24 & .01 \\
\hline $\operatorname{DN}(\mathrm{q})$ & $=1.84$ & 10 & 144.62 & 177.39 & 2 & .94 & .11 & 2.33 & 2.87 \\
\hline $\mathrm{DW}(\ell)$ & $=1.91$ & 15 & 226.20 & 264.23 & 3 & 1.99 & .55 & 2.49 & 5.65 \\
\hline DW(k) & $=2.10$ & 20 & 300.68 & 349.93 & 4 & 3.40 & 5.70 & 2.99 & 5.56 \\
\hline$R(8)$ & $=15$ & & & & & & & & \\
\hline
\end{tabular}

TESTS :

$$
\text { Hosking : } X^{2}(16 s-12) \quad \text { ARCH : } X^{2}(s)
$$

* The absolute values of asymptotic t-values are given within parentheses. The estimated coefficients of seasonal dumies have not been presented in the table. 


\section{4 Concluding. Remarks}

This chapter has been concerned with the multivariate adjustment rational expectations model. A solution of the stachastic control problem of the Irm has been given and the implications of the theoretical model for the factor demand equations have been discussed. In particular, ft has been shown that interrelation between factor demand does not result from possibilities for substitution between inputs or trade-off an the adjustment costs. It can result from the cross-correlation between the shocks affecting the production technology of the firm. In line with the lucas critique, special attention was paid to the implications of a structural change in the processes generating the exogenous variables. Flnally, the model has been applied to quarterly data for the mamufacturing it the Netherlands for the period 1971-1984.

As the hypothesis of cointegration of factor demand series and relative factor prices was not rejected by the data, the nonstationarity of the factor demand series has been modeled by including the levels of the relative prices in the demand schedules, instead af detrending them prior to the analysis.

To sumarize, the following conclusions were reached.

(1) A quadratic objective function does not imply interrelated adjustments of production factors. Cross-correlation of innovations in the production technology, however, does.

(ii) In line with the RE hypothesis, the nongtationarity of the factor demand series can be accounted for by the nonstationarity in the exogenous variables.

(iii) A structural step change in the constant term of the process of the exogenous variables leads to a step change in the factor demand 
equations. The magnitude of the change depenas on the siae of adjugtment costs and the Eirm"s technology.

(iv) The gradual learning about the nature of the structural change reay Induce paterns in the disturbances of the demand system that can be approxínated by an ARCH-process.

(v) For the Dutch manufacturing sector, labor and capital and their prices relative to the output price index are integrated of arder one. Moreover, the four series are found to be colntegrated.

In order to prevent misinterpretation of these results, some qualifications have to be made. First, the empirical analysis was based on aggregate data. Aggregation possibly bides the differences in the adjustments that have tan place in the various branches of the industry. Second, the rejection of the restrictions implied by the RE-adjustment cost model at the $5 \%$ level may be the result of the rather simple functional form of the production function and of the adjustment cost structure, a criticism which has often been made in the 1Lterature (e.g. Morrison (1986)). More complicated functional forms lead to nonlinear first order conditions for the optimization problem and may be prohibitive for getting a closed form solution in which case the Euler equatons can be analyzed using for instance an Instrumental variables technique (e.g. Hansen and Singleton (1982)). 


\section{CHAPTER FIVE}

THE STRUCTURE OF ADJUSTMENT COSTS FOR LABOUR IN THE DUTCH MANUFACTURING SECTOR 


\section{V.1 Introduction}

Thig chapter examand the appropriatemess of symetric quadratic specifications of adjutment costs for labour (ACL) in dynamic labour demand models. We lnterviewed personnel managers of Dutch manufacturing firms. The intervieks focussed on decisions of firms to change their productive workforce and the corts that arise from these changes. The general outcomes of the interifow are discussed in section. 2.

In section 3 we propose an alternative ACL specification which satisfies the properties of the dynamic theory of labour demand and includes the symmetric quadrat form as a special case. The merit of the novel specification is the possibility to measure the difference between hiring costs and fing costs. Econometric analysis of the alternative ACL function using data obtalned from annual reports of Dutch mamufacturing firms for the period 1978-1986 show that hiring costs exceed firing costs. This finding has an important implication. The speed of adjustment of the firm"s workforce to a moving target level is slower in economic uprises than it is in economic recessions. Conclusions are draw in section 4 .

\section{V.2 ACL in Practice}

In order to get a better insight into the structure of AcI in practice we Interviewed persomnel managers of DSM chemicals, FOKKER aircrafts, HOOGOWENS stel, VENDEX International and VOLWO cars. The interviews foeussed on decisions of the firms to change their productive workforce and the cost that arise from these changes. The choice of firms has been such that together: they represent the putch manufacturing sector as a whole. The firms are relatively large with outlets that reach beyond domestic makets. The various firms reflect differences in production technologies, that is, differences in production processes, required technologlical knowledge, and the imput of labour as a production factor. In 
this section we present the nost salient outcomes of the interviews. FOKKER and HODGOVENS stated that the rete of labour turnover amounts to 5 percent of the total warkorce per six months. Although start up costs of new entries are inversely related to the capacity and quality of a flrm. training department, the turnover adustment costs of labour do not increase at the margin. However, a growth up to 5 percent pield marginally increasing ACL, whereas an increase ower 5 percent is practically impossible, since this will lead to large fnefficiencies in the production process. If these statements hold true in general, the ACI function should be adjusted for the size of the firm.

The persomel managers of ald the firms agreed that ACL depend on union power, the expectation formation of labour input requirements in the near future and praduction technology. Labour unions hate a considerable effect on the costs of labour adustments through their influence on the rate of dismissal payments and the duration of application terms for dismissals. Tight dismissal regulations and high dismissal payments boost ACL. Given the power of labour unions, a firm that accurately forecasts its future sales and, accordingly, its future labour input minimizes ACL when the firm changes its workforce. The longer it takes firms to eire thelr workers, the higher are ACL when employment expectations do not match future realizations.

A dismissal application lasts between six and twelve months. Consequently. a firm that wants to reduce the workforce below the level of its labour turnover rate must stat the dismissal procedure this period in advance. Figure $1 \mathrm{a}$ and $1 \mathrm{~b}^{1)}$ illustrate how a firm"s expectation formation process

1) These figures were initially drawn by Ir. J. Zaaider of FOKKER. 


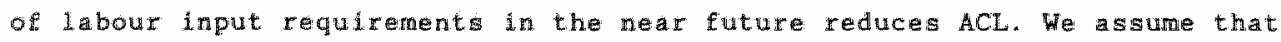
firm 1 confronted wth an unforeseen structural change in its economic mvironment at $t$, such that a decrease in employment becomes necessary. Given that the dismissal application term lasts one period, and assuming that the irm gradually reduces the workforce over one period, the costs of ineficient employment policy equals the labour surplus (shaded areas) times the average wage costs of these workers. In figure la the firm's expectation fomation process is rational, that is, it takes account of the tight dismisal regulations and applies for the firing of Li-Lin workers at

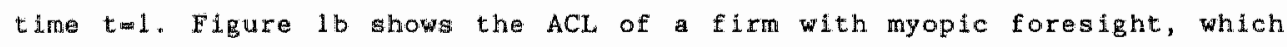
takes employment decisions structurally one period too late. At $t=1$ it applies for the dismissal of $L_{2}-L_{1}$, at $t=2$ it applies for the dismissal of $\mathbb{L}_{3}-\mathrm{L}_{2}$, and so on. Dur ${ }^{\mathrm{A}} \mathrm{ng}$ the time that the firm's target level of employment (L舟) does not remain constant the firm has a structural labour surplus.

Consequently, we may conclude that the expectations formation process of the firm is of crucial importance as to minimize the adjustment costs of labour. In a changing economic environment forces that 1 imit the firms to adjust optimajly to these changes, such as long application terms for dIsindsals, boost ACL.

The exterd to which ACI influence the firm"s reaction to a changing economic environment depends also on the labour-intensity of the production process. Fins with a high-tech labour-intensive production process, such as alrcrat indugtries (FOKKER), face high costs of labour adjustments. These firms mploy relatively many highly qualified workers, with large hiring and trafning costs. ACL differ significantly between silled and unskilled workers. This fact, surveyed in Nickell (1986), has also been underlined by the personnel managers of the Dutch firms. ACL of unskilled workers are low in comparison with their warlable wage costs. Firms using low-1evel know- 
Pigure 1a: ACL caused by once-only expectitional error in case of tight dismissal regulations.

employment

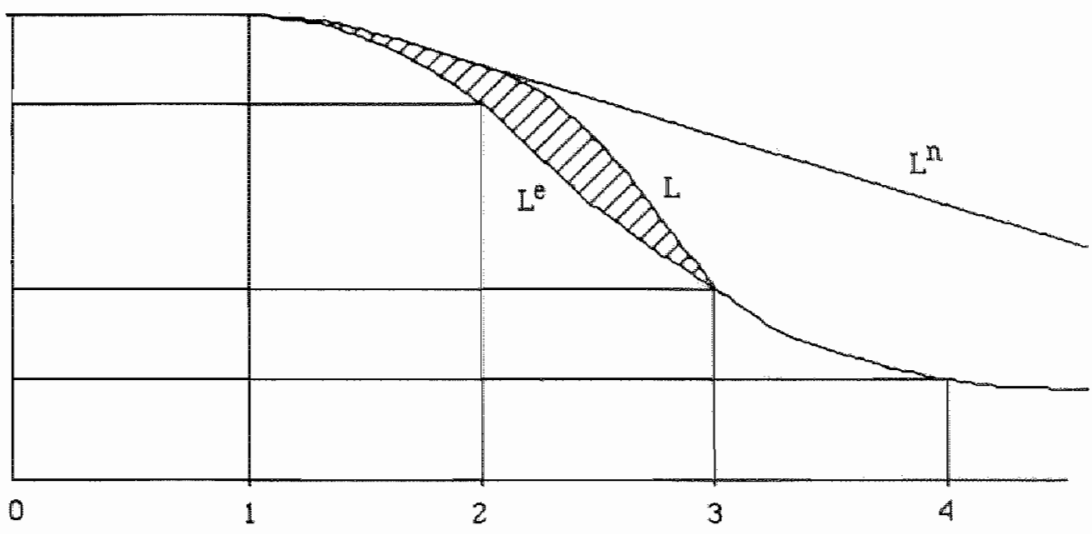

tine

Figure $1 \mathrm{~b}:$ : ACL cauged by a structural expectation enor of one period in the case of tight dismissal regulations.

employment

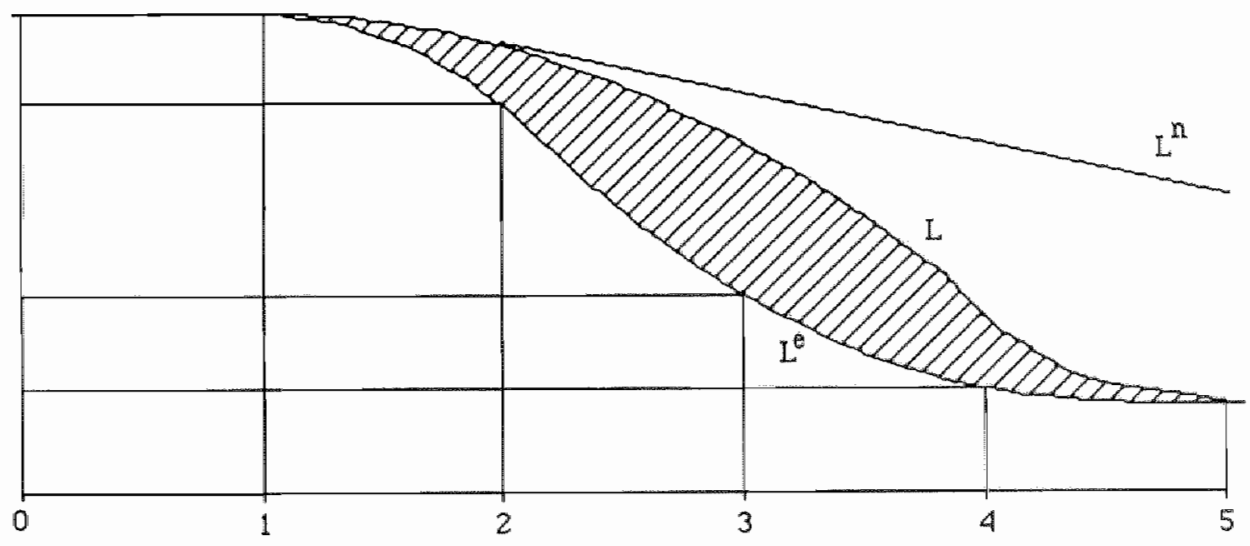

time

$L_{t}=$ the number of workers employed at period $t$

$\mathrm{L}_{\mathrm{t}}^{\mathrm{e}}=$ the fim's arget level of employment at period t

$\mathrm{L}_{\mathrm{t}}^{\mathrm{n}}=$ the fims's workforce at period $t$ red uced only by labour tumover 
how labout-intensive production technologies employ mainly unskilled recrute. For these firms variation in workforce is an important instrument to change output and production costs. Figure 2 ilustrates employment wduction when production casts ise above a permissable level and the board of directors cuts these costs through reducing the workforce 1 ). Given that the furm's departments are inclined to grow in size, with low ACL and in the absence of dismissal regulations, the least productive and rellativiy most expensive workers are fired at $t=1, t=2$, etc. In spite of the fact that ACL are low, this model leads to a cyclical pattern in the dymamic demand of labour.

Decisions to change the production capacity of a captal-intensive firm, Such as steel (HOOGOVENS) and chemical industries (DSM), are not based on congiderations of personmel costs. Such firms develop a marketing plan, which is followed by an investment plan, from which the employment plan is derived. Investment decisions are based on the product market, that is, the expectations of future product demand. The time lag between the investment decision and the resulting demand for 1 abour equals two years on average. Costs of recruiting, screening and training are less than one percent of the total investment. The ACL are part of the investment and are wituen down as such together wth the new capital.

\section{T.3 The shape of the ACL Function}

In this section we discuss the shape of the function that relates costs to the rate of workforce adjustments. Nickel1 (1986) discusses several 1 ikely

1) Eigure 2 was initially drawn by B. van Dijk of volvo cars. He called it "indentation employment policy". 
$-89-$

Figure 2 : Indentation employment policy.

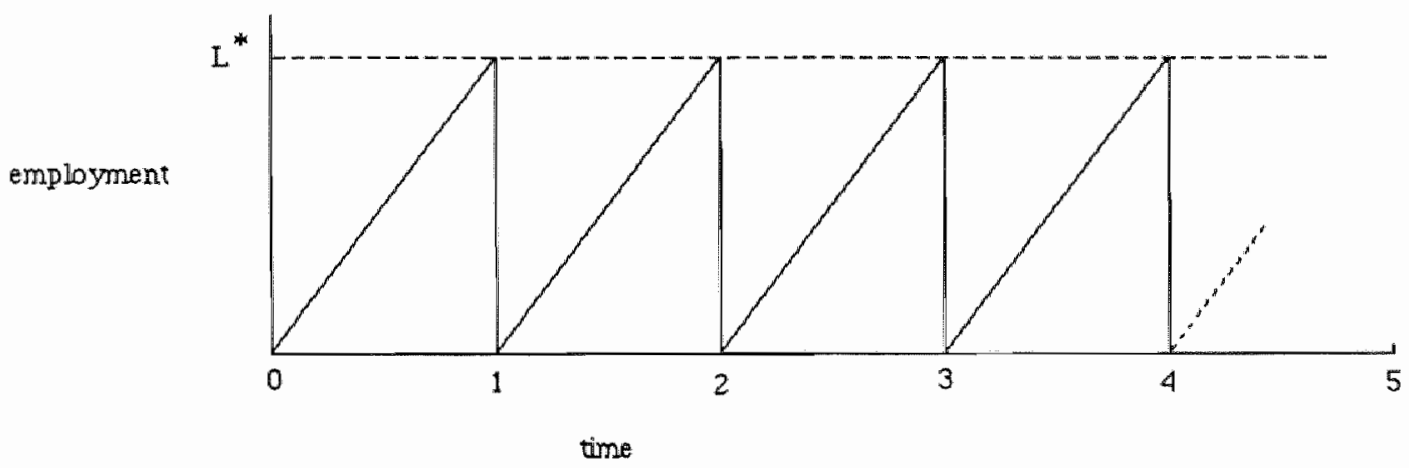


forms of ACL functions and the ir implications for dynamic labour demand theory. The lineat adjustment cost model, for instance, is found to be consigtent with the instantaneous hiring and firing of groups of workers. In the linear model there is no partial adjustment to the new long-run equilibrium, and consequent 1 y labour dermand is not dynamic.

As has been pointed out by 01 (1962), however, when labour is a quasi-fixed production factor, labour demand follows an autoregressive process. In the dymamic theory of the firm it is assumed that ACL is represented by a strjctly convex function with the following properties $(n=n u m b e r$ of workers employed, $\Delta \mathrm{n}=$ change in employment in one period).

$P_{1}:\left.\quad \operatorname{ACL}(\Delta n)\right|_{\Delta n=0}=0 \quad ;$

$\mathrm{P}_{2}: \quad \operatorname{aACL}(\Delta \mathrm{n}) / \partial \mathrm{n}>0$, if $\Delta \mathrm{n}>0$;

$P_{3}: \quad \partial^{2} \operatorname{ACL}(\Delta n) / \partial n^{2}>0$

The symmetric guadratic function which satisfies these properties is as follows.

ACL. $(\Delta n)=\gamma(\Delta n)^{2} \quad \gamma>0$.

In this section we propose an alternative $A C L$ function which measures the asymmetry between hiring and firing costs. The novel specification encompasses the quadratic form as a special case. The function is as follows

AGL $(\Delta n)=\alpha-B \Delta n+Y(\Delta n)^{2}+\exp (\delta \Delta n)-1$,

where $a, B, Y$ and 6 are constant parameters. $P_{1}$ to $P_{3}$ are satisfied in the following restricted version of (V.2).

$\operatorname{ACL}(\Delta n)=-\beta \Delta n+\gamma(\Delta n)^{2}+\exp (\beta \Delta n)-1$ 
where $\alpha=0$ and $B=\delta$. ACL represented by equation ( $V .3$ ) is not symetric im case of $B \neq 0$. If $B>0$ hiring costs are marginally higher than iring costs. If $\beta<0$ firing costs exceed hiring costs (see figure V. 3).

In order to estimate the ACL function we collected data on net changes in workforce per year and the corresponding ACL from annual reports of Dutel manufacturing firms far the period 1978-1986. Annual reports do not specify $A C L$ but sone of them contain the entry "total costs of rearganisation", which we assume to be proxy for ACL. ACL are measured in thousands of guilders and have been deflated by the $1980=100$ producers price index of domestic sales. Net changes in employment $(\Delta \mathrm{n})$ are expressed in hundreds of workers. The sample consists of 168 cases $(9$ years and 30 firms and 102 missing observations). For 119 cases firings exceeded hirings $(\Delta \mathrm{n}<0)$, whereas the workforce increased in 49 cases $(\Delta n>0)$. This corresponds to the overall employment trends in the Netherlands over the spel1.

We regressed the data on several forms of the ACL function. This allows us to test the importance of fixed costs $(\alpha \neq 0)$. We note that ACL is measured as tatal costs instead of variable costs. An example of fixed ACI is the fact that training departments are expensive even if no new lly hed workiv are trained. The estimation of the flexible form (V.2) also allows us to test the validity of the restrictions on the parameters implied by the dynamic theory (V.3) or the restrictions implied by the symmetric quadratic shape of $A C L(V .1)$. Results are given in table $V .1$. 
Pfore 3. The gtructure of ACL represented by equation 3.3.

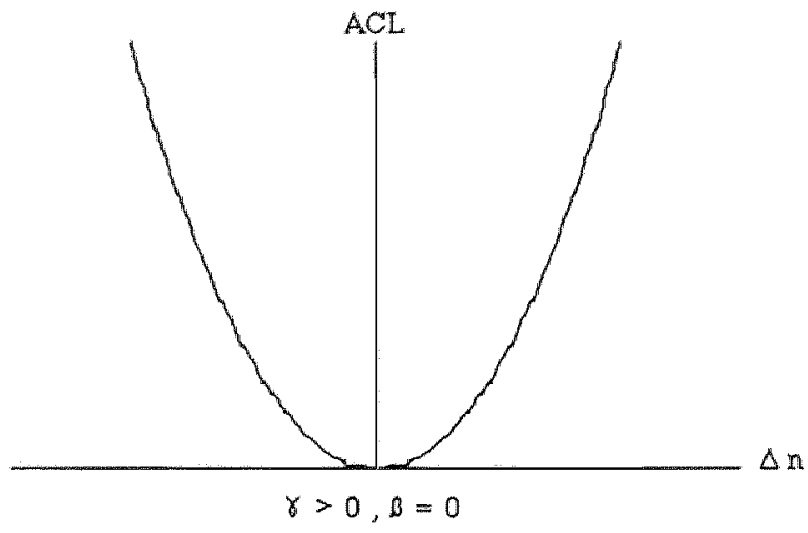

firing costs $=$ hiring costs

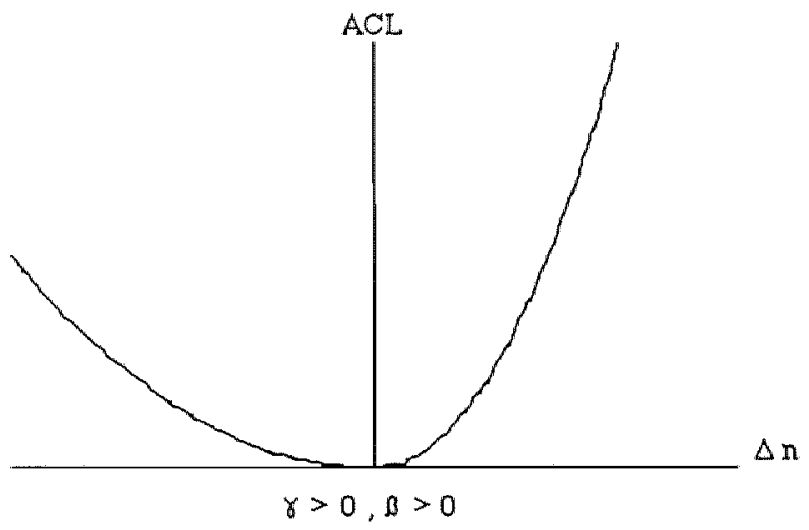

firing costs $<$ hining costs

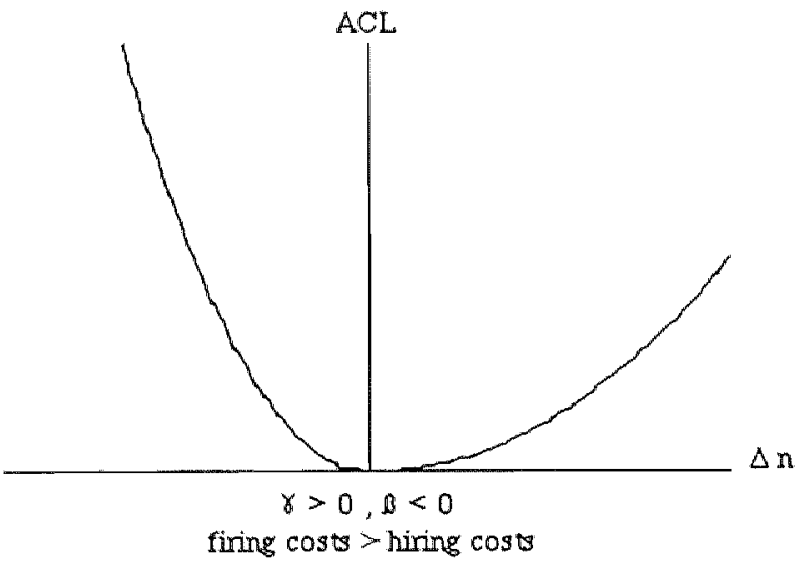


Table $V_{.1}$ : Fstimation Results and Hypothesis Tests of the ACL Function (standard errors are given ithin parentheses)

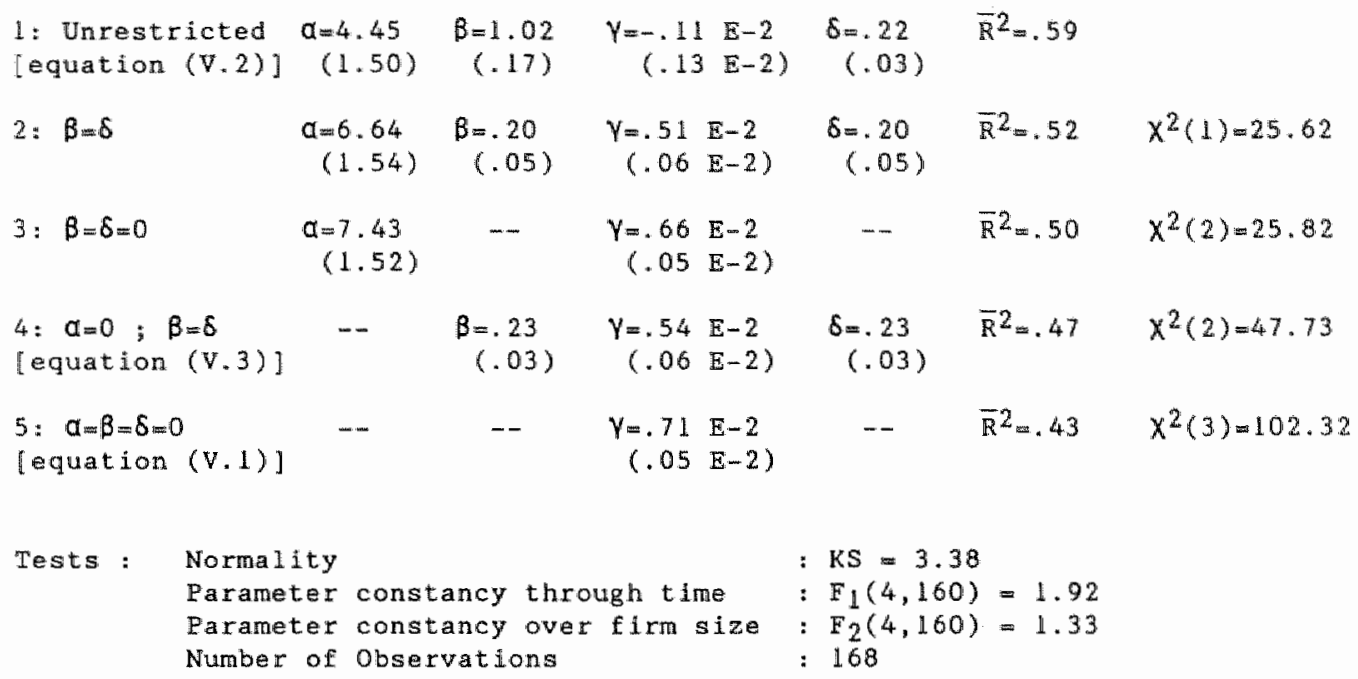

Chow"s test on parameter stability ( $\left.F_{1}\right)$ between the periods $1978-1982$ and 1983-1986 does not point at any structural change in the parameters through time. This fustifies regarding the data as a panel, and assuming the parameters of relation (V.2) to be time-independent. The F-statistio tests the hypothesis that the parameters in $(\mathrm{V}, 2)$ do not change with the size of the firm. The sample has been devided Lnto 91 cases of firms whis 1 es than 5000 employees on the one hand and 77 cases of firms that have 5000 or more employees on the other hand. The statistic $F_{2}$ does not reject the hypothem sis, which implies that the ACL function should not be adjusted by the size of the firm, as suggested in section 2. The Kolmogarov-Smirnov test (KS) point at some deviation from normality of the residuals, which implias that the tests may be biased.

Wald's tests $\left(X^{2}\right)$ on parameter restrictions and the adjusted $\vec{R}^{2}$ iven in table 1 show that the flexible ACL function (3.2) is superior to all the 
alternatives, including the smmetric quadratic form in a constant term mesuring fixed ACL (specification 3, table V.1) and equation (V.l) (specification 5, table V.1). Besides, the parameter restrictions implied by 1 to E3 are not in accordance with the data. Moreover, the parameter estimates indlcate that ACL are basically not symmetric. The estimates of $B$ and $\delta$ being both signifleantly greater than zero indicate that hiring costs exceed firng costs in the period 1978-1986. This finding has an important implication. The speed of employment adjustment to a (higher) target level of expanding firms is slower than the speed of employment adjustment to a (lower) target level of shrinking firms. Or, stated differentiy, during economic booms (hirings exceeding firings) employment will be lagged more behind the target level than during recessions (firings exceeding hirings).

\section{4 Conclusions}

From lntervlews wo have had with personnel managers of a selection of Dutch manufacturing firms we found that the costs of labour adjustments to a new tenrget level depend on the expectations formation process of a firm, and the labour-intensity of a firm's production process. Labour unions thave a substantial eftect an ACL through the bargained rate of dismissal payments and the duration of dismissal application terms. This $f_{i n d i n g}$ is in accordance wh recent research in the UK (Burgess, 1988, Burgess and Dolado, 1988).

Next, we have presented an alternative ACL function that measures the asymmetry between hiring and firing costs, and encompasses the symmetric quadratic form commonly used in models of dynamic labour demand as a special case. Under certain restrictions the novel specification of ACL, satisfies the properties of the dynamic theory of the firm. Estimation of the ACl function showed that in the period 1978-1986 hiring costs exceed 
Eiring costs in the Dutch manufacturing sector. Accordingly, during aconom mic booms, a firm"s employment ill be more lagged behind its target lewel than during periods of recession. We also found that ACL consist of both variable costs, as well as fixed costs that do not vary with the size of the adjustment. Results in support of this conclusion are glven by recent research on the structure of adjustment costs for labour faced by us manufacturing firms (Hamermesh, 1988).

Implementation of the ACL function into dynamic factor demand models and empirical examination of the differences in hiring and firing costg between production and non-production workersin manufacturing firms ill bo presented in the next chapter. 
CHAPTER SIX

ASYMMETRIC ADJUSTMENT COSTS OF LABOUR IN NONLINEAR RATIONAL EXPECTATIONS DEMAND MODELS 
VI. I Introduction

The costs of hiring a worker generally differ in size from the firing costs. This chapter investigates the implications of asymetric costs for production and nomproduction workers. It makes three contributions. First, two rational expectations asymetric adjustment cost models of the firm are analysed. In one model, capital is assumed to be predetermined when employment decisions are taken. The other assumes that investment and employment decisions are taken simultaneously. Second, the impact of unamticipated shocks in real factor prices, productiwity and technology on facm tor demand is investigated. Third, generalised method of moments (GMM) estimates of the structural parameters of nonlinear optimality conditions for production workers, nonproduction workers and capital, and specitication and structural stability tests are presented.

The outline of chapter 6 is as follows. A multivariate labour demand model in which adjustment costs are asymmetric and capital is predetermined is presented in section 2. The impact of a structural break in the process of the forcing variables on the decision rules of the firm is discussed. In section 3 we empirically analyse this model using annual ok manufacturing data for the period 1955 to 1986 and quarterly Dutch manufacturing data for the period $197 \Perp$. I to 1984. IV.

We find that for both countries, production and nomproduction employment in manufacturing can be adequately explained by means of the long run development of production and nonproduction real wage costs and the capltal stock, provided that step changes in the equilibrium levels due to the all crises are properly taken into account. We also find significant evidence for the asymmetry of adjustment costs. For both the Uk and the Netherlands, firing 
costo of production workers exceed hiring costs, whereas for nonproduction Horkerghring aeders to be more costly than firing.

In section 4 the model is extended. Capital and employment are simultaneous ly determined in the model. He present an alternative explanation for the "gestation" lag of the firm's capital as mentioned by kydland and Prescott (1982) and Rosis (1987) In the form of an asymmetric adjustment cost specification. The forcing variables of the model now become real production and nonproduction wage costs and the real price of capital assets. The analysis of the data casts some doubts upon the stability of the long run relationship between factor inputs and real factor prices. However, the nonstationarity of the decision variables can be adequately explained by inultaneously allowing for common stochastic trends (real input prices) and deterministic trends (technological changes). The asymmetry in adjustment costs of capital appears to be similar in UK and Dutch manufacturing. According to the model, it is optimal for the firm to slow down the scrapping of capital during recessions and to invest during economic uprises in anticipation of higher profits. Finally, conclusions are drawn in section 5 .

VI. 2 Labour demand under asymetric adfustment costs and predetermined $\operatorname{cop} 1$ iti 1

Consfor a representative firm which maximizes the expected present value of profits over an infinte horizon with respect to employment assuming that the labour market is competitive. Each decision period the firm chooses an employment contingency plan for $n$ types of labour $\mathbb{N}_{i}, i=1, \ldots, n$, conditional on a predetermined stock of capital and currently available information. Marginal productivity (MP) of labour il at time is

$\operatorname{MP}\left(N_{i, t}\right)=\alpha_{i}-\sum_{j=1}^{n} \lambda_{i j} N_{j t}-K_{i} K_{t}+\xi_{i t}, \quad i=1, \ldots, \mathbb{H}_{i}$ 
where $\alpha_{1}, \lambda_{1 j}$ and $k_{1}$ are constant parameters, $k_{t}$ denotes the firm"s caltal stock at time $t$, and $\xi_{1 t}$ denotes the impact of stochastic cechnological shocks.

In existing dynamic labour demand models, adjustment costs (AC) are a function of the changes in employment at time $t, A C\left(\Delta N_{t}=\left(\Delta N_{1 t}, \ldots, \Delta N_{n t}\right)\right)$, such that $\partial \mathrm{AC}\left(\Delta \mathrm{N}_{\mathrm{t}}\right) / \partial \mathrm{N}_{\mathrm{it}}<0$, if $\Delta \mathrm{N}_{\mathrm{it}}>0, \partial A C\left(\Delta N_{t}\right) / \partial \mathrm{N}_{\mathrm{it}}=\mathrm{AC}(0)$ a and $\mathrm{AC}$ has a positive definite Hessian matrix. These requirements have traditionally been implemented by assuming adjustment costs to be quadratic symmetric function of the changes in empioyment. Symmetry is, of course, a restrictive assumptiom as it implies that the costs of an expansion of the workforce are equal to those of a reduction af employment."

In chapter five we proposed more general functional form, which measures the difference between hiring costs and firing costs. The quadratric shape is nested in the extended specification, whereas it satisfies the convexity conditions of dynamic theory as well. The specification for the adjustment costs is as follows

$\Delta C\left(\Delta N_{i t}\right)=-B_{i} \Delta N_{i t}+\exp \left(B_{i} \Delta N_{i t}\right)+y_{2} \sum_{j=1}^{m} \gamma_{i j}\left(\Delta N_{j t}\right)^{2}, i=1, \ldots, n_{n}$

where $V_{1 j}$ and $B_{1}$ are constant parameters. Strict convexity is gats 100 iff the Hessian $\left(n \times n_{i}\right)-\operatorname{mat} r i x \partial^{2} \mathrm{AC}\left(\Delta N_{1}\right) / \partial^{2} \mathrm{~N}_{j \mathrm{t}}$ is positive definite. If $B_{1}$ $=0$, equation (VI.2) yields the traditional quadratic function, being symur metic iff $Y_{i j}=Y_{j i}$

What are the implications of asymetric adjustment costs $?$ The long run equilibrium level of employment is not affected since adjugment costs are assumed to only depend on chamges in employment. But asymetry has implications for the speed of adjustment to a new equilibrium level. 
As ume that the (non)-matrix $\Gamma=\left(\gamma_{j}\right)$ is positive definite (this is basiealy asumed in all linear modelg). If $B_{1}$ is negative, firing costs of laboti 1 exceed hiring costs and a downard adjustment of employment as a resut of a change in the target wil take more time than an upurd adjustment of employment due to a change in the target of the same size but in opposite direction. of course, it $\beta_{1}=0$ the adjustment pattern w11 be symmetrick

The objective of the $f$ ixm is to maximize the real present value of expected profits over an infinte time horizon, given all currently available infor mation. With real wage costs, Wit, $i=1, \ldots$, , being independent af $L_{i t}$ at each period $t$, the firm choosos employment contingency plans sat isfying the following first order (Euler) conditions

$M P\left(N_{i t}\right)-\operatorname{MAC}\left(\Delta N_{i t}\right)-W_{i t}+\tau \operatorname{E}\left[\operatorname{MAC}\left(\Delta N_{i t+1}\right) \mid \Omega_{t}\right]=0, \quad i=1, \ldots, n$,

where MAC is the marginal adjustment cost, $\tau$ is a real discount rate and $\Omega_{t}$ 1. the information set avallable to the firm at time $t$.

Together 1th the transwersality conditions, equations (VI.3) define the firm's employment policy. However, current decisions are based on unobserved future expectations. Idealy, one would like to obtain an explicit closed form forward looking golution for (VI.3). For linear first order conditong a closed form solution can be obtained (see e.g. Hansen and Sargent (1981), Kollintzas (1985)), whereas for nonlinear Euler equations this is only occasionally the case.

Explicit formard looking clased form solutions are useful to trace the efects of a structural change in the process generating the forcing varlables in the model. In the asymetric model, however, additional assumptions are needed on the distribution of forecast errors in order to identify the impact of an unanticipated structural change in the exogenous variables. In appendix A.4 we show that the expectational error of a decision variable defined as the difference between the first order condition 
(VI.3) and that same condition with the expected MAC replaced by the actud MAC is white noise provided the innovation of $L_{1}+1$ is nomally distibuted. Moreover, an unaticipated shock causing a step change in lat yields a step change in both unconditional mean and variance of the expectationd error of the firm. We also show that an unexpected exogenous shock that Leads to a persistent change of the firm's forecast error variance without affecting the slope coefficient of employment (e.g. an increase in uncertainty about the future behaviour of forcing variables) yieids a stiep change in unconditional mean and variance of the firm"s expectational error. Consequently, an unexpected exogenous shock can be modelled by using dummy variables that account for these step changes. Autoregressive conditional heteroscedasticity due to increased uncextainty in the disturbance can be introduced to madel the structural break in the wariance.

\section{3 Empirical analysis}

In this section we present parameter estimates for the optimality conditions in (VI.3). For the empirical analysis of the model we used seaso nally unadjusted quarterly data for manufacturing in the Wetherlands for the period 1971.I - 1984.IW, and annual data for the manufacturing in the JK for the period 1955-1986. All prices are mormalised by dividing by the output price index. All data have been divided by the ir sample man. Definitions and data sources are given in appendix A.S. Differences ln the adjustment of production workers $\left(\mathrm{N}_{1 \mathrm{t}}\right)$ and nonproduction workers (N $\left.2 \mathrm{t}\right)$ are due to differences between hiring costs and Eiring costs of both types of labour (cf. Nicke11 (1986)).

Structural changes in the forcing varlables, production and nonproduction real wage costs, Wlt, $W_{2 t}$, respectively, and capltal $K_{t}$, nay induce step changes in the employment level and in its wariances (see appendix A.4). 
In chapter IV model the learning in the presence of a structural change by including dumig variables in factor demand equations of a linear model and in the processes for input prices to account for the oil shocks. In Line wh those findings also use dumy variables in the present empirical analysis. The stochastic first order conditions (VI.3) do not yield a complete solution to the maximization problem of the firm. In order to estinate the structural parameters of the Euier conditions we apply the generalized method of roments (GMM) proposed by Hansen (1982) and Hansen and singletion (1982). The realised values of period $t+1$ are substituted for the unobserved expectations of one period ahead employment in (VI..3) and a vector forecast errors, $u_{t+1}$, of mean zero is added to the system (VI.3) ylelding

$\left[\begin{array}{l}\delta_{01} \\ \delta_{02}\end{array}\right] \operatorname{CoNST}+\left[\begin{array}{l}\delta_{11} \\ \delta_{21}\end{array}\right]$ OC1 $+\left[\begin{array}{l}\delta_{12} \\ \delta_{22}\end{array}\right]$ OC2 $-\left[\begin{array}{l}K_{1} \\ K_{2}\end{array}\right] K_{t}-\left[\begin{array}{ll}1 & 0 \\ 0 & 1\end{array}\right]\left[\begin{array}{l}w_{1 t} \\ W_{2 t}\end{array}\right]-\left[\begin{array}{ll}\lambda_{11} & \lambda_{12} \\ \lambda_{21} & \lambda_{22}\end{array}\right]\left[\begin{array}{l}N_{1 t} \\ N_{2 t}\end{array}\right]$ $+\left[\begin{array}{ll}\gamma_{11} & \gamma_{12} \\ \gamma_{21} & \gamma_{22}\end{array}\right]\left[\begin{array}{l}\Delta N_{1 t}-\tau \Delta N_{1 t+1} \\ \Delta N_{2 t}-\tau \Delta N_{2 t+1}\end{array}\right]-\left[\begin{array}{ll}\beta_{1}\left(\exp \left(\beta_{1} \Delta N_{1 t}\right)-\tau\right. & \left.\exp \left(\beta_{1} \Delta N_{1 t+1}\right)\right) \\ \beta_{2}\left(\exp \left(\beta_{2} \Delta N_{2 t}\right)-\tau\right. & \left.\exp \left(\beta_{2} \Delta N_{2 t+1}\right)\right)\end{array}\right]=\left[\begin{array}{l}u_{1 t+1}-\xi_{1 t} \\ u_{2 t+1}-\xi_{2 t}\end{array}\right]$, (VI. 4)

where the constant parameters $\delta_{f j}$ have replaced the productivity parameters $a_{1}$ and $a_{2}$ that are not identified due to a breakdown into a constant effect and oll shocks step changes $(\mathrm{OCl}$ and $\mathrm{OC} 2$ respectively). The composite error term, $u_{t+1}-\xi_{t}$, arises from forecast errors and productivity shocks.

Before proceding with estimation discuss the identification of the structural parameters. Nornalisation with respect to prices results from the fact that variable real wage costs are assumed to be proportional to labour input. Moreover, contrary to Inear closed form solutions, the real discount rate $\tau$ is identified in the first order conditions. However, in 
many applications $\tau$ is not very well determined from the Euler equations. One reason for this empirical finding is the nonstationarity of the compound error term due to omitted nonstationary forcing variables Cef. Dolado (1987)). We analyse the integrating properties of the variobles in the mode1. Furthernore, to prevent spuriaus regression, we test for cointegration between the decision and forcing variables.

First, we investigate the dynamic properties of the univariate series and their order of integration. Table VI. 1 presents the results of unit root tests of the production factors $\mathbb{N}_{1}, \mathrm{~N}_{2}$ and $\mathrm{K}_{\mathrm{t}}$, and the real factor prices Wt, $W_{2 t}$ and $Q_{t}$, where $Q_{t}$ is the real price of capital. According to Fuller's test statistic $T_{\tau}$ (see Fuller (1976), table 8.5.2) wa do not reject the hypothesis that the unjualate time series have one unit root.

Second, we test for cointegration between the decision and forcing variables. When these series are cointegrated, the nonstationarity of $N_{1}$ and $L_{2 t}$ may well be modelled by the nonstationarity of Wlt, W2t and $K_{t}$. Then equation (VI.4) can be interpreted as an error correction mechanism. Basically, according to the model, the adjustment to a linear long run relationship takes place in a nonlinear way. Howewer "an importat prom perty of the concept of stationarity is that it is preserved under sone nonlinear transformations (Escribano (1987)).

Consequent1y, we test for long run equilibriurm by computing dinear cointegrating regressions. Results are given in table VI. 2. Some of the parameters in the long run relationshlps have "wrong" signs, that is, ofl shocks are expected to have had a negative impact on employment, whereas increasing (non)production real wage costs are likely to reduce (non)production employment. The reason for this may be that short term effects overshadow long run relationships, since only a limited number of 
Table YI.I: Unit Roots Tests

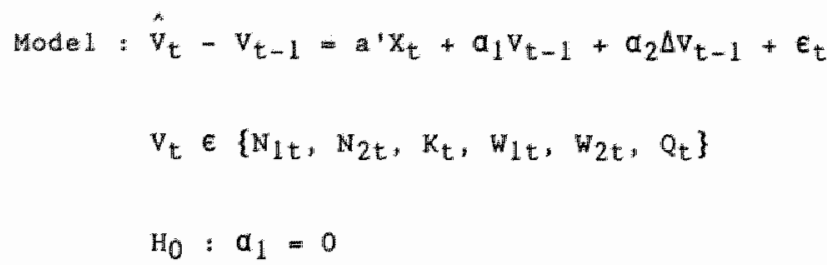

The Dutch manufacturing sector : $\mathrm{X}=\left(\mathrm{CONST}, \mathrm{Q}_{2}, Q_{3}, Q_{4}, \mathrm{OCl}, \mathrm{OC2}\right)^{*}$

$$
\left\{V_{t}: 1971 . I I I-1984 . I V\right\}
$$

$\begin{array}{llllll}N_{1 t} & N_{2 t} & K_{t} & W_{1 t} & W_{2 t} & Q_{t}\end{array}$

$\begin{array}{lrrrrrr}\text { Fuller's } \hat{\tau}_{\tau} & -2.48 & -.04 & -.15 & -1.05 & -2.16 & -1.50 \\ \text { Adjusted } \mathbb{R}^{2} & 1.00 & 1.00 & 1.00 & .99 & .99 & .90 \\ \text { DW-statistic } & 2.08 & 2.32 & 2.01 & 2.15 & 2.21 & 1.95\end{array}$

The UK manufacturing sector : $\mathrm{X}=(\text { CONST, TREND, OC1, OC2 })^{\text {* }}$

$$
\left\{V_{t}: 1957-1986\right\}
$$

$\begin{array}{llllll}N_{1 t} & N_{2 t} & K_{t} & W_{2 t} & Q_{t}\end{array}$

$\begin{array}{lrrrrrr}\text { Fulder's } \tau_{T} & -1.96 & -.34 & -2.00 & -.90 & -.74 & -1.20 \\ \text { Adjusted } \mathrm{R}^{2} & .98 & .92 & 1.00 & .99 & .99 & .90 \\ \text { DW-statistic } & 1.57 & 2.09 & 1.50 & 2.11 & 1.93 & 1.95\end{array}$

* $Q_{2}, Q_{3}$ and $Q_{4}$ are seasonal dumies, TREND denotes a 1 inear trend, $O C 1=1$ in 1973. IV and 1974, OC2 $=\mathbb{1}$ in 1979. II and 1979 for the Netherlands and the UK respectively and zero otherwise. No linear trend was included for UK capital and the real price of assets. 
observations was available for the empirical analysis. Note howewe the finding that only nonproduction read wage costs have a signifleant eftect on the emplayment level of production workers. This finding is consistent for both Dutch and UK manufacturing.

In arder to draw inferences we interpolate the critical walues of the tables for the Cointegrating Regression Durbin Watson (CRDW) statitics and the Augmented Dickey Fuller (ADF) statistics, applicable to our model.

Comparing the one lag version ADF-statisties given in table VI. 2 with the critical values in Engle and Yoo (1987), and companing the CRDW-statistic Wth the bounds on critical walues given in Sargan and Bhargava (1983), we may draw the following conclusions. The hypothesis of no colntegration is rejected at least at a 5 percent level for Dutch manufacturing nonproduction workers and for both types of employment in UK manufacturing. For manufacturing production workers in the Netherlands, the hypothesis of no cointegration is rejected at a 10 percent level.

If the composite error term in (VI.4) is stationary, $t$ w11 be close to unity. Estimating $\tau$ turned out to be difficult. No convergence was achieved when $\tau$ was estimated. Apparently, this is due to the high nonllnearity in parameters. However, when $t$ was set equal to unity in the nonlinear expressions of equation (VI.4), the estimate for $\tau$ in the linear expressions was .99 wh an asymptotic t-value of 22.2 for Dutch data. The UK real discount value was estimated in the same way, resulting in an estimate of .99 with an asymptotic t-value of 17.9 . Consequentiy, T wase equal to unity prior to estimation.

If the composite error term has a MA(1) representation, instumental variables have to be used for the future expectations of $\mathbb{N}_{1 t+1}$ and $\mathbb{N}_{2 t+1}$ to get consistent estimates. The information sets upon which the GMM estimates are based have been selected by principal component analysis. 
Table VI.2 : Colltegration tests : the forcing variables are $\left\{W_{1 t}, W_{2 t}, x_{t}\right\}$

Colntegrating regressions for the manufacturing sector in the Netherlands* $1971.1-1984 . \mathbb{W}$

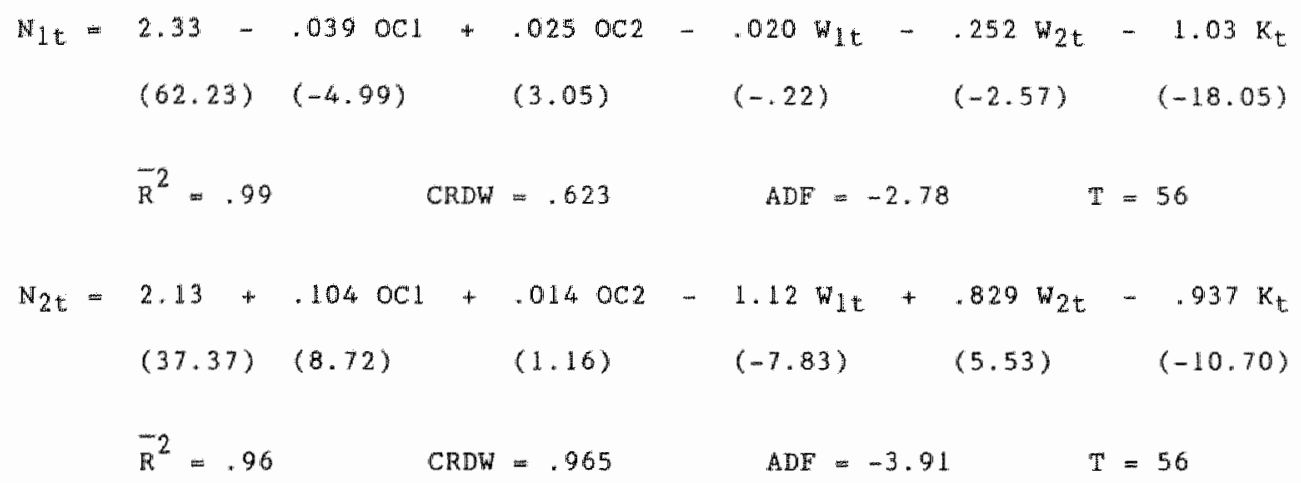

Cointegrating regressions for the manufacturing sector in the UK*

$$
1955-1986
$$

$$
\begin{aligned}
& N_{1 \mathrm{t}}=1.29-.130 \mathrm{OCl}-.0480 \mathrm{OC}+.29 \mathrm{~W}_{1 \mathrm{t}}-.893 \mathrm{~W}_{2 \mathrm{t}}+.375 \mathrm{~K}_{\mathrm{t}} \\
& \begin{array}{llllll}
(31.57) & (-4.83) & (-1.78) & (.91) & (-5.21) & (1.40)
\end{array} \\
& \bar{R}^{2}=.96 \quad \mathrm{CRDW}=1.01 \quad \mathrm{ADF}=-4.91 \quad \mathrm{~T}=32 \\
& N_{2 t}=.430-.2560 C 1-.0200 C 2+.775 W_{1 t}-1.73 W_{2 t}+1.63 \mathrm{~K}_{\mathrm{t}} \\
& \begin{array}{llllll}
(6.46) & (-5.84) & (-.46) & (1.48) & (-6.19) & (3.73)
\end{array} \\
& \mathbb{R}^{2}=.82 \quad \text { CRDW }=1.17 \quad \text { ADF }=-4.70 \quad T=32 .
\end{aligned}
$$

* Seasonal dummies are not reported. Asymptotic t-values are given within parentheses. OC1 $=1$ for the period 1973.IV - 1984. IV and 1974-1986, OC2 1 for the period 1979.II - 1984.IV and 1979-1986 for the regressions for the Netherlands and the UK respectively. 
For the Netherlands, the instrumental variables (IVs) are two perlods Lagged production and nonproduction employment, the rate on three montho loan to local authorities, the yield of long term government bonds. and the one period lagged first differences of production and nonproduction real wage costs, real price of capital, capital stock, unemployment rate, and manufacturing output, a constant, three sieasonal dummes, ocl and oc2. The total number of IVs equals 16.

The information set for the UK contains 13 IVs. These are one and two periods lagged production and monproduction labour and capital, one period lagged first differences of production and nonproduction real wag costs and manufacturing output, one period lagged price of material inputs, a constant, $O C 1$ and $O C 2$.

Table VI.3 contains estimated coefficients and model specification tests. The Sargan-Bhargava statistic (SB) that tests for nonstationarity in the residuals, does not point at a signiflcant random walk behaviour in any of the residual series. Hansen's J-statistic tests overidentifylng restrictions of the IV orthogonality conditions. The number of degrees of freedom of the $J$-test equals the number of structural equations (2) times the number of IVs minus the number of structural parameters in the model (for the Netherlands $=24 ;$ UK $=18$ ). The overidentifying restriction are not rejected. at a 5 percent level for the Netherlands and for the UK.

The ARCH statistic has been suggested by Engle (1982) to test for autoregressive conditional heteroscedasticity in the residuals. ARCH has a chisquared distribution with degrees of freedom equal to the number of autoregressive lags for which ARCH is being tested. According to this test there is no significant ARCH in the residuals for the two countries. This finding suggests that the firm"s learning in the presence of a structural change in the forcing wariables can indesed be modelled by adding dumy variables. 
Table VI.3 : OM octimation results of structural parameters and tests

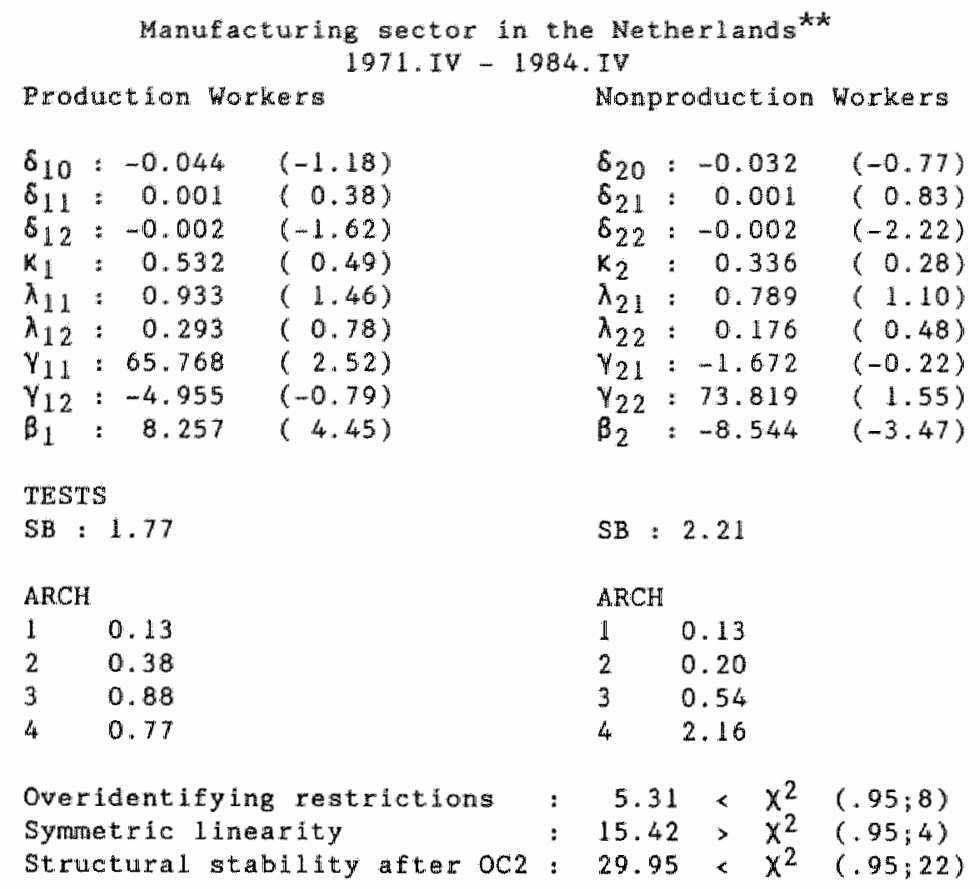

Manufacturing sector an the UK $1958-1986$

Production Workes

Nonproduction Warkers

$\begin{array}{lrr}\delta_{10}:-0.150 & (-1.94) \\ \delta_{11}:-0.006 & (-1.46) \\ \delta_{12}: & 0.002 & (0.52) \\ K_{1}:-0.302 & (-0.81) \\ \lambda_{11}: & 1.172 & (2.00) \\ \lambda_{12}:-0.653 & (-1.88) \\ \gamma_{11}: & 8.992 & (2.38) \\ \gamma_{12}:-0.521 & (-1.93) \\ \beta_{1}: & 2.929 & (4.42)\end{array}$

\begin{tabular}{|c|c|c|}
\hline 0 & $:-0.259$ & $(-1.33)$ \\
\hline 21 & $:-0.012$ & $(-1.62)$ \\
\hline 2 & $:-0.000$ & $(0.05$ \\
\hline$K_{2}$ & 0.585 & $(0.6$ \\
\hline$\lambda_{2}$ & 2.647 & ( 1.8 \\
\hline$\lambda_{2}$ & $:-1.224$ & $(-1)$ \\
\hline & 0.209 & $(0$. \\
\hline & $: 11.449$ & $(1.5$ \\
\hline 0 & $: \quad-3.128$ & $(-3)$ \\
\hline
\end{tabular}

TESTS

$S B: 2.05$

$\mathrm{SB}: 1.96$

$\begin{array}{ll}\text { ARCH } & \\ 1 & 0.00 \\ 2 & 0.05 \\ 3 & 0.44 \\ 4 & 0.49\end{array}$

ARCH

$1 \quad 1.26$

20.76

$3 \quad 0.84$

$4 \quad 1.42$

$\begin{array}{llr}\text { Overidentifying restrictions } & : 11.47<x^{2}(.95 ; 8) \\ \text { Symmetric linearity } & : 9.63>X^{2}(.95 ; 4) \\ \text { Structural stability after ocl }: 23.05 * x^{2}(.95 ; 16)\end{array}$

* Asymptotic t-values are given within parentheses.

** Seasonal dummies have not beem reported. 
As we mertioned before, the symmetric linear model that has generally been applied in rational expectations factor demand analysis. is mested in our mode1. We compute Gallant's (1987) likelihood ratio (LR)-mpe statistic to test for symmetric linearity, while simulaneously imposing the following 4 restrictions : $\lambda_{12}=\lambda_{21} ; \gamma_{12}=\gamma_{21} ; \beta_{1}=\beta_{2}=0$. For both the Netherlands and the UK, the test suggests that symmetric linearity must be rejected in favour of an asymmetric specification. Regime changes may have occurred after OCd and OC2. Structural stability of the parameters has been tested using the Chow-type test suggested by Andrews and Fair (1987). Due to a lack of available data, we could rot compute the impact of ocl on parameter estimates for the Netherlands and the impact of oc2 on parameter estimates for the UK. The tests reject the hypothesis that all the parameters for the UK (except $O C 1$ ) and for the Netherlands (except OC2) have undergone a structural change after $O C 1$ and OC2 respectively.

Least squares estimation applied to models with unobserved expectational variables produces inconsistent estimates. But there is, a trade off between efficiency and consistency. By including more $I V$ s in $\Omega_{t-1}$ GMM converges to nondinear least squares (NLS), which, apparently, leads to higher t-values. We have chosen to regtrict the number of IVs. Consequently, we find relatively low t-values for the parameter estimates.

The $(2 \times 2)$-matrix $\left\{Y_{i j}\right\}$ is found to be positive definite for both countries. This is a sufficiert (but not necessary) condition for atrlctly convex adjustment costs. The estimated coefficients are plausible and in accorm dance with results of comparable research (e.g. Pindyck and Rotembers $(1983 \mathrm{~b})$. Shapiro (1986)). Adjustment costs of nonproduction workers exceed adjustment costs of production workers $\left(V_{11}, V_{22}\right)$ whereas the off-diagonal. interrelated costs $\left(Y_{12}, Y_{21}\right)$ do not play an important role land therefore are usually restricted to zero pribr to estimation). 
The parameter estinates measuring the asymetry of the adjutment cost funtion $\left(\beta_{1}, \beta_{2}\right)$ are signiflcanty different from zero, for the Netherlands and the UK. The results are intuitively plausible and add an extra empirical element to the discussion of unblanced cyclical chamges in (un)employment betwen the two types of labour. The costs of firing production workers are low compared to the costs of hiring $\left(B_{1}>0\right)$. Asymmetric adjustment costs yield different speeds of adjustment during economic upswings (hirlngs exceding fírings) and recessions (firings exceeding hirings). Production workers are more easily fired during recessions than hired during upgings.

Firing costs exceed hiring costs for nonproduction workers ( $B_{2}$ \& 0 ). Costs that a firm faces for having a personnel management and training department that may be considered as on the job investment explain why firing costs exceed hirling costs for nonproduction workers. The empirical finding that f.rms often hoard nonproduction workers should be considered to arise from lower overall adjustment costs of production workers, not with standing the "anticyclical" differences between hiring and firing costs of the two types of labour.

\section{4 Factor demand with asymetric adjustment costs}

Jn the previous gection we assumed that firms maximize their expected real present value of profits by optimally choosing the input level of employment conditional on current information available and the capital stock being predetermined. However, in the literature on the demand for production factors under uncertainty it has often been argued that the current level of employment and the current capital stock are determined situltaneously (e.g. Meese (1980), Epstein and Denny (1983), Pindyck and Rotemberg $(1983 \mathrm{a}, \mathrm{b})$, Kokkelenberg $(1984)$, Epstein and Yatchew $(1985))$. 
In this section capital is assumed to be a decision variable too. Wo also assume capital to be quasi-fixed, that is, when the firm alters the capital. stock it faces adjustment costs. Kydland and Prescott (1982) noted that the failure of overidentifying restriction tests in linear rational expectations adustment costs models arises from dynamic misspecification. They argued that such models cannot possibly explain complicated gestation lags of the firm"s capital, whlch arise from time to build considerations. Rossi (1987) compared the two models and presented emplrical evidence in favour of the time to build model using two different Us data sets. We investigate whether the adjustment costs model is also found to be inadequate when the adjustment cost function is asymmetric.

In analogy with the previous section we assume that the costs of scrapping capital can differ from imwestment costs, i. e. adjustment costs of capital may be asymmetric.

Marginal productivity of factor input, $X_{i t}$, at period $t$, where $X_{1 t}$ w $\mathbb{N}_{1}$, $x_{2 t}=\mathbb{N}_{2 t}$ and $X_{3 t}=K_{t}$, is now modelled as follows

$\operatorname{MP}\left(x_{i t}\right)=\alpha_{i}-\sum_{j=1}^{3} \lambda_{i j} x_{i t}+\xi_{i t}, \quad i=1,2,3$

Marginal asymetric adjugtment costi of factor 1 become

$\operatorname{MAC}\left(\Delta X_{1 t}\right)=B_{1}\left(\exp \left(B_{1} \Delta X_{i t}\right)-1\right)+\sum_{j=1}^{3} Y_{i j} \Delta X_{j t}, \quad \mathbb{1}=1,2,3$,

where $\alpha_{i}, B_{i}, Y_{i j}$ and $\lambda_{i j}$ are constant parameters, and $\xi_{1 t}$ represent the unforeseen stochastic productivity shocks.

We assume that the firm faces linear variable costs that are proportlonal to factor input at each time $t$. In order to maximise the real present value of its expected profit stream the firm will make contingency plans for labour and capital satisfyimg the Euler conditions 
$M E\left(X_{1 t}\right)-M A C\left(\Delta X_{1 t}\right)-E_{i t}+\pi E\left[M A C\left(\Delta X_{i t+1}\right)+d P_{t+1} \mid \Omega_{t}\right]=0$

where $P_{t}=\left(W_{1 t}, W_{2 t}, Q_{t}\right), Q_{t}$ is the real price of capital, d is a diagonal $(3 \times 3)$-matrix $(0 ; 0 ;(1-8))^{\prime}$, and denotes the depreciation rate of capital which we assume to be constant. We used a value of 5 percent per year in the empirical analysis. After substitution of the realized values for the unobserved expectations in (VI.3)", the Euler equations lead to the following model

$\left[\begin{array}{l}\delta_{01} \\ \delta_{02} \\ \delta_{03}\end{array}\right] \operatorname{CONST}+\left[\begin{array}{l}\delta_{1} \\ \delta_{12} \\ \delta_{13}\end{array}\right] O C 1+\left[\begin{array}{l}\delta_{21} \\ \delta_{22} \\ \delta_{23}\end{array}\right] O C 2-\left[\begin{array}{lll}1 & 0 & 0 \\ 0 & 1 & 0 \\ 0 & 0 & 1\end{array}\right]\left[\begin{array}{l}w_{1 t} \\ w_{2 t} \\ Q_{t}\end{array}\right]+\left[\begin{array}{c}0 \\ 0 \\ \tau(1-\delta)\end{array}\right] Q_{t+1}$

$-\left[\begin{array}{lll}\lambda_{11} & \lambda_{12} & \lambda_{13} \\ \lambda_{21} & \lambda_{22} & \lambda_{23} \\ \lambda_{31} & \lambda_{32} & \lambda_{33}\end{array}\right]\left[\begin{array}{l}N_{1 t} \\ N_{2 t} \\ K_{t}\end{array}\right]+\left[\begin{array}{ccc}\gamma_{11} & 0 & 0 \\ 0 & \gamma_{22} & 0 \\ 0 & 0 & \gamma_{33}\end{array}\right]\left[\begin{array}{l}\Delta N_{1 t}-\tau \Delta N_{1 t+1} \\ \Delta N_{2 t}-\tau \Delta N_{2 t+1} \\ \Delta K_{t}-\tau \Delta K_{t+1}\end{array}\right]$

$-\left[\begin{array}{ll}\beta_{1}\left(\exp \left(\beta_{1} \Delta N_{1 t}\right)-\tau\right. & \left.\exp \left(B_{1} \Delta N_{1 t+1}\right)\right) \\ \beta_{2}\left(\exp \left(\beta_{2} \Delta N_{2 t}\right)-\tau\right. & \left.\exp \left(\beta_{2} \Delta N_{2 t+1}\right)\right) \\ \beta_{3}\left(\exp \left(\beta_{3} \Delta \kappa_{t}\right)-\tau\right. & \left.\exp \left(\beta_{3} \Delta k_{t+1}\right)\right)\end{array}\right]=\left[\begin{array}{ll}u_{1 t+1}-\xi_{1 t} \\ u_{2 t+1}-\xi_{2 t} \\ u_{3 t+1}-\xi_{3 t}\end{array}\right]$.

Production and nonproduction real wage costs and the real price of capital are now the forcing variables in the system. Therefore, we alternatively cest for cointegration between decision variables $N_{1 t}, N_{2 t}$ and $K_{t}$ on the one hand, and $W_{1 t}, W_{2 t}$ and $Q_{t}$ on the other hand. From the results, prem sented in table VI.4, we may draw the following conclusions. Sorne daubt is cast upon the existence of a long run equilibrium relationship between real factor prices and production employment and capital in the Netherlands, whereas the test of cointegration on nonproduction employment In the Netherlands and the UK manufacturing factor inputs seems to be only marginally significant. A possible explantion for this finding may be the coexistence of stochastic trends (real factor prices) and deterninistic trends (e.g. technological innovations). Hence, we also test for cointegration when a linear deterministic trend is included in the regression 
Table VI.4 : COINTEGRATION TESTS : THE FORCING VARIABLES ARE $\left\{\mathrm{H}_{1} t, \mathrm{~W}_{2} t, Q_{t}\right\}$.

Colntegrating regressions for the manufacturing sector in the Netherliands" 1971.I - 1984.IV

\begin{tabular}{|c|c|c|c|c|c|c|c|c|c|}
\hline CONST & OC1 & $0<2$ & TREND & $W_{1} t$ & $\mathrm{~N}_{2} \mathrm{t}$ & $a_{t}$ & $\bar{R}^{2}$ & CRDW & ADF \\
\hline$t \quad \begin{array}{c}0.67 \\
(3.68)\end{array}$ & $\begin{array}{c}0.00 \\
(0.00)\end{array}$ & $\begin{array}{c}0.04 \\
(2.16)\end{array}$ & & $\begin{array}{l}-0.51 \\
(-2.62)\end{array}$ & $\begin{array}{l}-0.70 \\
(-3.91)\end{array}$ & $(7.51)$ & 0.97 & 0.41 & -2.12 \\
\hline (11.72) & $\begin{array}{c}-0.07 \\
(-5.65)\end{array}$ & $\begin{array}{c}0.03 \\
(2.80)\end{array}$ & $\left(\begin{array}{c}-0.01 \\
(-10.16)\end{array}\right.$ & $\begin{array}{c}0.73 \\
(4.46)\end{array}$ & $\begin{array}{c}-0.52 \\
(-5.17)\end{array}$ & $\begin{array}{l}-0.49 \\
(-2.15)\end{array}$ & 0.99 & 0.95 & -3.36 \\
\hline$t \quad \begin{array}{c}0.56 \\
(2.92)\end{array}$ & $\begin{array}{c}0.14 \\
(7.52)\end{array}$ & $\begin{array}{c}0.03 \\
(1.77)\end{array}$ & & $\begin{array}{c}-1.59 \\
(-7.84)\end{array}$ & $\begin{array}{c}0.44 \\
(2.33)\end{array}$ & $\begin{array}{l}1.46 \\
(6.77)\end{array}$ & 0.94 & 1.06 & -3.20 \\
\hline $\begin{array}{c}1.56 \\
(10.39)\end{array}$ & $\begin{array}{c}0.07 \\
(5.40)\end{array}$ & $\begin{array}{c}0.02 \\
(2.08)\end{array}$ & $\begin{array}{c}-0.01 \\
(-9.79)\end{array}$ & $\begin{array}{l}-0.31 \\
(-1.78)\end{array}$ & $\begin{array}{c}0.62 \\
(5.63)\end{array}$ & $\begin{array}{l}-0.62 \\
(-2.53)\end{array}$ & 0.98 & 0.70 & -3.78 \\
\hline $\begin{array}{c}1.70 \\
(13.24)\end{array}$ & $\begin{array}{c}-0.04 \\
(-3.43)\end{array}$ & $\begin{array}{c}-0.02 \\
(-1.77)\end{array}$ & & $\begin{array}{c}0.51 \\
(3.74)\end{array}$ & $\begin{array}{c}0.42 \\
(3.31)\end{array}$ & $\begin{array}{c}-1.58 \\
(-10.89)\end{array}$ & 0.97 & 0.77 & -2.49 \\
\hline $\begin{array}{c}0.94 \\
(13.52)\end{array}$ & $\begin{array}{c}0.01 \\
(1.66)\end{array}$ & $\begin{array}{l}-0.02 \\
(-2.85)\end{array}$ & $\begin{array}{c}0.01 \\
(15.92)\end{array}$ & $\begin{array}{c}-0.45 \\
(-5.57)\end{array}$ & $\begin{array}{c}0.28 \\
(5.58)\end{array}$ & $\begin{array}{c}-0.01 \\
(-0.11)\end{array}$ & 1.00 & 0.92 & -3.77 \\
\hline
\end{tabular}

Colntegrating regressions for the manufacturing sector in the UK $1955-1986$

\begin{tabular}{|c|c|c|c|c|c|c|c|c|c|c|}
\hline & CONST & OC1 & 0,2 & TREND & $H_{1 t}$ & $w_{2 t}$ & $Q_{t}$ & $\bar{R}^{2}$ & CRDW & ADF \\
\hline $\mathbb{N}_{\mathbb{1} t}$ & $\begin{array}{l}1.47 \\
(4.09)\end{array}$ & $\begin{array}{c}-0.10 \\
(-4.58)\end{array}$ & $\begin{array}{c}-0.06 \\
(-2.10)\end{array}$ & & $\begin{array}{c}0.74 \\
(2.87)\end{array}$ & $\begin{array}{c}-0.97 \\
(-4.81)\end{array}$ & $\begin{array}{l}-0.18 \\
(-0.41)\end{array}$ & 0.96 & 0.85 & -3.80 \\
\hline & $\begin{array}{c}1.88 \\
(4.66)\end{array}$ & $\begin{array}{c}-0.15 \\
(-4.69)\end{array}$ & $\begin{array}{c}-0.04 \\
(-1.51)\end{array}$ & $\begin{array}{c}0.02 \\
(1.92)\end{array}$ & $\begin{array}{c}0.65 \\
(2.60)\end{array}$ & $\begin{array}{c}-11.30 \\
(-5.06)\end{array}$ & $\begin{array}{l}=0.42 \\
(-0.96)\end{array}$ & 0.97 & 1.15 & $-5,01$ \\
\hline$N_{2} t$ & $\begin{array}{c}0.54 \\
(0.78)\end{array}$ & $\left(\begin{array}{c}-0.16 \\
(-3.53)\end{array}\right.$ & $\begin{array}{c}-0.06 \\
(-1.13)\end{array}$ & & $\begin{array}{l}2.39 \\
(4.73)\end{array}$ & $\begin{array}{c}-1.89 \\
(-4.78)\end{array}$ & $\begin{array}{c}0.03 \\
(0.04)\end{array}$ & 0.73 & 1.03 & -3.27 \\
\hline & $\begin{array}{l}1.67 \\
(2.28)\end{array}$ & $\begin{array}{c}-0.28 \\
(-4.81)\end{array}$ & $\begin{array}{c}-0.02 \\
(-0.45)\end{array}$ & $\begin{array}{c}0.04 \\
(2.86)\end{array}$ & $\begin{array}{c}2.15 \\
(4.72)\end{array}$ & $\begin{array}{c}-2.78 \\
(-5.94)\end{array}$ & $\begin{array}{c}0.04 \\
(2.86)\end{array}$ & 0.79 & 1.28 & -4.66 \\
\hline$k_{t}$ & $\begin{array}{c}-0.35 \\
(-1.47)\end{array}$ & $\begin{array}{c}0.05 \\
(3.47)\end{array}$ & $\left(-\frac{0.02}{(-1.35)}\right.$ & & $\begin{array}{c}0.78 \\
(4.51)\end{array}$ & $\begin{array}{c}0.02 \\
(0.16)\end{array}$ & $\begin{array}{c}0.54 \\
(1.83)\end{array}$ & 0.99 & 1.66 & -3.38 \\
\hline & $\begin{array}{c}0.33 \\
(-2.40)\end{array}$ & $\begin{array}{l}-0.02 \\
(-1.88)\end{array}$ & $\begin{array}{c}-0.00 \\
(-0.18)\end{array}$ & $\begin{array}{c}0.03 \\
(9.27)\end{array}$ & $\begin{array}{c}0.63 \\
(7.43)\end{array}$ & $\begin{array}{c}-0.51 \\
(-5.90)\end{array}$ & $\begin{array}{c}0.14 \\
(1.00)\end{array}$ & 1.00 & 1.62 & -4.03 \\
\hline
\end{tabular}

* Asymptotic t-values are given within parentheses, oc1 a 1 for the period 1973. IV - 1984. IV and 1974-1986, OC2 $=1$ for the period 1979.1I - 1984 .IV and 1979-1986 in the regressions for the Netherlands and the UK respectively.

** Seasonal dummles are not reported. 
equation. The inclualon of trend remowes the random walk behaviour from the long run equilibria. Consequently, a Inear time trend wasided to the int order condition (VI. 4)".

Wote that in equation $\left(V_{1}, 4\right)^{*}$ we have restricted the matrix $\left[Y_{i j}\right]$ to be dasonal prior to estimation. The reason is threefold. First, it is conSigtent ith the literature on dynamic factor demand. Second, the findings of the prevlous section partly suggest it. Third, due to the computational complexity and limted mumber of observations, only a small number of structural parameters can be estimated. Also the sets of rvs have been chosen in accordance of the lmformation set $\Omega_{t}$ of the extended model. The information set for the Netherlands has been extended by including a Iinear time trend, whereas the lagged levels of production amd nonproducm tion employment and capital have been replaced by one period lagged first differences of these variables" The number of IVs in the imformation set for the Netherlands then equals 17 . In the information set for the UK a linear trend has been included as well. The one and two periods lagged decision variables ( $L_{1}$, L $\left.L_{2}, K\right)$ have been replaced by one period lagged Hrst differences, and the one period lagged first differenced real price of capital has ala been added. Then the number of IVs for the UK is 12. GMM paraneter estinates of the asymetric adjustment cost function and model specification tests are given in table VI.5. The estimates of other gtructural parameters have not been presented, but can be obtaimed from the author upon request.

There is significant widence for the presence of first order ARCH in the reslduals of nonproduction workers in the Netherlands. The sB statistic does not point at any significant nonstationarity in the residuals for the Netherlands. In the model for the Netherlands the overidentifying restrictions are not rejected. Limearity $\left(H_{0}: \beta_{i}=0, i=1,2,3\right)$ is rejected. There is no evidence in the data for the Netherlands that the parameters 
Table VI.5 : GMM estimates of adjustment costs parameters and tests

$$
\begin{gathered}
\text { Manufacturing sector in the Netherlands } \\
1971 . \text { IV }-1984 . \text { IV }
\end{gathered}
$$

\begin{tabular}{|c|c|c|c|c|c|}
\hline Production & lorkers & Nonproduction & Workers & Capital & \\
\hline $\begin{array}{l}Y_{11}: 50.76 \\
B_{1}: 7.48\end{array}$ & $\begin{array}{l}(3.07) \\
(5.85)\end{array}$ & $\begin{array}{l}Y_{22}: 75.66 \\
B_{2}:-9.08\end{array}$ & $\begin{array}{l}(1.85) \\
(-3.74)\end{array}$ & $\begin{array}{l}\gamma_{33}: 83.05 \\
\beta_{3}:-9.48\end{array}$ & $\begin{array}{r}(2.73) \\
(-5.22)\end{array}$ \\
\hline
\end{tabular}

\section{TESTS}

\begin{tabular}{llllll}
$\mathrm{SB}: 1.82$ & $\mathrm{SB}: 2.32$ & \multicolumn{3}{l}{$\mathrm{SB}: 2.26$} \\
$\mathrm{ARCH}$ & \multicolumn{3}{l}{ ARCH } & \multicolumn{3}{l}{ ARCH } \\
1 & 0.31 & 1 & 8.53 & 1 & 1.45 \\
2 & 0.84 & 2 & 7.27 & 2 & 2.68 \\
3 & 0.96 & 3 & 7.98 & 3 & 5.32 \\
4 & 1.37 & 4 & 8.45 & 4 & 5.89
\end{tabular}

$\begin{array}{ll}\text { Overidentifying restrictions } & : 15.64<x^{2}(.95 ; 15) \\ \text { Linearity } & : 15.35 \times x^{2}(.95 ; 3) \\ \text { Structural stability after oc } 2: & 40.92 \times x^{2}(.95 ; 33)\end{array}$

\section{Manufacturing sector in the UK $1958-1986$}

\begin{tabular}{llllll} 
Production workers & \multicolumn{3}{l}{ Nonproduction Workers } \\
Capitall \\
$Y_{11}: 9.61$ & $(1.95)$ & $\gamma_{22}: 7.14$ & $(1.22)$ & $\gamma_{33}: 97.16$ & $(1.47)$ \\
$B_{1}: 3.18$ & $(3.85)$ & $B_{2}:-2.47$ & $(-2.71)$ & $B_{3}:-11.06(-2.63)$
\end{tabular}

\begin{tabular}{|c|c|c|c|c|c|}
\hline & 1.95 & & 1.81 & & 1.59 \\
\hline \multicolumn{2}{|c|}{$\mathrm{ARCH}$} & \multicolumn{2}{|c|}{ ARCH } & \multicolumn{2}{|c|}{ ARCH } \\
\hline 1 & 1.77 & 1 & 0.69 & $\mathbb{1}$ & 0.58 \\
\hline 2 & 1.57 & 2 & 0.94 & 2 & 2.47 \\
\hline 3 & 2.77 & 3 & 1.48 & 3 & 3.31 \\
\hline 4 & 4.91 & 4 & 1.49 & 4 & 3.22 \\
\hline
\end{tabular}

\section{TESTS}

\footnotetext{
Overidentifying restrictions: $17.48 \times x^{2}(.95 ; 9)$

Linearity : $15.64 * x^{2}(.95: 3)$

Structural stability after OC1: $38.41 \times X^{2}(.95 ; 24)$

* Asymptotic t-values are given within parentheses.
} 
have undergone a tructurat change after oc2.

The SB at the point at the presence of nonstationarity in the residuals for capital in the UK (athough the power of this test is low). The oweridentifying restrietions and the structural stability are rejected at a 5 percent lewe1, but not at a 1 percent level. Linearity is rejected for the UK data as a 11 .

The estlruted value of $\mathrm{UK}^{\mathrm{I}} \mathrm{s} \mathrm{V}_{22}$ is unexpectedly low compared with 11 . Although this result 1 s not significant, it is inconsistent with the results presented $\mathbb{1 n}$ the previous section. The stimate of asymetry adjustment costs parameter of capltal, $B_{3}$, is negative for the Netherlands and for the UK. Therefore, scrapping of capital will take more time than bullding up new capital. The firm retains from scrapping capital during wecesslons, whereas the firm more quickly takes investment decisions during periads of an economic upawing.

\section{5 Conclusions}

In this chapter we developed and analysed dynamic demand models for the profit maximing firm with asymetric adjustment costs under uncertainty. Sections 2 and 3 have been concerned with decisions to employ production and nonproduction workers when the capital stock is predetermined. In section 4, the firm has ben as sumed to jointly determine the optimal level of labour and capltil. The models have been applied and tested, using quarterly time series data of the manufacturing sector in the Metherlands for the period $1971, I-1984 . I V$, and annul data for the manufacturing sector In the uk for the period 1955-1986.

To summatize, the following conclusions were reached.

1. Unexpected shocks in the (exogenous) environment of the firm give rise to step changes in the decision rules of the firm, and may well induce ARCH in the residuals due to increased uncertainty which can result from a structural change in the process of the forcing variables. 
2. When employment decisions are assumed to be taken conditionally on the available capital stack, the employment of production and nomproduction workers respectively is cointegrated with capital and production and nonproduction real wage costs. However, if decisions on production factor inputs are simultaneously taken, there is no significant evidence for the existence of a long run relationship between finctor inputs on the one hand and real factor prices on the other hand. There is however evidence for the coexistence of stochastic trends (real input prices) and deterministic trends (e.g. techmological innovations).

3. Hiring costs exceed firing costs of production workers.

4. Firing costs exceed hiring costs of nonproduction workers.

5. Scrapping costs exceed investment costs of capital.

By and large, we may conclude that the asymetric adjustment costs model is more appropriate for the data we analysed than the linear quadratic model. Moreover, we feel that the asymmetric model performs better than the symmetric one when the capital stock is assumed to be predetermined. A more extended comparison of time-to-build models of capital with asymmetic adjustment costs models wil be the subject of future research. 
CHAPTER SEVEN

CONCLUSTONS AND SUMMARY 


\section{WII. I Comclusions}

In this dissertation we examine labour demand from an employer"s point of view. Manufacturing firms are assumed to be represented chrough an enterprising agent called "the representative fim" who maximizes the expected real present value of future profits. The firm is assumed to form future expectations about the economic environment as accurately as possible, using all relevant information currently avallable, in order to develop an optimal intertemporal employment policy. Realizations of labour input plans are nevertheless stochastic because of unanticipated shocks in the economic environment of the firm.

The firm's optimal level of employment may change because market conditions change, for example through shifts in product demand, inptut price ratios, or due to technological innowation. However, rapid adjustment of the work force to a new target level can be very expensive if not impossible. Adjustment will be carried out gradually. As a consequence, labour demand is dynamic. Both factor and output markets are assumed to be perfectly competitive.

Initially, we impose a rather stringent mathematical structure on the redevant economic theory. This enables us to derive labour demand equations that are susceptible to empirical analysis, to estimate behavioural parameters and to assess their intuitive plausibility, and to test overidentifying parameter restrictions implied by economic theory. We gradually relax some of the theoretical restrictions in order to overcome some of the shortcomings of the linear symmetric labour demand model.

Chapter 2 presents a prototype labour demand model describing the stationary serial correlation structure of quarterly data on blue and white 
collar amployment and real wage costs in the Dutch manufacturing sector for the pertod 1971. I to 1984.IV. This chapter draws heavily upon Sargent (1978). The theoretical contribution of chapter 2 consists of insights into the identification of the structural parameters of the underiying economic theory obtained from a closed form solution of a linear rational expectation demand model for blue and white collar labout in which adjustment costs play a dominant role.

In chapter 3 some refinements are proposed with respect to the functional forms of production and adjustment costs specifications. The matheratical expressions of both specifications are extended so as to allow for interrelatednesg between the input decisions of blue and white collar labour. Nonstationarity of economic time series are considered to be essential part of the theoretical model. In chapter 3 capltal is assumed to be predetermined. Capital is modelled as a foreing variable with respect to employment decisions, and nonstationarity in the capital stock is used to explain nonstationarity in labour demand. The resulting dynamic labout demand model is used to describe the nonstationary correlation structure of quaterly data of the cotal number of weekly hours worked by blue and white collar labour in the Dutch manuacturing sector for the same period as the previous chapter.

Chapter 4. discusses the multivariate stochastic control problem of the firm, where capital and labour are assumed to be determined simultaneously. In particular, we examine the Impact of structural changes in the process of exogenous variables on factor demand both theoretically and empirically. Chapter 4 also focuses on cointegrating properties of production factors and real input prices. 
Ever since the first dynanic analysis of planing production and work foroe (Holt et.a1. 1960) the costs of hiring and firlig labour have been modelled jointly through a quadratic function of changes in employmert. This symmetry hypothesis implies that the costs of hiring a number of workers are equal to the costs of firing the same number of workers. Chapter 5 examines the appropriateness of guadratic adjustment costs of labout in dynamic labour demand models. We interviewed personnel managers of DSM Chem lcals, FOKKER Aircrafts, HOOGOVENS Steel, VENDEX International and Volvo Cars. The interviews concentrate mainly on these firms' decisions to change their productive work force and the costs that arise from these changes.

Also in chapter 5, we introduce, estimate and test a generalized function Which allows for asymetric adjustment costs and measures the difference between hiring casts and firing costs. In chapter 6 the asymetric function has been implemented into two dynamic labout demand models. In one model, capital is assumed to be predetermined when employment decisions are taken. The other model assumes that investment and employment decisions are taken simultaneously. Econometric analysis is also presented using time series data of Dutch and U.K. bilue and white collar manufacturing employment.

Sumarizing, the most important conclusions that may be draw from this dissertation are the following.

1. The empirical results confirm the wedl known fact that blue collar labour is easier to adjust to a new target level than white collat labour, due to lower hiring and firing costs.

2 : It is shown that interrelation of demand equations for various production factors, equations that are derived from a quadratic objective function, does not emerge from trade-off in costs or substitution bet- 
ween production factors. In such models the interrelation can only result from the way in which fims ract to random shocks by adjusting the input fint.

3 : The (dynatic) relation between blue and white collar labour is as followis As result of higher adjustment costs during an economic depression a firm will hoard white collar labour, blue collar workers gubstituting for white collar workers, thus upgrading the firm's work force. On the other hand, when more blue collar workers are hired, more supervising white collar workers are needed. Consequently, we may state that white collar labour is complementary to blue collar labour, whereas blue collar labour can be replaced by white collar labour.

4 : The gradual learning about the nature of structural changes may cause systematic patterns in the disturbances of the demand equations. Such misspecification can be detected by testing for autocorrelation and ARCH.

5 : When manufacturing employment decisions are assumed to be conditional on the available capital stock, blue and white collar employment are found to be cointegrated with capital and the real wage casts of the two types of labour. If decisions on inputs of blue collar labour, whlte collar labour and capital are assumed to be taken sifultaneously, there is significant ovidence for the existence of a long run relationship between factor inputs on the one hand and stochastic trends (reali input prices) and deterministic trends (technological innovatlons) on the other hand.

6. Adjustment costs of labour cannot be represented appropriately by a quadratic function. The asymmetric adjustment costs model fits our data better than the traditional linear-quadratic labour demand model. Moreover, hiring costs exceed firing costs of blue collar workers, whereas firing costs exceed hiring costs for white collar workers, both in the Dutch and U.K. manufacturing sectors. 
These are important findings, which should be taken into account when examining labour demand from an employer's point of view. But these results are also meaningful for macroeconomic modeling of labour demand. Broer (1985) presents a theoretical and empirical macroeconomic analysis of aggregate firm behaviour, based on putty-putty and putty-clay models of capital and labour inputs, using annual Dutch business and manufacturing data. The results of our study might be used to supplement Broer's study in the sense that we provide deeper insight into parameter identification of quadratic models with and without assuming capital being predetermined, and that asymmetric specifications of adjustment costs structures are appropriate for modelling dynamic labour demand.

In this dissertation effects of possible subsitution between hours worked and persons employed have not been considered. De Regt (1988) examines the hypothesis that the number of hours worked varies proportionally with standard working time, and that substitution takes place between the number of workers and average working time. For empirical analysis annual data are used for Dutch manufacturing aggregate employment from 1954 to 1982 . De Regt argues that the relation between the number of workers and the average working time crucially depends upon the elasticity of captual substitution with respect to labour services, and finds that a 10 percert. reduction of standard working time will increase employment by 4 percent. However, elasticities of substitution will differ between blue and white collar labour. Moreover, if firms do not plan their workforce and the optimal working hours simultaneously, the dynaric structure of employment does not depend upon the number of hours worked. Analysis of dynamic labour demand should be extended in these directions if well-considered answers are to be given to questions concerning the effects of introducing shorter working hours. 
Further research 1 also reed to investigat which dynamic relations exts between production techologies, technological innovation and factor Inputs, siffe nelther the growth of capital stock as a proxy, nor deterministic trends model technical progress adequately (see Nickell and Symons (1987)). Finally, extending the dynamic iabour demand model may prove frufteul in modelling the agent"s learning process after unforeseen shocks with time varying parameters, as suggested by Bray and Sawin (1986).

\section{2 Nederlandstalige samenvatting}

Het onderzoksproject "De vragg naar arbeid" makxt deel wit van het voorwardelifk getinancierde onderzoeksprogramma "Arbeidsmarkt en Arbeidsorganisaties", dat één var de drie aandachtsvelden is van de Faculteit der Economische Wetenschappen van de Rijksuniversiteit Limburg. De doelstelling van dit onderzaeksproject is "om in aansluiting op recent theoretisch en emplrisch onderzoek een bijarage te leveren aan de verklaring van de vrag naar arbeid op ondernemingsniveau en op bedrijfstakniveau" 1). Bij het modelleren van de vraag naar arbejd "staan de theorleën centraal over beslissen onder onzekerheid in een dynamische context, warbij expliciet rekenirig gehouden wordt met de anpassingskosten Veroorzakt door uitbreiding of inkrimping van de werkgelegenheid en de kapitalgoederenvoorrad" 1). In dit proefschrift worden de resultaten van dit onderzoek gepresenteerd, die tot nu toe zijn verkregen.

Er bestat nogal wat onduldelijkheld over de relatie tussen arbeidskasten en arbeldsvraag, Een belangrljke uitkomst van deze studie (zie hoofdstuk

1) Onderzoksprogramma Arbeidsmarkt en Arbeidsorganisaties, Wetenschapscommisie FdEW, 25 april 1985 , op cit. blz. 7 . 
twee en drie) is dat de kosten van werschillende soorten arbeid podanig kunnen verschillen dat niet kan worden ultgegaan van en eenduidige arbeidskosten-arbeidsvrag relatie. De oorzaak hiervan is niet zozer hot verschil in loonhoogte alswel het verschil in a anpassingskosten. Aanpassingskosten zijn kosten wan ultbreiding van werkgelegenheid (zookselectie-, en opleidingskosten) en inkrimping van werkgelegenheid (ontslagprocedurele kosten, verlies van menselijk kapital), en aijn van doorslaggevende betekenis voor persomelsmanagement. De aranpassingskosten van geschoolde arbeid (white collar workers) blijken zover hoger te zljn dan van ongeschoolde arbeid ( blue collar workers) dat het voor een bedrift efficlënter is om bij een noodzakelijke inkrimping, ondanks hun lagere variabele loonkosten, ongeschoolde werknemers ecrder te ontsian en hun werk te laten verrichten door geschoold personeel (substitutie). Een uitbreiding van ongeschoolde arbeid gat mutatis mutandis echter gepard met een toename wan geschoolde arbeid (suplementariteit).

De invloed van onverwachte veranderingen in de economie op de lange termijn relatie tussen arbeid en kapitaal wordt onderzocht in hoofdstuk vier en het tweede deel van hoofdstuk zes. We vinden als gevolg van olliecrises in 1973 en 1979 dat niveaweranderingen van de vrag nat produkt faktoren arbeid en kapitaal zijn opgetreden, maar dat de overige parameters van het theorew tisch model niet antoonbaar zijn veranderd.

In hoofdstuk vijf van dit proefschrift wordt en methode gentroduceerd om het verschil te meten tussen de kosten van uitbreiding en de kosten van inkrimping van werkgelegenheid (asymmetrie). Emplirische toepassing van deze methode voor de industriële sector in Nederland en Engel and in hoofdstuk zes toont a an dat voor ongeschoolde arbeid de ontslagkosten lager zijn dan de wervingskosten, terwijl voor geschoolde arbeid de ontalagkogten hoger zijn dan de werwingskosten. Dit resultat werpt en nieuw licht op de 
discusie over de onevenwichtige ontwikkeling van de werkgelegenheid tussen de twe onderscheiden categorieën arbeid. In een periode van economische groef met en tomame van de vraag naar arbeid zullen geschoolde werknemers relatife eerder worden aangenomen dan zif bij een neergaande economie, warbif de wrag naar arbeid afneemt, zullen worden ontslagen. Voor geschoolde arbeid is het ongekeerde het geval. In een periode van economische toruggang die gepaard gat met en verminderende vraag naar arbeid zal ongeschoold personeel relatief eerder worden ontslagen dan zij bij een groeiende economie zal worden aangenomen. 
$-127=$

APPENDICES 


\section{APEEUDIX A.1: OUTLINR OF HSTMPTOTIC LEAST SOUARES ESTIMATION}

In (II.15) the vactor of paraneters

$B=\left(\mu_{11}, \mu_{12}, \mu_{21}, \mu_{22}, p_{1}, p_{2}, \alpha_{12}, a_{22}, B_{1}, B_{2}\right)$

1 an estimable function of

$\theta=\left(\mu_{11}, \mu_{12}, \mu_{21}, \mu_{22}, \rho_{1}, \rho_{2}, \delta_{1}, \delta_{2}, \lambda_{1}, \lambda_{2}\right)$

say

$g(\theta)=\beta$.

If we have a consistent estimator of $\theta, \theta$, with large sample distribution

$V T\left(\theta-\theta_{0}\right) \sim N\left(0, \Omega\left(\theta_{0}\right)\right)$

a

where $\Omega$ is the covariance matrix of $\theta$ evaluated at the original true param meters: $\theta_{0}$ (Gouriéroux et.a1. 1985), then $\beta$ can be estimated by

$\hat{\beta}=g(\hat{\theta})$.

Furthermore,

$V_{\mathbb{T}}\left(B-B_{0}\right) \sim \mathbb{N}\left(0, Q \Omega Q^{\prime}\right)$

的

where $Q=\frac{\partial g(\theta)}{\partial \theta^{\prime}}$ 


\section{APPENDIX A.2 : EROOFS OF PROROSTTIONS OF CHAPTER THREE}

\section{Proof of Proposition 1:}

Let $s=\left[\begin{array}{ll}S & 0 \\ 0 & S\end{array}\right]$, where $s$ is a regular $(2 \times 2)$-matrix $s$ such that $S^{-1} \tilde{A} S$ is uppertriangular with eigenvalues $\mu_{\mathfrak{l}}$ and $\mu_{2}$ of $\tilde{A}$ on the diagonal.

Then $S^{-1}$ A $S=\left[\begin{array}{cc}S^{-1} & 0 \\ 0 & S^{-1}\end{array}\right]\left[\begin{array}{cc}0 & S \\ -\tau^{-1} S & \tilde{A} S\end{array}\right]=\left[\begin{array}{cc}0 & I_{2} \\ -\tau^{-1} I_{2} & S^{-1} \tilde{A} S\end{array}\right]$.

Now, the characteristic polynomial of $\mathbb{S}^{-1} \mathbb{A} \$$ and consequently of AA equals $\left(-\lambda^{2}+\mu_{1} \lambda-\tau^{-1}\right)\left(-\lambda^{2}+\mu_{2} \lambda-\tau^{-1}\right)$.

If $\mu_{1} \neq \mu_{2} \mathrm{~S}$ can be chosen such that $S^{-1} \tilde{A} S$ is diagonal. Then the columns of $S$ are the eigenvectors of $\widetilde{A}$.

\section{Proof of Propasition 3 :}

Redefine $\mathrm{H}^{-1}=\left(\mathrm{SC}_{22}\right)^{-1} \Delta_{2}^{-1} \mathrm{SC}_{22}, \Gamma_{1}=(\tau \mathrm{B})^{-1}$, and $\mathrm{Q}_{\mathrm{S}}=\Sigma_{\mathrm{i}=0}^{\infty} \mathrm{H}^{-1-1} \Gamma_{1^{-1}} \widetilde{\mathrm{R}}^{\mathrm{i}}$

Then $\mathrm{H}=\left(\mathrm{SC}_{22}\right)^{-1} \Lambda_{2} \mathrm{SC}_{22}$ and $\mathrm{HQ}_{\mathrm{S}}-\mathrm{Q}_{\mathrm{S}} \tilde{\mathrm{R}}=\Gamma_{1}$.

$\operatorname{vec}\left(H Q_{S}\right)-\operatorname{vec}\left(Q_{S} \widetilde{R}\right)=\operatorname{vec}\left(\Gamma_{1}\right)$.

$\left(I_{2} \cdot \operatorname{H}\right) \operatorname{vec}\left(Q_{s}\right)-\left(\tilde{R}^{\mathbb{T}}-I_{2}\right) \operatorname{vec}\left(Q_{s}\right)=\operatorname{vec}\left(\mathbb{\Gamma}_{1}\right)$.

$\operatorname{vec}\left(Q_{\mathrm{S}}\right)=\left[\mathrm{I}_{2} \cdot \mathrm{H}-\widetilde{\mathrm{R}}^{\mathrm{T}} \otimes \mathrm{I}_{2}\right]^{-1} \operatorname{vec}\left(\Gamma_{1}\right)$. 


\section{APEENDIX A.3: PARTIAL ADJUSTMENT, ERROR CORRECTION AND COINTEGRATION}

Let $x_{t}=\left(\ell_{t}, k_{t}\right)$ being a 2 -vector of instruments available to the firm to maximize its real present value of profits $(2.4)$ and $x_{t} \sim I(1)$. We can wate $x_{t}$ as a partial adjustment mechanism, say

$\Delta x_{t}=M\left(x_{t-1}-x^{*}\right)$

with $M=\Lambda_{1}-I$ and $x^{*}=\left(\Lambda_{1}-I\right) \sum_{i=0}^{\infty}\left(\Lambda_{1}\right)^{i+1} B^{-1} p_{t+1}^{*}$, where (for the case of simplicity) the ratrices $A$ and $B$ in (2.1) and (2.2) respectively are assumed to be diagonal and the real discount factor, $\tau$, is assumed to be one (quarterly data), and $p_{t+1}^{*}=\mathbb{E}\left(p_{t+1} \mid \Omega_{t}\right) \mathbb{1 s}$ a 2-vector of expectations at time $t$ of future values of exogenous variables.

We assume that $p_{t}$ follows an AR(2) process with a unit root and drift, say, $\Delta \mathrm{p}_{\mathrm{t}+\mathbb{1}}=\mathrm{PO}_{\mathrm{O}}+\mathrm{Q} \Delta \mathrm{P}_{\mathrm{t}+\mathrm{i}-1}+\xi_{\mathrm{t}+\mathrm{i}}^{\mathrm{p}}$

Then the expectation $\mathrm{p}_{\mathrm{t}+1}^{*}$ is as follows (cf. Mickell 1985):

$\stackrel{*}{\mathrm{p}_{\mathrm{t}+\mathbf{i}}}=\mathrm{p}_{\mathrm{t}-1}+\tilde{\mathrm{p}}_{0}+\left(I+\mathrm{Q}^{\mathbf{i}+1}\right)(\mathbb{I}-Q)^{-1} \Delta \mathrm{p}_{\mathrm{t}}$

whe re $\tilde{p}_{0}=\sum_{j=0}^{i-1}(i-j) Q^{j} p_{0}$

Substituting (II, ) and (II.3) into (II.1) we get

$\Delta \mathrm{x}_{\mathrm{t}}=\mathrm{x}_{0}+M \mathrm{x}_{\mathrm{t}-1}+\mathrm{B}^{-1} \Lambda_{1} \mathrm{M}^{-1} \mathrm{p}_{\mathrm{t}-1}+\tilde{\mathrm{Q}} \Delta \mathrm{p}_{\mathrm{t}}+\xi_{\mathrm{t}}^{\mathrm{x}}$

where $\tilde{Q}=\mathrm{B}^{-1}\left[\left(\left(\Lambda_{1} Q\right)^{-1}-I\right)^{-1}-\left(\Lambda_{1}^{-1}-I\right)^{-1}\right]^{-1}$, and $\mathrm{x}_{0}$ is a scalar.

Consequently, we have

$\left[I: B^{-1} \Lambda_{1} M^{-2} \rrbracket\left(x_{t-1}, p_{t-1}\right)^{\prime} \sim I(0)\right.$.

According to Granger's Representation Theorem (Engle and Granger (1987))

this implies that $x_{t}$ and $p_{t}$ cointegrate. 
AEPENDIX A.4: FORECAST ERRORS, EXPECTATIONAL ERRORS AND RANDON SHOCKS

The model with a quadratic production function and an adjustment cost function of the general quadratic exponential form given in equation (VI, 2 ) yields the following expectational errors:

(1) $u_{t+1}=-\tau Y\left(\Delta x_{t+1}-E_{t}\left[\Delta x_{t+1}\right]\right)-\tau \beta\left(\exp \left(\beta \Delta x_{t+1}\right)-E_{t}\left[\exp \left(\beta \Delta x_{t+1}\right)\right]\right)$,

where $x_{t}$ is a decision variable of the firm, $\gamma$ is the adjustment parameter of the quadratic term, and $B$ is the adjustment parameter, which expresses the asymmetry of the adjustment cost function, $\tau$ is the constant real discount rate, and $E_{t}=E\left[\cdot \mid \Omega_{t}\right]$, with $\Omega_{t}$ being the information set at tima t.

In order to trace the effects of a structural break, we make an additional distributional assumption. Let

(2) $x_{t+1}=E_{t}\left[x_{t+1}\right]+\epsilon_{t+1}$ or $\Delta x_{t+1}=E_{t}\left[\Delta x_{t+1}\right]+E_{t+1}$, since $E_{t}\left[x_{t}\right]=x_{t}$, and where $E_{t+1}$ is the forecost error at $t+1$.

(3) We assume that $\epsilon_{\mathrm{t}+1} \sim \mathrm{N}\left(0,0_{\mathrm{t}+1}^{2}\right)$.

If during a time interval (e.g. the sample period) no structural change occurs in the slope ox in the variance of the decision variable $x$, the expectational error, $u_{t+1}$, is a white noise process. This can be shown as follows.

From equations (1) and (2) we can derive

(4) $u_{t+1}=-\tau \gamma E_{t+1}-\tau \beta\left(\exp \left(\beta E_{t}\left[\Delta x_{t+1}\right]+\beta E_{t+1}\right)-E_{t}\left[\exp \left(\beta E_{t}\left[\Delta x_{t+1}\right]+\beta \epsilon_{t+1}\right)\right]\right)$.

From (3) it follows that $\exp \left(\epsilon_{t+1}\right)$ is lognormally distributed with zero mean and variance $0_{t+1}^{2}$. Then (4) becomes 
(5)

$$
\begin{aligned}
u_{t+1}= & -\tau \gamma e_{t+1}-\tau B\left(\exp \left(B E_{t}\left[\Delta x_{t+1}\right]\right) \exp \left(\beta \epsilon_{t+1}\right)\right) \\
& -\tau B\left(\exp \left(B E_{t}\left[\Delta x_{t+1}\right] \exp \left(2 / \beta^{2} \sigma_{t+1}^{2}\right)\right)\right.
\end{aligned}
$$

where $t a_{t+1}^{2}=E_{t}\left[a_{t+1}^{2}\right]$.

since $t^{2} \sigma_{t+1}=\sigma^{2}$, say, the unconditional expectation of $u_{t+1}$ equals zero, that 1 .

(6) $\mathrm{E}\left[\mathrm{u}_{\mathrm{t}+1}\right]=0$,

since $\mathbb{E}\left[\varepsilon_{t+1}\right]=0$ and $\mathbb{E}\left[\exp \left(\beta \epsilon_{t+1}\right)\right]=E_{t}\left[\exp \left(\beta \epsilon_{t+1}\right)\right]=1 / B^{2} \sigma^{2}$,

and

(7) $E\left[u_{t+1}^{2}\right]=\tau^{2}\left(\gamma^{2} \alpha^{2}+\beta^{2} \exp \left(2 \beta^{2} \alpha^{2}\right)-\beta^{2} \exp \left(\beta^{2} \sigma^{2}\right)+2 \gamma \beta v_{t+1}^{2}\right)$

where $v_{t+1}^{2}=E\left[\epsilon_{t+1}\left(\exp \left(\beta \Delta x_{t+1}\right)-E_{t}\left[\exp \left(\beta \Delta x_{t+1}\right)\right]\right)\right]$,

so that $u_{t+1}$ is white noise.

Now consider an unanticipated step change in the slope of $x$ occurring between $t$ and $t+1$, whereas the forecast error variance remains unaffected, that is

$\Delta x_{t+1}=c+\mathbb{E}_{t}\left[\Delta x_{t+1}\right]+E_{t+1} ; E\left[E_{t+1}^{2}\right]=E_{t}\left[E_{t+1}^{2}\right]=0^{2}$

Then

$\left(6^{\prime}\right) \mathbb{E}\left[u_{t+1}\right]=-\tau \gamma_{c}-\tau \beta \exp \left(\beta \mathbb{E}_{t}\left[\Delta x_{t+1}\right]\right) \cdot \exp \left(\beta_{\beta} \beta \sigma^{2}\right) \cdot(\exp (\beta c)-1)$.

and

(7') $E\left[u_{t+1}^{2}\right]=\tau^{2}\left(\gamma^{2} \alpha^{2}+\beta^{2} \exp (2 c)\left(\exp \left(2 \beta^{2} \sigma^{2}\right)-\exp \left(\beta^{2} \sigma^{2}\right)+2 \gamma \beta v_{t+1}^{2}\right)\right.$.

Consequently, when the foracast error is normally distributed an unexpected shock which changes the slope of the decision variable $x_{t}$ but not its 
wariance, leads to a step change in both the uneonditional mean and the wariance of the expectational error $\mathrm{ut}_{\mathrm{t}} \mathrm{l}$.

Analogously, an unexpected exogenous shock (e.g. Increased uncertalinty) which does not change the slope of $x_{t}$ but persistently changes the forecast error variance, also leads to a step change in the unconditional mean of the expectational error $u$ and its variance. 
AEPENDYX A. A

SOURCES OF THE QUARTERLY DUTCH MANUEACTURTHG (SEI 2/3) DATA

The base year of all prices and indices is 1980.

$L^{*}, L_{1}, L_{2}$ : The total numbers (in thousands) of blue collar workers (L) and wite collar workers (L2) have been computed from quarterly indices of total manufacturing employment ( $L^{*}$ ), obtained from the Centraal Bureall voor de statistiek (CBS), Algemene Industrie Statistiek, and manufacturing total aggregate numbers and the ratio of blue and white collar workers which have been interpolated from the CBS Loonstruktuur Onderzoek 1972 and the Arbeidskrachtentelling 1975, 1977, 1979,1981 , and 1983.

$\mathrm{H}_{1}, \mathrm{H}_{2}$ : Average wekly worklig hours including overtime hours for blue collar workers $\left(\mathrm{H}_{1}\right)$ and white collar workers $\left(\mathrm{H}_{2}\right)$ have been obtajned from the CBS Halfjarlijks Loononderzoek. These veries are sixmonthly data which have been interpollated.

$N_{1}, N_{2}$ : Total number of weekly hours worked by blue callar workers $\left(\mathbb{H}_{1}\right)$ and wite collar warkers $\left(\mathrm{N}_{2}\right): \mathrm{N}_{1}=\mathrm{L}_{1} * \mathrm{H}_{\mathrm{i}}, \mathrm{i}=1,2$.

Py : Producers price index of domestic sales; producenten Erijsindexciffers van de Binmenlandse afzet van de Nederlandse Industrie (SBI 2/3) are unpublished data which have been kindly provided by CBS.

$W^{*}, W_{1}, W_{2}$ : Gross hourly wage costs for blue callar workers (P1 ) and white collar workers $\left(\mathrm{P}_{2}\right)$ have been computed from the CBS Halfjaarlijks Loononderzoek, the CBS Driejaarlijks Loonkosten Onderzoek, started in 1972, and the quarterly index of wage costs in current prices ( $\left.W^{*}\right)$ obtained from the CBS Kartalonderzoek Verdiende Lonen. Real hourly wage costs $\left(\mathrm{W}_{1}, \mathrm{~W}_{2}\right.$ ) have been obtained by deflating $\mathrm{Pl}_{1}$ and $\mathrm{PL}_{2}$ respectively by $\mathrm{By}$.

I

- Index manufacturing output in constant prices, obtained from CBS Nationale Rekeningen.

K, Q : Not capltal stock (K) has been computed from annual manufacturing capital stock data which are used in the VINSEC model of the Central plan Bureau (CPB), and from guarterly aggregate data of capital stocks used in the CPB nodel KOMPAS. "The real price of capital has been obtained by deflating the price index of manufacturing investment goods in current prices (PK) by PY.

R3L, YGB : Rate on three months loans to local authorities (R3L) and the $y$ ield of long term government bonds (YGB) for the Wetherlands have been obtained from OECD Ma In Economic Indicators.

NUT

: Rate of registered unemployment in the Netherlands (NUR) abtalned from the Ministerie van Sociale zaken en We rkgelegenheid. 


\begin{tabular}{|c|c|c|c|c|c|c|c|c|c|c|}
\hline$t$ & $\mathbf{N}_{1}$ & $N_{2}$ & $x$ & $W_{1}$ & $w_{2}$ & 0 & $\gamma$ & R3L & NUR & YOB \\
\hline $\begin{array}{l}1971.1 \\
1971.2 \\
1971.3 \\
1971.4 \\
1972.1 \\
1972.2 \\
1972.3 \\
1972.4 \\
1973.1 \\
1973.2 \\
1973.3 \\
1973.4 \\
1974.1 \\
1974.2 \\
1974.3 \\
1974.4 \\
1975.1 \\
1975.2 \\
1975.3 \\
1975.4 \\
1976.1 \\
1976.2 \\
1976.3 \\
1976.4 \\
1977.1 \\
1977.2 \\
1977.3 \\
1977.4 \\
1978.1 \\
1978.2 \\
1978.3 \\
1978.4 \\
1979.1 \\
1979.2 \\
1979.3 \\
1979.4 \\
1980.1 \\
1980.2 \\
1980.3 \\
1980.4 \\
1981.1 \\
1981.2 \\
1981.3 \\
1981.4 \\
1982.1 \\
1982.2 \\
1982.3 \\
1982.4 \\
1983.1 \\
1983.2 \\
1983.3 \\
1983.4 \\
1984.1 \\
1984.2 \\
1984.3 \\
1994.4\end{array}$ & $\begin{array}{l}3506.63 \\
3459.76 \\
3447.06 \\
3355.53 \\
3286.47 \\
3242.74 \\
3229.75 \\
3179.31 \\
3132.43 \\
3115.00 \\
3097.60 \\
3058.33 \\
3019.30 \\
2958.51 \\
2953.11 \\
2834.40 \\
2785.94 \\
2745.57 \\
2713.84 \\
2687.51 \\
2663.28 \\
2657.40 \\
2678.72 \\
2651.63 \\
2626.29 \\
2635.25 \\
2640.92 \\
2612.20 \\
2565.05 \\
2564.64 \\
2564.23 \\
2535.87 \\
2535.46 \\
2507.10 \\
2535.05 \\
2503.64 \\
2483.37 \\
2477.22 \\
2488.29 \\
2451.14 \\
2408.42 \\
2391.29 \\
2388.72 \\
2343.14 \\
2305.83 \\
2286.84 \\
2269.70 \\
2216.52 \\
2172.10 \\
2154.86 \\
2129.42 \\
2069.18 \\
2079.81 \\
2076.84 \\
2079.27 \\
2071.04\end{array}$ & $\begin{array}{r}1304.27 \\
13102.24 \\
1313.55 \\
1301.56 \\
1297.92 \\
1296.78 \\
1307.67 \\
1308.41 \\
1309.98 \\
1323.30 \\
1336.61 \\
1342.22 \\
1347.67 \\
1341.93 \\
1364.26 \\
1361.67 \\
1344.51 \\
1338.01 \\
1327.08 \\
1309.35 \\
1285.57 \\
1258.92 \\
1245.94 \\
1220.18 \\
1196.91 \\
1192.75 \\
1191.80 \\
1174.99 \\
1152.18 \\
1152.58 \\
1152.98 \\
1140.49 \\
1140.89 \\
1129.80 \\
1144.53 \\
1130.20 \\
1121.55 \\
1119.53 \\
1124.77 \\
1111.07 \\
1094.95 \\
1087.70 \\
1084.07 \\
1066.74 \\
1050.22 \\
1041.76 \\
1034.50 \\
1011.88 \\
992.94 \\
984.50 \\
972.04 \\
957.19 \\
948.40 \\
948.80 \\
950.40 \\
948.00\end{array}$ & $\begin{array}{l}66563.63 \\
68072.59 \\
69701.30 \\
70348.00 \\
71243.97 \\
72395.92 \\
73639.30 \\
74133.00 \\
74808.35 \\
75676.65 \\
76613.37 \\
76986.00 \\
77819.71 \\
78891.62 \\
80048.61 \\
80508.00 \\
81012.65 \\
81366.78 \\
81419.91 \\
82562.00 \\
82833.66 \\
83437.36 \\
83709.03 \\
84031.00 \\
84510.83 \\
84973.52 \\
85179.16 \\
85222.00 \\
85722.60 \\
86287.12 \\
86585.35 \\
87512.00 \\
87654.11 \\
88173.68 \\
88637.61 \\
89459.00 \\
90116.23 \\
90700.43 \\
91771.46 \\
91881.00 \\
92629.93 \\
93414.53 \\
933155.09 \\
94318.00 \\
96023.14 \\
96280.52 \\
96071.40 \\
97117.00 \\
98309.02 \\
98798.05 \\
99439.91 \\
100311.00 \\
101596.39 \\
102435.46 \\
103595.88 \\
104792.00\end{array}$ & $\begin{array}{l}18.08 \\
18.46 \\
18.94 \\
19.00 \\
19.04 \\
19.09 \\
19.29 \\
19.57 \\
19.79 \\
20.00 \\
19.97 \\
19.95 \\
20.03 \\
19.76 \\
19.60 \\
20.41 \\
20.82 \\
21.58 \\
21.76 \\
21.95 \\
22.14 \\
21.94 \\
22.15 \\
22.58 \\
22.77 \\
22.97 \\
23.30 \\
23.82 \\
24.21 \\
24.60 \\
24.84 \\
25.49 \\
26.14 \\
25.86 \\
25.52 \\
25.34 \\
25.17 \\
24.88 \\
25.03 \\
25.18 \\
24.89 \\
24.59 \\
24.59 \\
24.59 \\
25.02 \\
25.26 \\
25.33 \\
25.94 \\
26.11 \\
26.27 \\
25.98 \\
25.69 \\
25.70 \\
25.68 \\
25.73 \\
25.93\end{array}$ & $\begin{array}{l}24.56 \\
24.90 \\
25.32 \\
27.05 \\
28.13 \\
29.20 \\
29.54 \\
29.88 \\
30.44 \\
30.34 \\
29.95 \\
30.07 \\
29.90 \\
29.73 \\
30.03 \\
30.65 \\
31.30 \\
32.30 \\
32.34 \\
32.61 \\
32.87 \\
32.50 \\
32.71 \\
33.15 \\
33.47 \\
33.78 \\
34.15 \\
35.01 \\
35.53 \\
36.06 \\
36.21 \\
37.12 \\
38.02 \\
37.63 \\
36.99 \\
36.77 \\
36.55 \\
36.12 \\
36 . .06 \\
36.00 \\
35.88 \\
35.75 \\
35.69 \\
35.63 \\
36.33 \\
36.76 \\
37.03 \\
37.58 \\
38.19 \\
37.91 \\
37.67 \\
37.42 \\
37.55 \\
37.60 \\
37.52 \\
37.45\end{array}$ & $\begin{array}{l}1.03 \\
1.04 \\
1.04 \\
1.05 \\
1.05 \\
1.06 \\
1.06 \\
1.05 \\
1.04 \\
1.03 \\
1.02 \\
1.01 \\
0.97 \\
0.97 \\
0.97 \\
0.97 \\
1.00 \\
1.03 \\
1.03 \\
1.02 \\
1.02 \\
1.02 \\
1.02 \\
1.02 \\
1.02 \\
1.02 \\
1.02 \\
1.03 \\
1.04 \\
1.05 \\
1.05 \\
1.05 \\
1.05 \\
1.04 \\
1.02 \\
1.02 \\
1.00 \\
1.00 \\
1.00 \\
1.00 \\
0.98 \\
0.98 \\
0.96 \\
0.96 \\
0.97 \\
0.98 \\
0.98 \\
0.98 \\
0.99 \\
0.99 \\
0.97 \\
0.96 \\
0.95 \\
0.96 \\
0.96 \\
0.95 \\
1.95 \\
1.06\end{array}$ & $\begin{array}{r}79.10 \\
82.98 \\
76.01 \\
84.53 \\
79.88 \\
85.30 \\
77.56 \\
89.18 \\
85.30 \\
89.95 \\
84.53 \\
95.37 \\
92.27 \\
95.37 \\
86.85 \\
94.60 \\
84.36 \\
88.66 \\
78.33 \\
92.96 \\
88.66 \\
97.27 \\
86.94 \\
99.85 \\
91.24 \\
97.27 \\
86.08 \\
99.85 \\
92.10 \\
108.03 \\
108.02 \\
98.99 \\
89.52 \\
105.01 \\
92.10 \\
111.96 \\
105.01 \\
93.82 \\
105.82 \\
100.02 \\
105.96 \\
90.04 \\
103.98 \\
95.98 \\
103.98 \\
92.96 \\
105.96 \\
97.01 \\
92.02 \\
102.00 \\
102\end{array}$ & $\begin{array}{r}5.01 \\
5.14 \\
5.24 \\
5.53 \\
2.83 \\
2.56 \\
1.63 \\
4.63 \\
2.47 \\
4.85 \\
10.52 \\
13.43 \\
9.30 \\
10.44 \\
10.94 \\
8.23 \\
7.27 \\
3.36 \\
3.48 \\
5.50 \\
2.99 \\
6.20 \\
12.22 \\
6.32 \\
5.58 \\
2.54 \\
4.04 \\
6.50 \\
5.40 \\
4.61 \\
6.91 \\
10.38 \\
7.46 \\
8.73 \\
9.95 \\
14.80 \\
11.63 \\
10.82 \\
10.45 \\
9.77 \\
10.81 \\
11.99 \\
13.06 \\
11.20 \\
8.97 \\
8.84 \\
7.87 \\
5.73 \\
4.34 \\
5.93 \\
6.16 \\
6.18 \\
6.11 \\
6.12 \\
5.80 \\
\end{array}$ & $\begin{array}{l}1.70 \\
1.20 \\
1.40 \\
2.20 \\
3.20 \\
2.40 \\
2.50 \\
3.00 \\
3.40 \\
2.50 \\
2.50 \\
2.90 \\
3.70 \\
2.90 \\
3.20 \\
4.10 \\
5.00 \\
4.50 \\
5.00 \\
5.40 \\
5.80 \\
4.90 \\
5.30 \\
5.30 \\
5.30 \\
4.60 \\
5.10 \\
5.20 \\
5.30 \\
4.60 \\
5.20 \\
5.20 \\
5.40 \\
4.70 \\
5.20 \\
5.20 \\
5.30 \\
5.00 \\
6.30 \\
7.20 \\
8.10 \\
8.10 \\
9.50 \\
10.60 \\
11.30 \\
11.50 \\
13.10 \\
14.30 \\
16.40 \\
16.30 \\
17.50 \\
17.80 \\
13.00 \\
17.10 \\
17.40 \\
16.80\end{array}$ & $\begin{array}{r}7.56 \\
7.56 \\
7.85 \\
7.79 \\
7.26 \\
7.56 \\
7.05 \\
7.50 \\
7.28 \\
7.80 \\
8.42 \\
9.01 \\
9.34 \\
10.15 \\
10.43 \\
9.09 \\
8.82 \\
8.33 \\
8.97 \\
8.61 \\
8.32 \\
9.34 \\
9.80 \\
8.40 \\
8.29 \\
8.17 \\
7.83 \\
8.11 \\
7.45 \\
7.35 \\
7.78 \\
8.48 \\
8.52 \\
9.01 \\
8.77 \\
9.29 \\
11.45 \\
9.99 \\
10.25 \\
10.48 \\
11.38 \\
11.49 \\
12.30 \\
11.28 \\
10.37 \\
10.53 \\
9.99 \\
8.40 \\
8.03 \\
9.22 \\
8.80 \\
8.58 \\
8.40 \\
8.68 \\
7.72\end{array}$ \\
\hline
\end{tabular}


The base year of all prices and indices is 1980.

"ho collowing ma in da sources were used:

\begin{tabular}{|c|c|c|}
\hline $\mathrm{BB}$ & $:$ & Bue Book: \\
\hline DEG & $:$ & Department of Employment Gazette \\
\hline ETHS & : & Teonomic Trend Annual supplement \\
\hline HABLS & : & Hetorical Abstract of British Labour Statistic \\
\hline$M M$ & $:$ & 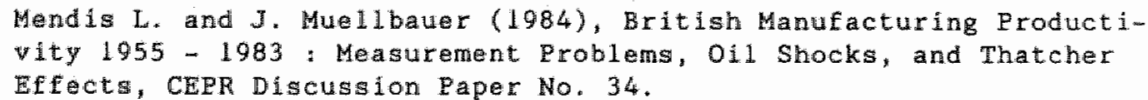 \\
\hline
\end{tabular}

$N_{1}, N_{2}$ : Total (ful1 tine and part time) number of production workers (No) and nonproduction warkers $\left(\mathrm{N}_{2}\right)$ have been computed from the ETAS total number of employees in U.K. manufacturing, and DEG employment shares.

Y, Py : Index of total manufacturing output ( $Y$ ), and producers price index of home sales of all manufactured products (Py) have been obtained frort ETAS.

$W_{1}, W_{2}$ : Index of real weekly eanings of fuld time production workers (W1) and nonproduction workers ( $\mathrm{H}_{2}$ ) have been obtained by deflating gross weekly earnings of mamal and nonmanual workers respectively (pre-1970 data : HABLs; from 1970 on data: New Earnings Survey in DEG) by Py.

K, Q : The gross capital stock at constant prices (K) have been obtained Erom $B B$ for data from 1963 and from MM for pre-1963 data. The real price of capital (Q) has been obtained by dividing the series for manufacturing investment in current and constant prices obtained from ETAS and deflating this series by Py. turling industry (ETAS). 


\begin{tabular}{|c|c|c|c|c|c|c|c|c|}
\hline$t$ & $N_{1}$ & $N_{2}$ & K & 1 & $W_{2}$ & $Q$ & $\gamma$ & $P_{\mathrm{fm}}$ \\
\hline $\begin{array}{l}1955 \\
1956 \\
1957 \\
1958 \\
1959 \\
1960 \\
1961 \\
1962 \\
1963 \\
1964 \\
1965 \\
1966 \\
1967 \\
1968 \\
1969 \\
1970 \\
1971 \\
1972 \\
1973 \\
1974 \\
1975 \\
1976 \\
1977 \\
1978 \\
1979 \\
1980 \\
1981 \\
1982 \\
1983 \\
1984 \\
1985 \\
1986\end{array}$ & $\begin{array}{l}6484.27 \\
6467.86 \\
6419.33 \\
6271.26 \\
6274.28 \\
6501.66 \\
6523.38 \\
6448.28 \\
6350.46 \\
6412.31 \\
6460.23 \\
6371.75 \\
6126.70 \\
6032.88 \\
6081.79 \\
6018.05 \\
5791.26 \\
5609.06 \\
5655.00 \\
5667.95 \\
5358.88 \\
5231.73 \\
5249.90 \\
5175.05 \\
5074.40 \\
4835.51 \\
4348.59 \\
4054.46 \\
3852.20 \\
38016.84 \\
3833.08 \\
3755.15\end{array}$ & $\begin{array}{l}1525.37 \\
1552.99 \\
1584.37 \\
1635.94 \\
1653.65 \\
1739.49 \\
1828.66 \\
1851.56 \\
1847.05 \\
1888.50 \\
1944.60 \\
2013.16 \\
2046.05 \\
2066.89 \\
2102.86 \\
2150.41 \\
2145.79 \\
2048.64 \\
2038.85 \\
2072.85 \\
2034.16 \\
1927.13 \\
1967.34 \\
2015.42 \\
2064.61 \\
2031.91 \\
1739.84 \\
1748.41 \\
1554.99 \\
1508.84 \\
1443.07 \\
1394.87\end{array}$ & $\begin{array}{r}90.35 \\
93.98 \\
98.12 \\
101.85 \\
105.48 \\
109.31 \\
114.25 \\
119.19 \\
123.22 \\
127.46 \\
132.40 \\
137.54 \\
142.58 \\
147.43 \\
152.97 \\
159.02 \\
165.07 \\
170.01 \\
174.45 \\
175.76 \\
180.50 \\
184.50 \\
188.60 \\
193.10 \\
197.80 \\
201.40 \\
203.00 \\
204.40 \\
205.40 \\
207.20 \\
209.50 \\
211.20\end{array}$ & $\begin{array}{l}0.49 \\
0.51 \\
0.52 \\
0.56 \\
0.56 \\
0.59 \\
0.60 \\
0.61 \\
0.64 \\
0.66 \\
0.70 \\
0.74 \\
0.78 \\
0.80 \\
0.86 \\
0.91 \\
0.90 \\
0.93 \\
0.97 \\
0.90 \\
0.97 \\
1.01 \\
0.96 \\
1.02 \\
1.07 \\
1.10 \\
1.09 \\
1.13 \\
1.12 \\
1.15 \\
1.18 \\
1.20\end{array}$ & $\begin{array}{l}0.57 \\
0.62 \\
0.63 \\
0.65 \\
0.71 \\
0.73 \\
0.75 \\
0.77 \\
0.80 \\
0.83 \\
0.87 \\
0.90 \\
0.97 \\
1.00 \\
1.06 \\
1.12 \\
1.12 \\
1.16 \\
1.18 \\
1.08 \\
1.17 \\
1.21 \\
1.15 \\
1.23 \\
1.28 \\
1.37 \\
1.41 \\
1.46 \\
1.51 \\
1.55 \\
1.58 \\
1.67\end{array}$ & $\begin{array}{l}0.84 \\
0.85 \\
0.87 \\
0.89 \\
0.89 \\
0.88 \\
0.88 \\
0.88 \\
0.91 \\
0.90 \\
0.90 \\
0.92 \\
0.92 \\
0.91 \\
0.91 \\
0.93 \\
0.94 \\
0.96 \\
1.00 \\
0.97 \\
0.97 \\
0.99 \\
0.97 \\
0.98 \\
0.99 \\
1.00 \\
1.00 \\
0.99 \\
0.98 \\
0.97 \\
0.98 \\
0.98\end{array}$ & $\begin{array}{r}66.80 \\
66.60 \\
68.20 \\
67.60 \\
71.50 \\
77.20 \\
77.40 \\
77.60 \\
80.30 \\
87.60 \\
90.10 \\
91.80 \\
92.30 \\
99.30 \\
103.00 \\
103.40 \\
102.30 \\
104.50 \\
114.20 \\
112.80 \\
105.00 \\
106.90 \\
109.00 \\
109.70 \\
109.50 \\
100.00 \\
94.00 \\
9.4 .20 \\
96.90 \\
100.80 \\
103.70 \\
104.70\end{array}$ & $\begin{array}{l}0.18 \\
0.18 \\
0.18 \\
0.17 \\
0.17 \\
0.17 \\
0.17 \\
0.17 \\
0.18 \\
0.18 \\
0.19 \\
0.19 \\
0.19 \\
0.21 \\
0.22 \\
0.23 \\
0.24 \\
0.25 \\
0.33 \\
0.49 \\
0.55 \\
0.158 \\
0.79 \\
0.82 \\
0.92 \\
1.00 \\
1.09 \\
1.17 \\
1.25 \\
1.36 \\
1.38 \\
1.27\end{array}$ \\
\hline
\end{tabular}


$-138-$

REFERENCES 
REEERENCES

Andrews, D.W.K., and R.C. Fair (1988), "Inference in Nonlinear Beonometric Models ith Structual Change", Review of Econonic Studies 55, 615-639.

Blanchatd, $0 . J$. and C.M. Kahn (1980), "The solution of linear difference models under rationa 1 expectations", Econometrica $48,1305-1311$.

Bray, M.M. and N.E. Savin (1986), "Rational Expectations Equilibria Learning and Model Specification ${ }^{\text {, Econometrica } 54,1129-1160 .}$

Berndt, E.R., M.A. Euss, L. Wavermand (1979), "A dynamic model of costs of adjustment and interrelated factor demands, with an emplicical application to energy demand in U.S. Manufacturing", Institute for Policy Analysis, University of Toronto, Norking Paper 7925.

Broer, D.P. (1985), "Neoclassical Theory and Empirical Models of Aggegate Elrm Behaviour" Ph. D. Thesis, Eramus University, Rotterdam.

Burgess, S. (1988), "Employment Adjustment in U.K. Manufacturing" "Economic Journa1 $98,81-103$.

Burgess, S. and J.J. Dolado (1988), "Intertemporal Rules with Vardable Spead of Adjustment : an Application to U.K. Manufacturing Employment", Economic Journa1, forthcoming.

Chamberlain, G. (1982) : "Multivariate regression models for panel data", Journal of Econometrics, $18,5-46$.

Chow, C.C., Ph.J. Reny (1985), "On two methods for solving and estimating linear simultaneous equations under rational expectations" Journal of Economic Dynamics and Control $9,63-75$.

De Regt;, E.R. (1988), "Iabor Demand and Standard Working Time in Dutch Manufacturing, 1954-1982", in R.A. Hart, ed." "Employment, Unemployment and Labor Utilization", Unwin Hyman, London.

Dolado, J.J. (1987), "Employment, price and inventory In manufacturing Indum stry" ${ }^{* 1}$. D. Phil. Thesis, University of Oxford.

Eichenbaum, M.S. (1984), "Rational expectations and the smoothing properties of inventories of finished goods", Journal of Monetary teonom $1 \mathrm{cs}$ 14, $71-96$.

Engle, R.F. (1982), "Autoregressive Conditionel Heteroskedasticity with Est imates of the Variance of U.K. Inflations" Econometrica 50, 987 - 1008 .

Engle, R.F., and C.W.J. Granger (1987), "Co-integration and Error Correction: Representation, Estimation and Test1ng", Econometrica 55, $251-276$.

Engle R.F., and B.S. Yoo (1987), "Forecasting and Testing in Cointegrated Sysm tems" "Journal of Econometrics 35, 143-159. 
Epsted, L.G. and M.G.S. Denny (1983), "The Multivariate Flexible Accelerator Model: It Empleical Restrictions and an Application to U.S. Manufacturing", Ecomometrica $51,647-674$.

Eptern, L. G. and A.J. Tatchew (1985), The Emplrical Determination of Technology and Expectatomo A Stmplified erocedure", Journal of Econometrics $27.235-258$.

Escribano, A. (1987), "Error-corection systems : Wonlinear adjustments to 1 hear long-run relationships", 29 pages.

Fuller, W. (1976), Introductlon to Statistical Time Series, Ney York, Wiley.

Gallant, A.R. (1987), Nonlinear Statistlcal Models, Wew York, John Wiley.

Geweke, J.F. (1978), "Testing the exogenelty specitication in the complete dynamic simultaneous equation model" "Journal of Econometrics $7,163-185$.

Gouriéroux, C. A. Monfort, and A. Trognon (1985), "Moindres carrés asymptotiques", Annales de 1 "IMSEE 58, $91-122$.

Hammermesh, D.S. (1988), Labor Demand and the Structure of Adjustment Clost.s" National Bureau of Economic Research, Working Paper No. 2572.

Hannan, E.J., and L. Kavalieris (1984), "Wultivariate Iinear time series mode1s" . Advances in Applied Probab11ity 16, 492-561.

Hansen, L.P. (1982), "Large Sample Properties of Generalized Methods of Moments Estimatiors", Econometrica 50, 1029-1054.

Hansen, L., T. Sargent (1980), "Formulating and estimating dynamic 1 inear rational expectations models" Journal of Economic Dynamics and Control 2, $7-46$.

Hansen, L. and T. Sargent (1981), "Formulating and estimating dymamic linear rational expectation models", in Rational Expectations and Econometic Practice, ed. by R.E. Lucas, Jr., and T. Sargent, Minneapolls : University minnesota Bress.

Hansen, $\mathbb{L}_{\text {. }}$. and $\mathbb{K}$. Singleton (1982), "Gereralized Instrumental Variables Estimation of Nonlinear Rational Expectations Models" Econometrica 50 , $1269-1286$.

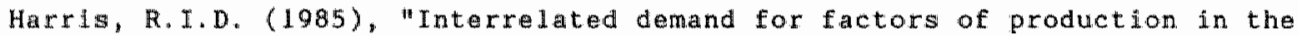
U.K. Engineering Industry, 1968-1981", The Economic Journal 95,1049 1068.

Holly, S., P. Smith (1986), "Interrelated factor demands for manufacturing: A dyname translog cost function approach", Centre for Economic Forecasting, London Business School, discussion paper 18-86.

Holt, C.C., F. Modigliani, J.F. Muth and H.A. Simon (1960), Planning Froduction, Inventorfes and Work Force, New Jersey, Prentice-Hall.

Hosking, J.R.M. (1980), "The multivariate portmanteau statistic", JASA 75 " $602-600$. 
Kenman, J. (1979), The Estimation of Partial Adjustment Modols win Rational Expectations ${ }^{\text {依 }}$, Econometrica $47,1441-1455$.

Kokkelenberg, E.C. (1984), whe specification and estimation of interrelated factor demand under uncertainty" Journal of Economic Dytames and Control $7,181-207$.

Kokkelenberg, E.D., C.W. Bischof (1986), "Expectations and factor demand", Review of Economics and Statistics $65,423-431$.

Kollintzas, T. (1985), "The Symmetric Linear Rational Expectations Modeli", Econometrica $53,963-976$.

Kydland, F., and $\mathbf{E}$. Prescott (1982), "Time to Build and Aggregate Fluctuatlons", Econometrica $50,1345-1371$.

Liu, L.M., G.B. Hudak, G.E.P. Box, M.E. Muller, G.C. TIa (1986), The ScA Statistical System - Reference Manual for Forecasting and pime Series Amalysis, Illinois : SCA-Press.

Ljung, G.M. and G.EP. Box (1978), "On a Measure of Lack of Fit in Time Series Models', Biometrika $65,297-303$.

Lucas, R.E., Jr. (1976), "Econometric policy evaluation : A critique" in

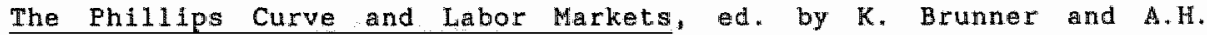
Me1tzer, Ansterdam, North-Holland, $19-46$.

Lïtkepoh1, H. (1984), "Forecasting contemporaneously aggregated vector ARMA processes", Journal of Business Economic Statistics 2, 201-214.

Meese, R. (1980), "Dynamic factor demand schedules for labor and capdtal under rational expectations" Journal of Econometrics $14,141-158$.

Marrison, C.J. (1986), "Structural models of dynamic factors demand with nongtatic expectations: An empirical assessment of alternative expectation specifications", International Economic Review $27,365-386$.

Morrison, C.J., and E.R. Berndt (1981), "Short-run Labor Productivity in a Dynamic Mode 1", Journal of Econometrics $16,339-365$.

McCa11um, B.T. (1976), "Rationall expectations and the natura rate hypothesis some consistent estimates", Econometrica $44,43-52$.

McIntosh, J. (1982), "Dymamic interrelated factor demand systems: The United Kingdom 1950-1978". The Economic Journal 92, Conference Papexs Supplement, $79-86$.

Nadiri, I., and S. Rosen (1969), "Interrelation factor demand funotions", American Economic Review 59, 457-471.

Nadiri, M.T., S. Rosen (1974), A Disequilibrium Model of Demand for Factors of Production, New York, NBER.

Neftçi, S.H. (1978), "A time series analysis of the real wages-employment relam tionship", Journal of Political Economy 86, 281-291.

Nicke11, 5.J. (1984), "An investigation of the determinants of manufacturing employment in the United Kingdom", Rewiew of Economic Studies 51 , $529-557$. 
Micke11, 5.J. (1985), "Eror Correction, Partial tujustment and all that : an expostury note" "Oxford Bulletin of Economic and Statistics $47,119-$ 129.

Nleke11, S.J. (1986), "Dynamic Models of Labour Demand", in O. Ashenfelter and R. Layars, eds. Handbook of Labor Economics, Elsevier, Amsterdam.

Hicke11, S.J. and J. Symons (1987), "The Real Whe - Employment Relationship in the Unlted Statest, Working Paper, University of Oxford.

O1, (1962), "Labor as quasi-flxed factor" Journal of Political Economy 70, $538-555$

Plndyck, R.S., J.J. Rotemberg (1983a), "Dynamic factor demands and the effects of nergy price shocks", American Economic Review 73, 1066-1079.

Pindyck, R.S., J.J. Rotemberg (1983b), "Dynamic factor demands under rational expectations", Scandinavian Journal of Eiconomics 85, 223-238.

Ross. "P.E. (1987), "Comparigon of Dynamic Factor Demand Madels", 357-376, in Barnett W.A., E.R. Berndt, and H. White (eds.) : Dynamic Econometric Modeling, Cambridge, Cambridge University Press.

Sargan, J.D., and A. Bhargava (1983), "Testing Residuals from Least Squares Regression for Being Generated by the Gaussian Random Walk", Econometrica $51,153-174$.

Sargent, T.J. (1978), "Estimation of dynamic labor demand schedules under rational expectations", Journal of Political Economy 86, $1009-1044$.

Sargent, T.J. (1979), Macroeconomic Theory, New York, Academic Press.

Shaplte, M.D. (1986), "Dynamic demand for capital and labor", Quarterly Journal of Economics $101,513-542$.

Sims, C.A. (1980), "Macroeconomics and reality", Ecomometrica 48, 1-47.

Smith, D. (1984), "Short Run Employment Functions when the Speed of Adjustment depends on the Unemployment Rate", Review of Economics and Statistics $66,138-142$.

TIaO, G.C., G.E.P. Box (1981), "Modeling multiple time series with applications" Jourmi of Anerican Statistical Assaciation 76, 802-816.

IInsley", D. (1971), "A Varlable Adjustment Model of Labor Demand" "International Economic Review 12, 482-510.

Treadway, A.B. (1971), "The Rational Multivariate Flexible Accelerator", Econometrica $39,845-855$. 


\section{CURRICULUN WITAE}

Gerard Antonie Pfann is geboren op 9 december 1959 te Dostzan. Vanaf 1972 geniet hij voorbereidend wetenschappelijk onderwijs an de scholengemeonschap Naord te Amsterdam en slagt in 1978 voor het eindexamen Atheneum B. Vanaf 1978 studeert hij Econometrie an de Universitejt van Amsterdam, en halt in 1985 het doctoralexamen, met als hoofdvak ifet-lineaire micro-econometrie.

In de periode 1982-1985 is hij in dienst van de Economische Faculteit van de Universiteit van Amsterdam en 1 id van de wakgroep Micro-economie : tot me 1985 a ls candidaatsassistent van Prof.dr. J. Hartog; en wan mei 1985 tot oktober 1985 als wetenschappelijk assistent. Van oktober 1985 tot oktober 1989 is hij als wetenschappelijk assistent en lid van de vakgroep Kwantitatieve Economie werkzaam aan de Economische Faculteit van de Rijksuniversiteit Limburg te Mastricht. In de perioden april-me 1988 en oktober-december 1988 bezoekt hil het Institute of Economics and Statistics van de University of oxford in Fingelland. Voor dit bezaek antuing hij een beurs van NWO. 